Alma Mater Studiorum - Università di Bologna DEPARTMENT OF ECONOMICS

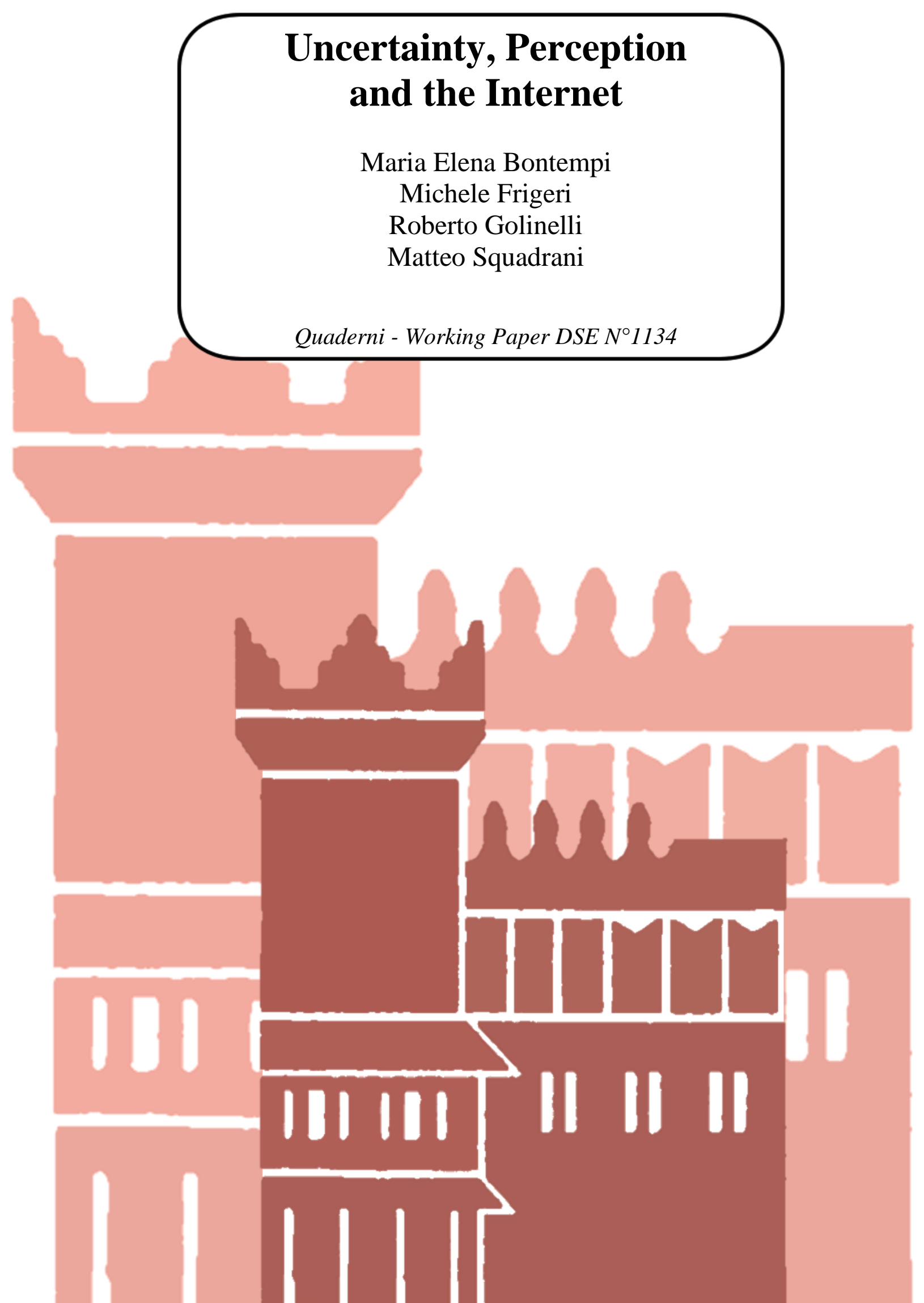




\title{
Uncertainty, Perception and the Internet
}

\author{
Maria Elena Bontempi ${ }^{*}$ Michele Frigeri $^{* *, a}$ Roberto Golinelli ${ }^{* *}, \mathrm{~b}$ and Matteo Squadrani ${ }^{* *}, \mathrm{c}$
}

\begin{abstract}
Macroeconomic uncertainty consists of three components: the unobservable, the heterogeneous and the "uncertain". We are unaware of exactly when economic agents perceive uncertainty and which type of uncertainty interests them. This paper introduces and outlines a way of conducting large-scale data searches on the Web. We create the EURQ index of "economic uncertainty related queries" for both the USA and Italy. We show that the $E U R Q$ encapsulates agents' need to gather more information during periods of uncertainty. This need either spontaneously arises in the case of macro-real and political uncertainty, or is induced by the media in the case of normative and financial uncertainty. This distinction is extremely important when trying to understand the immediate impact of fiscal policy uncertainty on economic variables, and how financial shocks can produce a significant short-term impact on economic activity. It is also helpful when trying to solve the identification and endogeneity issues encountered in the literature when assessing the role of uncertainty.
\end{abstract}

\section{Version: 01/10/2019}

Keywords: macroeconomic uncertainty measurement; perception of uncertainty; Internet searches; Google Trends; finance-based indexes; survey-based indexes; news-based indexes.

JEL classification numbers: D80, D91, E66, C32, H30.

\author{
* Corresponding author, Department of Economics, University of Bologna, Strada Maggiore, 45; 40125 \\ Bologna (Italy), mariaelena.bontempi@unibo.it \\ ** Department of Economics, University of Bologna, Strada Maggiore, 45; 40125 Bologna (Italy) \\ a michele.frigeri@studio.unibo.it \\ b $\underline{\text { roberto.golinelli@unibo.it }}$ \\ cmatteo.squadrani@studio.unibo.it
}

\section{Acknowledgements}

The monthly updated versions of our new EURQ indices for the USA and Italy are downloadable from the Economic Policy Uncertainty Index webpage edited by Steven Davis, Nick Bloom and Scott Baker at: http://policyuncertainty.com/EURQ_monthly.html. Research began in 2013, and since then has greatly improved thanks to the observations made by participants at the following events: the $35^{\text {th }}$ International Symposium on Forecasting organized by the International Institute of Forecasters, Riverside, June 21-24, 2015; the $2^{\text {nd }}$ workshop on macroeconomic uncertainty held at University College London, May 12-13, 2016; the Stanford Institute for Theoretical Economics (SITE) session on the macroeconomics of uncertainty and volatility, Stanford University, September 7-9, 2016; the IAAE International Association for Applied Econometrics Conference, Montreal, Canada, June 26-29, 2018; and the $12^{\text {th }}$ International Conference on Computational and Financial Econometrics held at the University of Pisa, Italy, December 14-16 2018. The usual disclaimers apply. 


\section{NON-TECHNICAL SUMMARY}

This paper introduces the new uncertainty measure labelled as Economic Uncertainty Related Queries (EURQ), an index that measures the volume of Internet searches of uncertainty-related topics. The $E U R Q$ is available at a monthly frequency from January 2004, and, at present, is available for United States and Italy. In this paper we motivate and explain the construction of the index, and test and discuss the $E U R Q$ index in comparison with other indexes of uncertainty, at the aggregate level and for distinct categories of economic and policy uncertainty.

An attractive feature of $E U R Q$ is that, being based on Internet search activity, it measures people's interests and desires for more knowledge. The choice of search queries is of paramount importance to capture uncertainty feelings. For the US, we selected 184 queries closely related to 210 search terms that Baker, Bloom and Davis (QJE, 2016) use to create the Newsbank version - based exclusively on news data - of their EPU indexes. To construct EURQ Italy, we adjusted the pool of Newsbank search terms to fit the Italian case, and ended up with a list of 163 queries.

From a methodological point of view, $E U R Q$ is related to a news-based approach. However, replacing the frequency of newspaper articles that contain specific terms with the intensity of individual searches of similar words involves a shift in focus, from the channel through which the message is conveyed (the press, the media) to the receivers of the message (individuals). This is a second attractive feature of $E U R Q$ : our understanding of economic uncertainty is improved by comparing $E U R Q$ with other uncertainty indicators (news-based, forecast-based and finance-based, capturing, respectively, opinions of journalists, feelings of the respondents to surveys, and risk aversion and sentiment of investors).

Another attractive aspect of $E U R Q$ is its reliance on an "open-source survey" of the population of searchers on the web, and of detecting changes in people's moods and feelings at any early stage. $E U R Q$ is downloadable in real time, updated frequently, and is easy to compute. The authors are working to compute analogous indexes for France and the UK, that will be soon added and downloadable from the same Economic Policy Uncertainty Index webpage edited by Steven Davis, Nick Bloom and Scott Baker at: http://policyuncertainty.com/EURQ_monthly.html. An additional interesting point is the possibility to compute separate indexes specific to macroeconomic, financial and political/normative uncertainty, once the appropriate lists of search terms are developed. 


\section{Introduction}

This paper introduces the Economic Uncertainty Related Queries $(E U R Q)$ index, a new index that uses Internet searches to measure the widespread interest of all economic agents that is driven by uncertainty. The index creates a connection between two important facts.

On the one hand, despite uncertainty being a fundamental determinant of economic activity (e.g. Bloom, 2014), it is of a heterogeneous nature, varying as it does depending on the period considered, it is difficult to measure, and the degree to which it is distributed among economic agents is an unknown quantity. The uncertainty indicators developed by the literature (Bekaert et al., 2013, Bloom, 2009, Jurado et al., 2015, Bachmann et al., 2013, Ludvigson et al., 2015, Rich and Tracy, 2010, Rossi and Sekhposyan, 2015, Scotti, 2016, and Baker et al., 2016) only manage to account for certain specific aspects of uncertainty. We have finance-based, forecast-based and news-based indexes, which respectively account for investors' risk aversion and feelings, the feelings and disagreements of professional forecasters responding to surveys, and the opinions of journalists.

On the other hand, despite the fact that online search technology is a relatively recent development (about it first emerged in around 1993), nowadays economic agents make trillions of online searches worldwide each year, and this information is of importance when measuring various aspects of uncertainty.

Google is currently the leading search engine, with a worldwide market share in February 2017 of about $80.5 \%$ for desktops and of $98.9 \%$ for laptops, tablets and other portable devices. Sirotkin (2012) claims that since users are unlikely to be experts in traditional information retrieval systems and query language, Web search engines target the average Internet user, or to be more precise, any Internet user, whether new to the web or a seasoned Usenet veteran. Remarkably, the literature has recently started to use Internet search data with different aims and interpretations: either as predictors in forecasting (Vosen and Schmidt, 2011, Carrière-Swallow and Labbé, 2013, D'Amuri and Marcucci, 2017, Bulut, 2018, Gotz and Knetsch, 2019), as an index of well-being (Algan et al., 2016), as an index of job search activity (Baker and Fradkin, 2017), or as a measure of individual moods (the investors' sentiment in Da et al., 2011, 2015, the interest that the municipal balance sheet generates among voters in Repetto, 2018, and investors' need for information about earnings announcements in Drake et al., 2012).

According to Sirotkin (2012), query distribution by type of query sees of navigational queries (when the user looks for a specific web page that is known or supposed to exist) accounting for 12$15 \%$, transactional queries (when the user looks to perform a transaction like buying or downloading) accounting for $22-27 \%$, and informational queries accounting for $58-66 \%$ of total queries and characterized by an average query consisting of two or three terms with no phrase operators. 
The percentage share of the latter type of query suggests that the Internet is viewed by a large number of people as being an effective way of collecting information. Many surveys have stressed that a large portion of the population gets at least some information through websites, apps or social networking sites. In fact, the online channel is presently the second most important source of information after television, and the most popular among people who prefer to read news stories rather than watching or listening to the news.

The volume of informational queries specifically related to economic and political issues is the main ingredient of our EURQ index: it measures the quantity of searches on uncertainty-related topics in order to quantify the uncertainty perceived by economic agents. We demonstrate how Internet search volumes can be used to obtain a reliable measure of the interest/ confidence/ feelings/ worries/ fears expressed by people driven by uncertainty. In this regard, we show that the few papers that have tried to measure uncertainty by using Internet searches (BBVA, 2012, Dzielinski, 2012 and Donadelli, 2015) are all affected by methodological biases.

Our new EURQ index offers five main advantages over the uncertainty measures presently available. Firstly, it is based on Google Trends, which is publicly available, free and very easy to access and download. So, the first appealing aspect of the EURQ index is its reliance on a "freely available survey" of web searchers. Secondly, a further advantage that is connected to the first one is that the $E U R Q$ is downloadable in real time, is updated frequently, and is easy to compute. This means that the EURQ can detect changes in people's moods and feelings at an early stage. Thirdly, searchbased measures reveal attitudes rather than inquire about them, and consequently they may disclose more personal information in cases when non-response rates in surveys are particularly high or the incentive for truth-telling is low (Da et al., 2015). Fourthly, the $E U R Q$ can refer to different geographic locations, both at regional level within the same country, and at country level inside areas characterized by heterogeneous degrees of development. In this paper we present the EURQ constructed at a monthly frequency for the USA and Italy. We are currently working on an $E U R Q$ for France, the UK, Germany, Azerbaijan and South Africa, i.e. also for countries that are usually not covered by uncertainty measures. A fifth interesting aspect of the EURQ is the possibility it offers to compute specific indexes measuring financial, economic, political and normative uncertainty, provided that appropriate lists of search terms are drawn up.

In order to appreciate the positive advantages of the $E U R Q$ over its competitors, the definition of appropriate search terms that individuals usually ask Google when requiring further information, is of paramount importance if feelings of uncertainty are to be gauged. In the case of the USA, we selected 184 queries closely related to 210 search terms that Baker et al. (2016) had used to create the Newsbank version - based exclusively on news data - of their EPU index. To construct the EURQ for 
Italy, we adjusted the list of Newsbank search terms to fit the Italian case, and ended up with a list of 163 queries. Hence, the $E U R Q$ index is related to the news-based approach, but the replacement of the frequency of newspaper articles containing specific terms with the frequency of individual queries involving similar search terms, represents a shift in focus: a shift away from the channel through which the message is conveyed (the press, the media), towards the receivers of the message (individuals). This shift in perspective implies that the index may also be available for countries/regions where press coverage is incomplete, wanting and/or substantially biased. In addition, the EURQ's effectiveness in capturing uncertainty does not depend - as that of news-based measures does - on the intensity of media newspapers use, as Web-search activities can also refer to local sources of information (i.e. information gleaned "chatting with neighbours over the garden fence”); see Lahiri and Zhao (2017).

Given the nature of our new index, we carry out two series of comparisons.

The first series compares our EURQ with a list of finance-based, forecast-based and newsbased mainstream indexes over different periods (1970-2014, 1985-2014, 2004-2014 and 2004-2017, depending on availability). We label the list of these indexes the $F F$ (the Fantastic Five), and we also add the few existing search-based indexes available (BBVA, 2012, Dzielinski, 2012, and Donadelli, 2015). From this comparison, we find that output responses change depending on the nature and intensity of the uncertainty shocks. Although all uncertainty proxies are measured with errors (Carriero et al., 2015), measurement errors affect the finance-based and forecast-based indexes more than the news-based and search-based indexes, although the search-based indexes consisting of few terms are particularly biased.

The second comparison examines whether the interest manifested by economic agents is driven by the press' emphasis on specific events, or whether certain specific topics can spontaneously generate people's interest. Topics relating to taxes, health and crises generate the spontaneous interest of people, while topics that only affect their lives after changes have been made to rules/regulations and monetary/foreign policies, do not stimulate the interest of economic agents until the press has conveyed the corresponding message. Extremely important topics concerning employment and terrorism simultaneously generate the interest of both people and the press.

The paper is organized as follows. Section 2 presents the conceptual framework and the technical issues associated with the construction of our new index, the EURQ. Section 3 compares the EURQ with the $F F$ uncertainty indicators for the USA and for Italy as a case study. Section 4 assesses which components of uncertainty generate spontaneous interest among Americans. Section 5 discusses our results and offers our conclusions. All the outcomes discussed in the paper are supported by the detailed results reported in a complementary online Appendix. 


\section{Using Internet search volumes to construct a new uncertainty index}

\subsection{The conceptual framework of the EURQ index}

The science of uncertainty quantification (see, among others, Der Kiureghian and Ditlevsen, 2009) establishes that uncertainty may be either aleatory (statistical) or epistemic (systematic). While aleatory uncertainty is irreducible as it arises naturally from our perceptions of real-life facts or from "observing the system", epistemic uncertainty represents a lack of knowledge about potentially knowable facts. ${ }^{1}$ Epistemic uncertainty is due to $(i)$ non-specificity, meaning that there is a large set of hidden variables that could inform individuals about a topic and allow them to recover the truth from many alternatives, and (ii) conflict, meaning a lack of consensus or clear disagreement. Both non-specificity and conflict depend on a narrow information set (Harmanec, 1999), and their perception fuels individuals' need to gather more information when they want to make decisions. ${ }^{2}$

In recent years, the Internet has become an effective means of collecting and divulging information for an increasing number of people in the USA. About 85\% of Americans in 2016 (95\% in 2018) got at least some of this information through websites, apps and social networks. The online channel is the second most frequently-used source of information after television, and the most popular among people who prefer to read news stories rather than watching and listening to the news. ${ }^{3}$ According to the query-type distribution reported by Sirotkin (2012), 58-66\% of Internet search activity consists of informational queries revealing people's collective interest in, and desire for greater, knowledge.

Therefore, Internet search volumes can be utilised to build an indicator of economic agents' interest in greater information, and specifically their need for more information, when they are worried about something that is uncertain and could have consequences affecting them. Such a measure of uncertainty, which is what our EURQ index is, offers numerous advantages. It is based on a "freely available survey" of queries. It is downloadable in real time and frequently updated so that it can detect changes in people's moods and feelings at an early stage. Finally, it reveals attitudes of people and can provide information in cases when non-response rates in surveys are high, or the

\footnotetext{
${ }^{1}$ For example, with regard to uncertainty in relation to official economic statistics, Manski (2015) considers uncertainty as the lack of knowledge deriving from an incomplete understanding of the provided information about an economic concept, or from the lack of clarity of the concepts themselves.

${ }^{2}$ Examples come from various disciplines. In the field of economic psychology, individuals respond to greater uncertainty by intensifying their search for more information (Lemieux and Peterson, 2011). In economics, imperfect (noisy) and sticky information models predict that "more volatile shocks [greater uncertainty] lead to the more frequent updating of information, since inattentiveness is costlier in a world that is rapidly changing" (Reis, 2006, p. 803), and that "more tranquil times should be ceteris paribus associated with greater information rigidities" (Coibion and Gorodnichenko, 2015, p 2674).

3 For further information regarding Internet users in North America, see the Pew Research Center survey http://www.internetworldstats.com/stats2.htm, and http://www.netmarketshare.com/ regarding search engines' market shares.
} 
incentive for truth-telling is low (Da et al., 2015). For all of these reasons, the EURQ has a considerable advantage over other uncertainty indexes. In fact, forecast- and news-based indexes derive from specific categories of economic agents, and usually take longer to be released and updated, whereas finance-based indexes, which are less affected by delays, focus exclusively on certain specific aspects of uncertainty.

\subsection{The main problems associated with, and the required conditions underlying, the EURQ index}

The positive features previously depicted with regard to the EURQ uncertainty index throw up two main problems that need to be tackled, subject to three specific conditions

Problem \#1 (P1): The choice of search engine by means of which the relationship "the more the economic system is uncertain, the more economic agents need information and make searches on the Web" is to be established. We chose Google Trends to measure search volumes for the simple reason that Google is currently the leading search engine, boasting a worldwide market share (February 2017) of $80.5 \%$ for desktops and $98.9 \%$ for laptops, tablets and other mobile devices. However, as is the case with many other large data providers, Google Trends also suffers from a certain opaqueness in regard to the way Google builds its Google Trends index.

Condition \#1 (C1): The condition to be met in order to deal with problem P1 is to devote a lot of energy to analysing the index's statistical properties, validating the outcomes of such analyses, and verifying the robustness of the results.

Problem \#2 (P2): To obtain search volumes that are interpretable as the aggregate interest in, and the need for, more information of all those economic agents driven by uncertainty, we must exclude other motives such as curiosity or the desire to know more about something that has nothing to do with economic and policy uncertainty. Take, for example, searches for the terms "baseball" and "European Central Bank". In the first case, people of course do not feel any "economic" uncertainty, and the volume of searches for this term invariably peaks during the (baseball) World Series, while it is generally stable over time (apart from certain clear seasonal effects): the time series characteristics of the search query "baseball" have nothing to do with uncertainty. In the second example, some people search for "European Central Bank" because they need to analyse Mario Draghi's speeches and to better understand the Bank's views regarding a possible sovereign debt crisis (and this is interest due to uncertainty). However, other people could search for "European Central Bank" because of their individual, extemporaneous interest in the Bank's research agenda, and wish to examine the most recently published working papers (this motive is unrelated to uncertainty and/or interest in monetary policy issues). As a result, the aggregate fluctuations of the "European Central Bank" query reflect a collective uncertainty-driven interest when their timing and dynamics are driven 
by common factors represented by millions of simultaneous Internet searches. Conversely, a purely idiosyncratic interest unrelated to uncertainty is mere noise, uncorrelated across individuals and randomly fluctuating without any specific pattern. ${ }^{4}$

In a nutshell, problem P2 concerns the selection of search terms and the trade-off between signal and noise. The conditions to be met in order to deal with problem P2 must magnify the signal against the noise, and are as follows:

Condition \#2 (C2): a careful selection of the terms to be included in the search queries;

Condition \#3 (C3): verification that these search queries - although probably pertinent to the measurement of economic uncertainty - are not submitted sporadically or for futile reasons.

Under C2, we have a trade-off between selecting a long list of search terms in order to take advantage of the statistical averaging effect across many different queries (i.e. to encompass a variety of diverse sources and symptoms of uncertainty and interest), and so as to minimize arbitrariness in both the selection of the list and the specific wording of the queries. In line with the epidemiological model of Carroll (2003), we assume that the wording of the search terms used by Web users are affected by the jargon of journalists, because the news published represents the main way of propagating the need for further information among the entire population. Thus, the EURQ is related to the news-based approach of Baker et al. (2016), henceforth BBD. However, it should be noted that replacing the counts of specific words used by the press with the intensity of individual web searches using these words implies a shift in focus from the channel through which the message is conveyed (the press, the media), to the receivers of the message (individuals). While the BBD news-based measure uses journalists' feelings about uncertainty, and its representativeness is related to the newspapers selected and the regularity with which they are read, the $E U R Q$ is based on how Internet users explicitly manifest their interest through a greater intensity of searches. For this reason, search activities may also include gathering news locally (e.g. "talking with neighbours over the garden fence"), and not only from newspapers. When agents are concerned about something, they submit specific queries on the Web, and discovering the degree to which their interest is affected by journalists' opinions/feelings considerably helps improve our understanding of the channels by means of which uncertainty is established. Furthermore, the comparison of the EURQ with the feelings of respondents to a survey (as expressed by the forecast-based measures of uncertainty) or with the risk aversion and sentiment of investors (part of the finance-based indexes), furthers our knowledge regarding different aspects of the unobservable uncertainty.

\footnotetext{
${ }^{4}$ A spike in the search volumes may also occur after the ECB changes interest rates, i.e. in a moment that should reflect the resolution of uncertainty rather than uncertainty itself. However, this occurrence points to the fact that, despite the implemented policy change, the state of agents' knowledge is not yet perceived as fully satisfactory, hence the need to gather additional information in order to temper uncertainty.
} 
Under condition $\mathrm{C} 3$, the $E U R Q$ must capture the signal of uncertainty-driven interest instead of the noise due to idiosyncratic searches; and the signal must be related to the common components induced by the diffusion of uncertainty through conversations between, and the imitating behaviour of, agents (Sims, 2003), and/or the news divulged by the media. This means that the volume of specific queries (containing the terms spread, unemployment, inflation rate, public debt, for example) expresses the uncertainty deliberatively manifested by economic agents if, and only if, such queries peak at the time of the corresponding episodes characterized by a high degree of uncertainty. Of course, this check can only be made after having selected the queries and downloaded the index. In fact, the online Appendix reveals that the opposite procedure of selecting those query terms most closely correlated with the uncertainty indexes available in the literature (the so-called "correlate approach") delivers few, generic, spurious search terms that have nothing to do with uncertainty. ${ }^{5}$

\subsection{The practical implementation of the EURQ index}

To construct the EURQ index we extracted Google Trends series for queries closely related to the search terms employed by BBD when creating the Newsbank version - based exclusively on news data - of their EPU (Economic and Policy Uncertainty) index. ${ }^{6}$ To be included in the BBD's Newsbank uncertainty index, newspaper articles must include the words "uncertain" or "uncertainty" (U), "economy" or "economics" (E), and one of the following policy terms (P): "congress, deficit, Federal Reserve, legislation, regulation or White House", together with 210 specific terms related to economic and policy topics (L), including a number of specific policy-related terms such as "government spending", "debt ceiling", "money supply" and "tort reform". All this may be symbolized as "U\&E\&P\&L". Our EURQ index starts from the BBD's Newsbank "L" list of 210 search terms, and preserves a final list of 184 queries that people are most likely to use when seeking information in order to overcome their feelings of uncertainty.

\footnotetext{
${ }^{5}$ These results also underlie our significant skepticism regarding the reliability of uncertainty indices based either on few terms or on the correlate approach, such as those proposed by BBVA (2012), Dzielinski (2012), and Donadelli (2015).

${ }^{6}$ The BBDs' indexes are based on articles to be found in the Access World News Newsbank - a database of about 2,000 national and regional newspapers in the USA. The complete list of queries can be found in the appendix of Baker et al. (2016) and on their website, at the page http://www.policyuncertainty.com/categorical_terms.html. For more information on the audit process regarding BBD's selected words, see the Audit Guide at http://www.policyuncertainty. com/media/Coding_Guide.pdf. Interestingly, this audit examination (designed to ascertain whether the uncertain mood is pervasive in those articles reporting the listed words) supports the terms we started from in our query definition. Without an audit, the selection of terms could be criticized as purely arbitrary. For example, Castelnuovo and Tran (2017) subjectively selected search terms "referring to words that are connected to uncertainty" reported in sentences of "various editions of the Beige Book and the Monetary Policy Statements". Similarly, the indexes of Donadelli and Gerotto (2018) and Kupfer and Zorn (2019) derive from two specific features of the search volume extraction on Google Trends (search topics and search categories) that do not depend on specific lists of search terms, and for this reason are unseen boxes the contents of which cannot be validated.
} 
In establishing the "final" list, we sometimes have had to add or exclude certain words in order to narrow down the list and focus more clearly on the specific search reflecting the underlying uncertainty of the agents concerned. ${ }^{7}$ The review and re-wording of the queries is necessary to clear up ambiguity in the searches and to obtain those words used by everyone: not only by journalists, but also by investors, forecasters, "ordinary people" and "neighbours chatting over the garden fence". The final list must reflect a neutral, independent way of measuring the degree to which people need further information when they are worried, uncertain and, more generally, interested in getting a better grasp of a given economic or political issue.

We have subdivided our final list of 184 queries into 8 categories representing the same 8 policy areas of the BBD's Newsbank series, and then grouped the categories together to form the aggregate EURQ index. Each search is normalized by the total number of Google searches within the same period. This procedure is run at the beginning of each month, when we use Web scraping to gather Google Trends data; we have written a Python routine based on the Pytrends package, which allows us to automatically download Google Trends data starting from the list of our 184 queries. This routine also allows us to parametrically set the time span, the country and the usage of the compare feature via a user interface. The monthly updated versions of our new EURQ indices for the USA and Italy are downloadable from the Economic Policy Uncertainty Index webpage edited by Steven Davis, Nick Bloom and Scott Baker at http://policyuncertainty.com/EURQ_monthly.html.

The annotated chart of the monthly EURQ index for the USA, 2004m1-2018m12, is reported in Figure 1.

\section{Figure 1}

The index clearly spikes in correspondence with important episodes of uncertainty, such as the Lehman Brothers bankruptcy and the Emergency Economic Stabilization Act in late 2008, the Affordable Care Act in 2010, the debt ceiling dispute in mid-2011, the US Government shutdown in late 2013, and the election cycle at the end of 2016.

A detailed online Appendix presents all the checks that we made on the EURQ index. The main results of those checks are summarised here. We used the sequence of real-time vintages of EURQ obtained with the Python routine, to analyse the informational content of the downloads in different months. The results suggest that data revisions do not mix up the real EURQ signal. We

\footnotetext{
${ }^{7}$ For example, regarding the search term "healthcare", the BBD counts only include those articles containing both the terms "uncertain" or "uncertainty" and the terms "economy" or "economics" and "healthcare", whereas our counts refer only to the term "healthcare reform". The BBD approach focuses exclusively on newspaper coverage of specific healthcare issues related to economic uncertainty, while excluding generic newspaper articles about medicine. Instead, "healthcare reform" satisfies the first condition of selecting appropriate search terms, because we add the word "reform" that disambiguates the overly generic "healthcare". Furthermore, Internet searches for the emended term identify, per sé, the need to gather information about healthcare legislation, and thus our second condition of not being searched for sporadically is met.
} 
assessed the sensitivity of the $E U R Q$ series to the presence or absence of subsets of search terms, by constructing alternative EURQ indices that do not take account of blocks of search terms. The robustness of all the resulting series to the omission of given terms is confirmed by the high correlations (in the 0.89-0.95 range) with the EURQ index based on the full list of terms. We investigated how the intensity of Internet use over time could affect the search volumes used to construct the EURQ. Since the advent of Google Trends in 2004, Internet penetration rates in the USA have been increasing (the extensive margin), while at the same time search activity has evolved depending on the size and coverage of the issues on the web (the intensive margin). Being scaled to the total traffic the volumes of searches for each individual term, the EURQ index cannot be significantly affected by the extensive margin. Despite the fact that quantification of the impact of the intensive margin is more complex, due to changes in the composition of searches, our checks show that spurious low-frequency unit root-like fluctuations can be excluded: the $E U R Q$ tends to spike during periods of considerable uncertainty rather than showing smoothed local trends.

\section{The performance of the $E U R Q$ index in measuring uncertainty}

\subsection{The statistical properties of the EURQ index}

Measuring uncertainty cannot be unique or objective, as the literature has shown (Julio and Yoox, 2012, Rich and Tracy, 2010, Rossi and Sekhposyan, 2015). Therefore, we compare our EURQ index with the proxies most frequently used in the literature. To do so we selected five main uncertainty indexes (which we collectively label the "Fantastic Five" or $F F$ ), as they represent the three approaches used to measure uncertainty, each of which is characterized by a series of pros and cons.

The first approach is "finance-based", as it utilizes somewhat sophisticated methods to process the financial information thrown up by stock market volatility (see, for example, Bekaert et al., 2013, Bloom, 2009, Gilchrist et al., 2014, and Knotek and Khan, 2011). The assumption is that financial volatility can be a guide to the state of macroeconomic uncertainty, despite the fact that not everyone invests in the stock market (Romer, 1990) or shares the same information that financial market actors have access to. Within this approach, we have selected: $(F F \# 1)$ the CBOE Volatility Index VIX (Chicago Board Options Exchange, 2009), and (FF \#2) the corporate bond spread index SPREAD of Bachmann et al. (2013). Both indexes are generally defined as "uncertainty measures". The VIX is used in many empirical studies (such as Bloom, 2009), but its ability to capture macroeconomic uncertainty is 
questionable, as it is only based on stock market information ${ }^{8}$; the same criticism may be made of the SPREAD proxy. ${ }^{9}$

The second approach is "forecasts-based", as it estimates uncertainty by relying on the concept of economic predictability, and on the measurement of discrepancies among professional forecasters (Bachmann et al., 2013, Henzel and Rengel, 2014, Jurado et al., 2015, Rich and Tracy, 2010, Rossi and Sekhposyan, 2015, Scotti, 2016, and Segal et al., 2015). Here the assumption is that the lack of predictability and the substantial differences between forecasters' views reflect (and are perceived as signs of) a more uncertain economy. Within this approach we have selected: $(F F \# 3)$ the one-month ahead macro-uncertainty indexes PREDICT1 of Jurado et al. (2015), generally defined as "macroeconomic uncertainty"; and $(F F \# 4)$ the heterogeneous evaluation made by senior company executives of their own idiosyncratic future business situations, FDISP, of Bachmann et al. (2013), generally defined as "business-level uncertainty index". The PREDICT1 proxy is a computationally intensive set of procedures that is not directly related to the uncertainty perceived by the public, but is a mixture of economic and financial indicators and events. Being based on qualitative data, the FDISP proxy suffers from serious conceptual problems, as it is almost perfectly negatively correlated with the corresponding balance measure (Das et al., 2019). Where possible, we supplemented the comparison with the macro (MPRED) and the finance (FPRED) components of PREDICT1, which are characterized by different degrees of exogeneity, proposed by Ludvigson et al. (2015), ${ }^{10}$ and the SCOTTI index (Scotti, 2016) that is updated every time new information about the state of the economy is released.

The third approach is "news-based". To the question "how does the average citizen comprehend the implications of stock market volatility and economic predictability underlying her uncertainty?", the answer given is "media is the messenger" (see Alexopoulos and Cohen, 2015). The assumption is that when certain causes of uncertainty matter, they are likely to be reported by journalists using specific words. In other terms, the media are assumed to be able to gauge any uncertainty indicated by market outcomes, professional economists and political debate, and to draw the general public's attention to uncertainty through the recurrent use of specific words. Hence, the degree of uncertainty in each period is proxied by the frequency with which a lengthy list of words related to uncertainty appears in journalistic articles. This approach - which offers a certain analogy

\footnotetext{
${ }^{8}$ According to Bekaert et al. (2013), the VIX is a mixture of uncertainty and risk-aversion, with the latter accounting for a sizeable part of VIX, so much so that Whaley (2000) refers to VIX as the "investor fear gauge". Da et al. (2015) describe the VIX as a market-based measure with the disadvantage of being the equilibrium outcome of many economic forces.

${ }^{9}$ For example, Gilchrist et al. (2014) use credit spreads to measure the degree of financial market friction - rather than uncertainty - and suggest that credit spreads are an additional channel through which uncertainty fluctuations may spread to the real economy.

${ }^{10}$ While MPRED is an endogenous response to other shocks that cause business cycle fluctuations during recessions, FPRED is the exogenous source of the fluctuations.
} 
with the narrative analysis designed to identify monetary and fiscal policy shocks (see, for example, Romer and Romer, 2004, and Ramey, 2011) - leads to the news-based uncertainty measures formulated, for example, by Alexopoulos and Cohen (2015), BBD, and by Knotek and Khan (2011). As a leader of this approach we have selected: $(F F \# 5)$ the Economic Policy Index EPU of BBD, in the specific form of the HNEWS. Given that the "representativeness" of news-based indexes is related to the intensity of use of media sources, the recent argument that households depend less on media and more on local sources of information ("chatting with neighbours over the garden fence"), can weaken their effectiveness in measuring uncertainty (Lahiri and Zhao, 2017).

Figure 2 allows for the visual comparison of the temporal pattern, over the common period 2004m1-2014m12, ${ }^{11}$ of the finance-based measures VIX and SPREAD (in the first row), of the forecast-based measures PREDICT1 and FDISP (in the second row), and of the news-based and Internet-based measures $H N E W S$ and EURQ (in the third row). The NBER downturns are shown by the shaded areas.

\section{Figure 2}

As expected, not only the three approaches but also the indexes resulting from the same approach, produce heterogeneous results: some series (SPREAD and PREDICT1) are smoother and clearly spike in recession periods only, while others (FDISP and HNEWS) are affected by noisier fluctuations over time; the VIX time series shows additional spikes outside downturns, at times of financial crisis. In 2004-2005, the EURQ's levels were above average, whereas no other index exceeded its average during that period. However, as extensively explained, the high levels recorded during the first two years $E U R Q$ was available do not indicate any distortive effect due to the extensive and intensive margins in Web use, and in any case can be amended by appropriate dynamics in the modelling phase.

Table 1 reports the results of the univariate analysis of the EURQ and the $F F$.

\section{Table 1 here}

Well-known stylized facts emerge in the case of all the indexes concerned. Firstly, all the uncertainty indexes are counter-cyclical. Only the fluctuations of the news-based (HNEWS) and searches-based $(E U R Q)$ indexes are weakly associated with the cycle, suggesting that their shocks might disentangle negative political and social events from the mix of the other events which - in the other indices - over-represent macroeconomic conditions. This issue will be examined further in Section 4, by comparing how specific sub-sets of the BBD categories - indicating different political and social events - are perceived by journalists and by Web users.

\footnotetext{
${ }^{11}$ EURQ is promptly updated and downloadable at the beginning of each month, while some other indexes used in the comparison are available until 2014.
} 
Secondly, ARMA models/unit root tests, and the estimates of ARFIMA models, together suggest that uncertainty indexes are stationary with persistent dynamics, and persistence is the important feature of uncertainty according to those theories arguing that uncertainty is a driver of lengthy economic downturns (Schaal, 2015). After the occurrence of an uncertainty shock, the gap between the actual level of uncertainty and its steady-state level in "normal times" is halved in less than one year; PREDICT1 is the only exception to this rule, as its average lag is three times longer than those of the other indexes. These dynamic features denote remarkable stability over time, as they are independent of the length of the timespan (results for the 1970m1-2014m12 period can be found in the online Appendix). ${ }^{12}$

Either the co-movement, or the different timing, of peaks and troughs shown in Figure 2, together with the dynamic causation across the shocks to the different uncertainty indices, are assessed by modelling the pre-whitened residuals of ARMA/GARCH models as a second-order VAR and then testing for Granger causality over both the long (1970m1-2014m12) and short (2004m1$2014 \mathrm{~m} 12$ ) periods. ${ }^{13}$ With specific reference to the $E U R Q$, and following Da et al. (2015), the VAR approach is very useful when trying to understand if uncertainty in a given month is correlated with the intensification of interest/searches over the following months, and/or if the fear of specific future events may generate early interest from economic agents, before this event is identified and measured by the $F F$ uncertainty indexes. Four blocks of results emerge.

Firstly, in the long term, PREDICT1 shocks - obtained using a mixture of several updated economic and financial indicators - anticipate almost all the other indexes, and are hardly ever Granger-caused. Only the HNEWS shocks significantly Granger-cause PREDICT1, since the latter may be lacking in news-based information. The HNEWS shocks also fuel shocks to the variability of the FDISP forecasts, because of possible Carroll's epidemiological effects conveyed by newspapers to senior executives' information. ${ }^{14}$ The non-relevance of FDISP shocks in causing those of the other indexes, may be due to the slow updating of information available to the survey-respondents, and confirms the statistical caveats raised by Das et al. (2019).

Secondly, in the short term, the Great Recession dominates and weakens the evidence of Granger-causality. However, we can suppose that the advent of the Great Recession makes the job of

\footnotetext{
${ }^{12}$ All the univariate models account for potential seasonal effects by using dummy variables when significant. Seasonal effects always emerge (except in the case of the FDISP series which is based on seasonally-adjusted data), suggesting that the seasonality issue must be handled carefully when modelling uncertainty.

13 Besides economic reasoning, GARCH modelling of ARMA errors is also suggested by the evidence of heteroskedasticity in Table 1 . The ARMA/GARCH results discussed here are broadly confirmed if compared with those coming from an alternative pre-whitening of uncertainty indicators using an ARMA model with (endogenous) breaks.

${ }^{14}$ Conversely, the Granger causality from FDISP to PREDICT1 is apparent: both indicators being based on forecasts, past FDISP data - computed using six-month forecasts - overlap the one-month horizon of PREDICTI (rather than driving it).
} 
journalists easier, since they act as the timely messengers of many different uncertainty shocks, and the HNEWS index is strongly simultaneously correlated with financial-based and forecast-based shocks.

Thirdly, in the short term, shocks to the finance-based indicators VIX and SPREAD, are Granger-caused by $E U R Q$ shocks, but not by HNEWS shocks. This result is in line with the sentiment index of Da et al. (2015) which is based on Google Trends and is a strong predictor of future VIX. The leading ability of EURQ also confirms the findings of Bouri and Guptain (2019), where the predictive content of $E U R Q$ is statistically stronger than that based on the news-based uncertainty index, when it comes to predicting the returns on Bitcoins.

Fourthly, in the short term, the simultaneous correlation between HNEWS and EURQ is quite strong (about 0.30 ); in addition to the common role played by the Great Recession, this correlation may also be explained by the aggregation of the BBD's different policy categories into an overall index that mixes up the leading and lagging disaggregated information. We will further examine the disaggregate relationships between $E U R Q$ and $\mathrm{BBD}$ categories in Section 4.

\subsection{The macroeconomic dynamics of EURQ}

The empirical literature suggests that uncertainty shocks exert a negative impact on economic activity (Fernandez-Villaverde et al., 2015, Mumtaz and Theodoridis, 2016, Leduc and Liu, 2016 within the context of DSGE models), and Stock and Watson (2012, p. 81) have argued that the shocks producing the 2007-2009 recession were primarily associated with a heightened degree of uncertainty, together with financial disruptions. However, the entity and persistence of the effect of uncertainty on economic activity remains open to question, as the empirical evidence tends to be conflicting and varies depending on the measures of uncertainty shocks adopted. Further, it is still unclear, a priori, what each uncertainty index does effectively represent.

Here we rectify the lack of a comparison, made over common time spans and within a common empirical framework, of the outcomes of alternative uncertainty indexes including our EURQ. This specific type of comparison has undoubted advantages: not only does it encompass the bulk of evidence (contained in various papers) about the role of uncertainty on economic activity, but it also prevents the comparison being affected by specific events occurring during the given period for which a specific index, used in a specific paper, was available.

As a first example, Bloom (2009) sustains the over-shooting impact of a financial uncertainty shock (the "wait and see" dynamics) on the real economy: because of the shock, the economy suffers in the short run, but the initial level of output is exceeded in the long run. Bachmann et al.'s findings (2013, Fig. 6) suggest that Bloom's over-shooting is due more to the use of finance-based indexes 
than to any genuine uncertainty effect. Choi (2013) and Beetsma and Giuliodori (2012) substantiate this idea by showing that the impact on real activity of shocks to stock market volatility is not robust over time. ${ }^{15}$ These findings also support our caveats about the reliability of measures of macroeconomic uncertainty based exclusively on financial information, since certain transitory crises and random events could be mistaken for uncertainty shocks. ${ }^{16}$ As a second example, Jurado et al. (2015) and Bachmann et al. (2013) utilize forecast-based measures to show that the dynamic response of output to uncertainty shocks is a sharp reduction in the level of production, with effects that persist well beyond the horizons considered in their exercises (i.e. for more than 4-5 years after the shock). And, as a final example, in Baker et al. (2016) shocks to the news-based economic-policy uncertainty index produce a negative dynamic response of manufacturing production in the short term only. Unlike the case of forecast-bases indexes, these output responses are significantly negative for the first 15-18 months, after which they return to zero, without overshooting.

Our comparison avoids the permanent effects in Jurado et al. (2015) and Bachmann et al. (2013) differing from those found in Baker et al. (2016), simply because the sample period is long (it begins in the 1960s) in the first two cases, while it is considerably shorter (it begins in the mid-1980s) in the third case. Unlike the long term, the short term excludes all noisy observations prior to the Great Moderation, and is also permeated by the Great Recession, when "large shocks were not simply feeding through the usual dynamics. [...]. The usual dynamics did not explain what was going on for several months around the peak of the crisis." (Sims, 2012, p. 143).

To further our understanding of the role of in-sample events and how they are depicted by alternative uncertainty indicators, our comparison covers three different time spans (1969-2014, 1985-2014 and 2004-2014) common to the $F F$ and EURQ (when available). We also use a common VAR modelling approach, because as Baker et al. (2016, p. 1628) have pointed out, the magnitude of the uncertainty effects, their dependence on specific measures, and their correlation with other factors, are given meaning by VAR models.

Regarding our VAR specification, we selected 5 variables from the wide range of options offered by the literature. On the one hand, small bivariate VAR models - with only uncertainty and output, as in Bachmann et al. (2013) and Scotti (2016) - offer the advantage of parsimony but are subject to biases due to the omission of relevant macroeconomic channels. On the other hand, large VAR models - like the 11 variables imitating the macroeconomic model of Christiano et al. (1995)

\footnotetext{
${ }^{15}$ In addition, Jurado et al. (2015) argue that Bloom's over-shooting is a data figment mainly due to his HP filtering of uncertainty, since the over-shooting dynamics vanish with raw data.

16 This point is clearly explained in Carriero et al. (2016): the authors tackle the issue of estimating the impact of uncertainty shocks in the context of VAR models with measurement errors in uncertainty.
} 
in Jurado et al. (2015) - offer the advantage of a satisfactory theoretical basis, but suffer from inefficient estimates due to the curse of dimensionality. ${ }^{17}$ Our unrestricted VAR is as follows:

$$
\left[\begin{array}{l}
Z_{t} \\
x_{t}
\end{array}\right]=\left[\begin{array}{l}
\alpha_{1} \\
\alpha_{2}
\end{array}\right]+\left[\begin{array}{ll}
B_{11,1} & B_{12,1} \\
B_{21,1} & B_{22,1}
\end{array}\right]\left[\begin{array}{l}
Z_{t-1} \\
x_{t-1}
\end{array}\right]+\cdots+\left[\begin{array}{ll}
B_{11, p} & B_{12, p} \\
B_{21, p} & B_{22, p}
\end{array}\right]\left[\begin{array}{l}
Z_{t-p} \\
x_{t-p}
\end{array}\right]+\left[\begin{array}{l}
e_{1 t} \\
e_{2 t}
\end{array}\right]
$$

Given that the orthogonal shocks originating the impulse-response functions are recovered by means of a Cholesky decomposition, the way the variables are ordered is of paramount importance. Hence, $z_{t}$ is uncertainty, proxied in turn by: the predictability-based macroeconomic uncertainty index $(M P R E D)$ and the financial uncertainty index (FPRED), both of which were proposed by Ludvigson et al. (2015); the forecast disagreement index (FDISP) from Bachmann et al. (2013); the news-based policy uncertainty index, EPU, of BBD; the uncertainty measure (SCOTTI) from Scotti (2013); the VIX; our index based on internet searches (EURQ). ${ }^{18}$ Our second VAR component is the vector $x_{t}=\left(s p_{t}, f f_{t}, e m p_{t}, \text { ipman }\right)^{\prime}$, where: $s p$ are the log-levels of the S\&P 500 index; ff is the log of one plus the federal funds rate; emp represents the log-levels of manufacturing employment; and ipman represents the log-levels of the manufacturing production index. ${ }^{19}$ The order of our VAR implies that on impact, uncertainty shocks can affect the rest of the system, while uncertainty is assumed to be contemporaneously exogenous to the rest of the system. Our choice is coherent with the uncertainty exogeneity discovered by Carriero et al. (2018).

Figure 3 shows the dynamic response of the manufacturing production index to one standard deviation of the changes in uncertainty obtained from our VAR. Parameters are estimated over three different sample periods: (1) the largest one (1969-2014), over which MPRED, FPRED, FDISP and VIX are available; (2) a medium-length sample period (1985-2014) which adds the EPU to our comparison; (3) the shortest sample period (2004-2014) in which EURQ is also available.

\section{Figure 3 here}

Over the longest period, shocks to both MPRED and FPRED gradually reduce output, with effects persisting over the entire time span. Initially, the response monotonically decreases up to 1820 months after the shock, before stabilizing thereafter. In the long run, a one standard deviation innovation in MPRED and FPRED entails a loss of about $0.8-0.9 \%$ in the manufacturing production level. When implied volatility (VIX) is used to proxy uncertainty, the long-term effect of the uncertainty shock is much smaller in magnitude (about $-0.5 \%$ ), but still very persistent. The response

\footnotetext{
${ }^{17}$ In our case, this problem would be exacerbated by the short span available for our EURQ uncertainty measure.

${ }^{18}$ Here we use $E P U$ instead of $H N E W S$, so as to be in keeping with the literature on the role of uncertainty in economic activity. We take logs for FDISP, EPU, EURQ and VIX due to their more numerous outliers compared to other measures. ${ }^{19}$ Given the evidence of seasonality at the univariate level, we seasonally adjusted the data using the Census X13 filter. For each subsample, the lag length $p$ of each VAR is set using the AIC criterion (starting from $p=7$ ). If necessary, $p$ is slightly altered to induce white noise error terms and to ensure the stability of the VAR. The selection of the lag length slightly changes across samples.
} 
to an increase in forecast dispersion (FDISP) is relatively shorter lasting, but the negative effect still reaches its peak within the second year after the shock, and recovery is slow. This outcome is in line with those reported in Jurado et al. (2015, Fig. 6 and 7) and in Bachmann et al. (2013, Fig. 6). ${ }^{20}$ Overall, regardless of the size of the VAR, the use of forecast-based indicators qualifies uncertainty shocks as significant and persistent determinants of output fluctuations.

This result is, however, extremely arguable if we consider the stability of the VAR parameters, by measuring the dynamic response patterns of output to uncertainty shocks, over different sample periods. Over the medium-length 1985-2014 period, a shock to FDISP does not affect output significantly, with a peak effect of only $-0.2 \%$. FPRED and VIX still show the strong persistence of uncertainty shocks, with very slow or no recovery. Changing the sample does not affect estimates of the short-term impact produced by an uncertainty shock in MPRED, but a period of moderate growth follows the initial downturn. Notably, after excluding the noisy real shocks of the 1970s, the impact of uncertainty shocks on output in the long-term is essentially the same whether financial (FPRED and $V I X)$ or macroeconomic (MPRED) proxies are used. These estimations are slightly different from those obtained using the $E P U$, which show a decline in production over the first year and then a quick return to pre-shock conditions.

The estimates over the shorter 2004-2014 period confirm that the change in the sample period affects the dynamics of output responses much more than the use of different uncertainty indicators does. Although data limitation means that caution needs to be exercised when interpreting the results, the output responses clearly display negative short-run implications, and recovery in the long term, with a tendency to overshoot in the case of MPRED. Uncertainty shocks implied by all measures have no statistically significant impact on industrial production after the third year. Importantly, this short period was permeated by substantial financial shocks, while the dynamics of output responses to shocks in non-financial indexes resemble the short-lived impact that Bloom (2009) obtained with a finance-based measure of uncertainty over a long sample period. Shocks to the $E U R Q$ produce effects very similar, both in magnitude and persistence, to those of the $E P U$, curbing output in the short-run and with a negative effect that dissipates quickly.

Figure 4 shows the impact of increases in the uncertainty indexes set equal to the uncertainty shock caused by the Lehman bankruptcy. Specifically, we normalize the shock size of each uncertainty proxy to be equal to the increase from the average value in June-August 2008 to the average value in September-November 2008. Although we control for the size of the shock, the dynamics of output clearly change in the different temporal subsamples. The intensity of the negative response of industrial production is sharper for the most recent sample period, and a rapid recovery

\footnotetext{
${ }^{20}$ Our standard error bands are smaller because of the greater parsimony of our VAR.
} 
is observed. Shocks in forecast-based proxies lead to a stronger impact on economic activity compared to other measures, since according to such proxies fluctuations in uncertainty of a magnitude equal to the Lehman collapse are extremely rare events that are much more severe than others occurring during the temporal subsamples. ${ }^{21}$

\section{Figure 4 here}

Overall, the findings from a common VAR setting comparatively estimated over alternative periods, show that the different historical events specific to each period determine the output responses more than the use of different uncertainty measures does. ${ }^{22}$ In other words, different uncertainty measures produce different output responses to shocks simply because each of them represents the historical events differently.

On the one hand, a lengthy time-span comprising an era of substantial, noisy real shocks (in the 1960s and 1970s) reveals the significant long-term effects of uncertainty on output (regardless of whether forecast-based or finance-based). On the other hand, a short time-span almost entirely centred on large, noisy financial shocks (those that occurred during the Great Recession) reveals strong shortterm effects which quickly abate (in about a year) and are then followed by a period of recovery.

We provide two possible explanations for this based on two recent strands of research together with our own interpretation. The "statistical view" supports our idea that shocks of a different nature and intensity, at different periods of time, are measured differently by the diverse uncertainty indexes. The "economic view" suggests that different events are related to structural changes in the model parameters.

According to the "statistical view", the measurement errors create attenuation bias in the estimates; for example, Carriero et al. (2015) show that accounting for measurement errors produces a larger and more persistent estimated impact of shocks to financial uncertainty than that estimated by Bloom (2009). ${ }^{23}$ We suggest that the extent of the bias will depend on the ratio of the signal conveyed by the uncertainty proxies (relating to the size and composition of the economic shocks) to the noise (the measurement errors). The noise is probably less important over the 1960-2014 sample period, because the large real shocks to the cycle witnessed in the 1960s and 1970s are expected to prevail over any measurement errors: the impulse-response patterns will be slightly downward biased.

\footnotetext{
${ }^{21}$ The magnitude imposed for the calibration is about 14 times the average monthly increase in MPRED, 11 times that of FPRED, 6 times that of VIX, 4.5 times that of EPU, 3.8 times that of SCOTTI, 3.4 times that of EURQ and 1.0 times that of FDISP.

${ }^{22}$ A similar effect was witnessed in a different context by Rossi (2006).

${ }^{23}$ See the last two plots of Figure 3 in Carriero et al. (2015). Measurement errors are accounted for in their proxy SVAR by using instrumental variables. The results are quite interesting, even if the task of finding exogenous variations in uncertainty, in order to identify genuine responses, is a tough one, as can be seen by the results in Stock and Watson (2012) and the ensuing strong criticism of those results.
} 
Over the shorter sample period (2004-2014) on the other hand, the measurement errors tend to prevail over the signal because noisy financial shocks jeopardize the other (macroeconomic) uncertainty signals. All the uncertainty measures are unavoidably affected by measurement errors, but the impression is that forecast-based and finance-based indexes are probably the most significantly affected.

Moreover, from the "economic view" we can affirm that the decreasing persistence of the output response to uncertainty shocks in the shorter period is due to events specific to that period. For example, Mumtaz and Theodoridis (2016) simulate a DSGE model to explain the empirical (FAVAR) evidence of the effects of uncertainty shocks on real activity which systematically declines over time. The weakening persistence of the effect of an adverse uncertainty shock in more recent periods (such as our shorter sample period) can be explained by an increase in the Federal Reserve's antiinflationary stance (in line with the shift before and after Volcker's appointment as Fed Chairman in 1979, as suggested by Clarida et al. (2000)), and by a change in the parameters of the Phillips curve, implying a rise in price stickiness and a fall in indexation to past inflation, as confirmed by Stock and Watson (2007), and by Cogley et al. (2010).

Finally, our results are in line with Scotti (2016) and Caggiano et al. (2014, 2017). By operating a bivariate VAR exercise with employment and uncertainty proxies for the USA over the last decade (2003m5-2016m3, close to our short period), Scotti (2016) shows that when uncertainty is strictly related to real activity as measured by her real-activity uncertainty index, it potentially has a weaker impact on economic activity than when uncertainty is more generally related to economic and financial conditions as measured by the VIX (whose impact on real-activity variables seems to be stronger and faster). By using a smooth transition VAR with different parameters in recessions and periods of growth, Caggiano et al. $(2014,2017)$ find that the response of output and unemployment to uncertainty shocks is greater during recessions. Since our short period is permeated by Great Recession data, our results in Figure 4 are in line with the wait-and-see dynamics of output reported in figure 6 of Caggiano et al. (2014).

\subsection{A case study: the EURQ index for Italy}

Key factors for a successful country-specific EURQ index: the amount and adequacy of the search terms. Given the multifaceted nature of uncertainty, a high-quality EURQ index must derive from an accurate list of several clearly explicable search terms specific to the country under analysis. The construction of the EURQ index for Italy is based on the same Condition \#2 (C2) used in the American case: Web searches represent the need for more information fuelled by uncertainty, if the queries include the Italian equivalent of the $210 \mathrm{BBD}$ terms used to construct the EURQ index for the 
USA. More specifically, starting from the classical BBD list, the definition of an adequate Italian list regards in part the pure translation of terms from English to Italian, whereas what really matters is a careful consideration of the features and facts specific to the Italian economy and to Italian politics. The following examples may make this clearer. The English term WTO, World Trade Organization, has not been translated because it registers a higher number of searches than the Italian acronym OMC, Organizzazione Mondiale del Commercio. Conversely, the term "terrorism" has been translated into the Italian "terrorismo", while the Italian word "tassazione" easily translates to the English "taxation". On the other hand, the term “collective bargaining law", which in the USA refers to negotiations between an employer and a group of employees to determine the employment conditions, has been substituted by the term CCNL, the Italian acronym for "Contratto Collettivo Nazionale di Lavoro", that is, a national agreement between trade unions and employers (National [Collectively Bargained] Labour Agreement) specific to Italy.

At the end of this process of assessment, we ended up with a final list of 136 search terms which, when aggregated following the same web-scraping procedures introduced in Section 2.3, led to the vintages of the $E U R Q$ index for Italy. The annotated graph of the January 2019 vintage can be seen in Figure 5.

\section{Figure 5 here}

The main features of the $E U R Q$ for Italy are compared with those of seven alternative uncertainty indexes. As regards the case of the USA, we use three Italian equivalents of the $F F$ finance-based, forecast-based and news-based indicators, namely: the volatility index of the Italian stock market (SVOL), the uncertainty index MUI of Jurado et al. (2015), and the NEWS index of BBD (2016) for Italy. ${ }^{24}$ The comparison is completed by the addition of the Italian versions of the three Google-based indexes proposed by the literature; these indexes could be considered EURQ's competitors, but being based on very narrow sets of search terms their reliability is questionable: the $U I$ of BBVA (2012) has 15 terms, the GSI of Donadelli (2014) has 3 terms, and the ECON of Dzielinski (2012) has one term only. Finally, we also compute another search-based index labelled EPUGT, obtained using the Italian translations of the 9 terms used by BBD to compute their NEWS index for Italy. Figures 6 and 7 present the patterns of the $E U R Q$ for Italy together with the seven alternative indexes, over the common period 2004m1-2017m12 (2004m1-2015m12 for MUI and SVOL).

\section{Figures 6 and 7 here}

\footnotetext{
${ }^{24}$ Both SVOL and MUI for Italy are reported in Meinen and Roehe (2017), while NEWS for Italy is downloadable from the BBD Web page of the Economic and Policy Uncertainty index.
} 
The finance-based, forecast-based and news-based indexes for Italy display historical patterns that are qualitatively similar to those for the USA. The EURQ index for Italy is in line with MUI, SVOL and NEWS, but it adds important information, such as the sharp increase in uncertainty due to the fallout from the European debt crisis of 2011, and seems to better capture the higher uncertainty associated with the labour market reforms (2012m6 and 2015m3), the election cycle in 2013m2, and the constitutional referendum dispute in $2016 \mathrm{~m} 11$.

Conversely, the four search-based uncertainty measures created by utilising fewer terms (GSI, but particularly ECON, $U I$ and EPUGT) display odd temporal paths in continuous decline since their initial creation in 2004. As pointed out above, the indexes based on Web searches may be affected by measurement errors and biases if an adequate, large set of queries is not selected.

The macroeconomic dynamics of the EURQ index for Italy. As for the USA, we estimate the impulse response functions of output to uncertainty shocks measured by alternative indexes also in the case of Italy. Again, for the purposes of comparability with the results given in Section 3.2, the VAR used is similar to that in equation (1), where $z_{t}$ is uncertainty, proxied in turn by: EURQ, SVOL, MUI and NEWS. Our second VAR component is the vector $x_{t}$ composed of: $\log (\mathrm{FTSE}-\mathrm{MIB})$, i.e the benchmark Italian Stock Exchange index; $\log (1+$ one-month Euribor); $\log (\mathrm{employment})$; $\log$ (industrial manufacturing production). ${ }^{25}$ The impulse response functions are shown in Figure 8.

\section{Figure 8 here}

Following a $E U R Q$ shock, industrial production registers an immediate decline followed by a recovery with no overshooting. A shock in either $M U I$ or $S V O L$ determines negative mid-term effects: the lowest troughs occur after about 2 years, and are followed by slow recovery. On the contrary, a shock in NEWS involves an inexplicable short-run increase in industrial production followed by a long-term decline in such. This odd pattern of responses is related to the downward trend of the index (similar to that of its search-version EPUGT), and may be ascribed to a measurement of events producing uncertainty in Italy that is inevitably less accurate than that of the $E U R Q$ for Italy. Once again, these results corroborate the idea that the search-based indexes must be based on a large, adequate and duly motivated set of queries.

\section{4. $E U R Q$ as a means of assessing how specific uncertainty components are perceived}

In pondering the relationship between news and the Internet, a recent Pew research centre found that "Six in ten American adults (61\%) get news online on a typical day, placing it third among the six major news platforms asked about in the survey, behind local television news and national or

\footnotetext{
${ }^{25}$ We take logs for the uncertainty indexes, and we use seasonally-adjusted levels if seasonality is significant. Optimal lag length selection is also defined by statistical procedures as in the case of the USA.
} 
cable television news. While the internet is growing as a news platform, it has not displaced completely offline news sources for most American adults: Most Americans (59\%) get news from a combination of online and offline sources on a typical day. Just over a third (38\%) relies solely on offline sources, while just $2 \%$ rely exclusively on the internet for their daily news.". Given this situation, the relationship between press coverage and the information that people want to obtain from the Web needs to be analysed; and it is even more important to try and understand what type of uncertainty is perceived by economic agents before the press begins to divulge the news in question, and conversely, what kind of news attracts the interest of economic agents and encourages them to look for information online. Whether or not a specific uncertainty is a harbinger of fear, to be searched for on the web before the press starts mentioning it, will certainly have repercussions in terms of economic policy.

The present section thus offers a comparison between our EURQ index and the BBD's Newsbank series, in terms of 8 policy categories: fiscal policy, monetary policy, healthcare, national security and war, regulation, foreign sovereign debt and currency crises, entitlement programs, and trade policy. ${ }^{26}$

\section{1 - The methodological framework}

The basic ingredients of our experiment are two sets of series measuring searches for the same terms belonging to policy category $c$ : Newsbank $k_{c t}$ (BBD news-based counts), and $E U R Q_{c t}$ (Google Trends search volumes), where $c=1,2, . ., 8$ (policy categories), and $t$ are monthly observations over the period 2004m1-2014m12 (with $T=132$ months). Although referring to the same search terms, these two variables are different: according to Newsbank $k_{c t}$, journalists are the messengers of uncertainty, which they convey by using specific words; according to $E U R Q_{c t}$, Google users are the ones who manifest their interest/uncertain mood by searching more/less intensively for the same words used by the newspapers.

The dynamic relationship between Newsbank $k_{c t}$ and $E U R Q_{c t}$ can be assessed within the context of the VAR model. Let us suppose that for the $c^{\text {th }}$ category, the $k$-dimensional stationary $\operatorname{VAR}(p)$ process $y_{c t}$ consists of the $m$-dimensional process $z_{c t}$ and the $(k-m)$-dimensional process $x_{c t}$ with non-singular white noise covariance matrix $\Sigma_{\mathcal{E} c}$ :

$$
y_{c t}=\left[\begin{array}{l}
z_{c t} \\
x_{c t}
\end{array}\right]=\left[\begin{array}{l}
\mu_{c 1} \\
\mu_{c 2}
\end{array}\right]+\left[\begin{array}{ll}
A_{c 11,1} & A_{c 12,1} \\
A_{c 21,1} & A_{c 22,1}
\end{array}\right]\left[\begin{array}{c}
z_{c t-1} \\
x_{c t-1}
\end{array}\right]+\ldots+\left[\begin{array}{ll}
A_{c 11, p} & A_{c 12, p} \\
A_{c 21, p} & A_{c 22, p}
\end{array}\right]\left[\begin{array}{c}
z_{c t-p} \\
x_{c t-p}
\end{array}\right]+\left[\begin{array}{l}
\varepsilon_{c 1 t} \\
\varepsilon_{c 2 t}
\end{array}\right]
$$

\footnotetext{
${ }^{26}$ Some empirical research (e.g. Eberth et al., 2014) has focused on modelling the ways information is divulged via the Internet, and the speed at which this happens, albeit in topics not concerned with assessing the role that uncertainty plays in generating people's interest and concern.
} 
where, in our bivariate context: $k=2$ and $m=1 ; y_{c t}=\left(N e w s b a n k_{c t}, E U R Q_{c t}\right)^{\prime}$ is the vector of the variables of interest for the $c^{\text {th }}$ category (therefore, $z_{c t}=N e w s b a n k_{c t}$ and $x_{c t}=E U R Q_{c t}$ ); scalars $\mu_{c}$ and matrices $A_{c}$ are heterogeneous parameters (they are allowed to differ across categories); and $\varepsilon_{c t}=\left(\varepsilon_{c 1 t}, \varepsilon_{c 2 t}\right)^{\prime}=\left(\varepsilon_{c t}^{N e w s b a n k}, \varepsilon_{c t}^{E U R Q}\right)^{\prime}$ is the vector of the random shocks to the Newsbank and $E U R Q$ uncertainty measures for $c$. The lag length $p$ is first set by using the AIC criterion (starting from $p=13$ ), and the corresponding residuals are tested for white noise errors (otherwise $p$ is slightly altered until the white noise residuals target is met). The joint stationarity of all the variables listed in the VAR model, i.e. the system (2) has full rank, is assessed by means of the Johansen (1995) trace test. Finally, seasonal dummies, if significant, are included in the VAR models.

The analysis conducted using the VAR system (2) relies on two basic concepts: Grangercausality and instantaneous-causality. Granger causality involves the assessment of the null hypotheses: $A_{c 12, i}=0$ for $i=1,2, \ldots, p$ (which implies that Newsbank is not Granger-caused by $E U R Q$ ), and $A_{c 21, i}=0$ for $i=1,2, \ldots, p$ (which implies that $E U R Q$ is not Granger-caused by Newsbank). ${ }^{27}$ In our context, Granger causality from Newsbank to EURQ for a certain category $c$ implies that past news-based shocks are related to present Google searches: past newspaper headlines lead people to seek further knowledge about $c$ even after the news shock has occurred. In other words, the news-based measure of the uncertainty category $c$ - informing people about what is happening now - drives Google searches that, over time, propagate following their own dynamics $A_{c 22, i}$ as in the epidemiological model of Carroll (2003). Conversely, Granger causality from EURQ to Newsbank for a certain category $c$ can be explained as if journalists feed readers' constant need for information regarding subject $c$ and continue to satisfy that need in their newspapers. In this second case, Google searches - signalling readers' interest in $c$ - "drive" the news-based measure of this category. This second case is excluded in the context of Carroll's model, where the direction of causality can only be from the news towards peoples' actions.

Although we must be very careful when interpreting the outcomes of statistical tests in behavioural terms, for the sake of brevity we shall now label Granger causality from Newsbank to $E U R Q$ as "news-pooled" uncertainty, and Granger causality from EURQ to Newsbank as "querydriven" interest. Given that each category is made up of a number sub-groups, and each sub-group is made up of single search terms, after detecting the direction of the Granger causality for each category the outcomes by category may be expanded on by replacing the $E U R Q$ measure for category $c$ in the

\footnotetext{
${ }^{27}$ When the Johansen's test does not reject the null of reduced rank (i.e. that not all the variables are stationary), Granger causality is tested by means of the Toda and Yamamoto (1995) approach.
} 
bivariate VAR with its component sub-groups, followed by the most relevant single search terms within each sub-group.

Given that VAR residuals are not orthogonal, i.e. the covariance matrix $\Sigma_{\varepsilon}$ is usually not diagonal because these models are in a reduced form, the presence of a significant instantaneous correlation between Newsbank and EURQ shocks $\left(E\left(\varepsilon_{c 1 t} \varepsilon_{c 2 t}^{\prime}\right) \neq 0\right)$ simply means that the two measures of uncertainty for $c$ are coincident, i.e. that news and Internet search shocks regarding uncertainty/interest about category $c$, occur in the same month.

\section{2 - Empirical results by policy category}

The main results of using VAR system (2) are summarised in the upper section of Table 2, where two columns and three rows delimit six areas (cases) containing the 8 categories. The columns are used to classify the categories as cases of high/low instantaneous correlation (degree of coincidence), depending on whether the value of such correlation is higher or lower than 0.25 (the level denoting $1 \%$ statistical significance). The 8 categories are classified into three cases along the rows: the case of news-pooled uncertainty (when Newsbank Granger causes EURQ), the case of query-driven interest (when EURQ Granger causes Newsbank), and finally the case of no-dynamicsuncertainty-interest (when Granger causality is not statistically significant in either direction).

\section{Table 2 here}

"Fiscal policy" (FP) and "Sovereign debt and currency crisis" (SDCC) are carefully monitored by people: the number of Internet searches for such terms increase as soon as shocks occur, even if newspapers do not give the same importance to them. Internet activity and newspaper mentions overlap significantly, with the instantaneous correlation coefficient always high (in the 0.40-0.50 range) and strongly significant. "Health care" (HC) also leads news-based uncertainty, but with lower significance and intensity. When investigating the main components (at the level of individual search terms) of this query-driven uncertainty, we found the following. As far as the "Fiscal policy" category (FP) is concerned, the most relevant Google search terms are "Debt ceiling" and "Government deficits", while "Sovereign debt and currency crisis" (SDCC) searches were mostly accounted for by the term "Sovereign debt" (although "Currency devaluation" and "Euro crisis" also played a significant role). Finally, the "Health care" $(\mathbf{H C})$ category result is due mainly to use of the search term "Affordable Care Act".

The direction of Granger causality is reversed in the case of "Monetary policy" (MP) and "Regulation" (RE): people only start searching the web for more information about these categories after the newspapers have begun to mention them; in such cases, news-based shocks drive Google searches. The "Trade policy" (TP) category behaves rather similarly, albeit at a considerably lower 
level of instantaneous correlation, which probably denotes the general public's limited interest in the news within this category (the correlation coefficient here is about 0.10 , against values of 0.55 and 0.31 recorded in the previous two cases, respectively).

Finally, the "Entitlement programs" (EP) and "National security and war" (NS) categories do not display any Granger causality from press and media reports to Google searches, or vice versa. However, they behave differently as far as the degree of simultaneity is concerned. In fact, for "Entitlement programs", the Newsbank and EURQ are correlated (above 0.40), denoting in the same month a substantial overlap of press reports and internet searches. Instead, in the case of "National security and war", the instantaneous correlation is halved, suggesting that the need for knowledge that feeds the Google searches is not related to any great degree to newspaper headlines, as readers were already aware of the matter in question as a result, for example, of "chatting with neighbours over the garden fence”. On the terrorism issue, see the recent Jetter (2019).

In order to relate these findings to the discussion in Section 3.2, the identification and measurement of specific types of uncertainty is extremely important, since the output responses to uncertainty are influenced by the nature (and intensity) of the occurred shocks. Macro-real uncertainty is a spontaneous and autonomous driver of the agents' economic behaviour, while uncertainty related to normative, monetary and financial issues only captures people's interest after having been the object of journalistic interest. In the latter case, newspapers can feed the worries of agents, and this could explain why the reduction in economic activity is more pronounced during periods more greatly affected by financial shocks.

\section{Results and discussion}

Our results can be discussed on the basis of our paper's two main aims. The first aim is to use Internet searches to create the new $E U R Q$ index measuring the volumes of "economic uncertainty related queries". EURQ is based on the effective behaviour of all economic agents and represents their need for information when they are concerned and uncertain about political and economic events. Being based on people's moods, $E U R Q$ can quantify additional important qualitative aspects of uncertainty that are not easily accounted for by the uncertainty indexes proposed in the literature. By comparing $E U R Q$ with a list of finance-based, forecast-based and news-based indexes within the context of the same VAR modelling framework, and over the same periods, we find that output responses to uncertainty are influenced by the nature and intensity of the shocks, rather than by the type of uncertainty index used. The literature shows that each uncertainty measure has its own dynamic effects on output: finance-based uncertainty induces overshooting effects, forecast-based uncertainty induces highly persistent effects, and news-based uncertainty induces transitory effects. 
These differences in the responses to uncertainty are less relevant if they result from common time spans and VAR modelling, and our evidence supports the idea that the different uncertainty measures produce different output responses to shocks simply because each of them accounts for historical events differently. All the uncertainty proxies are measured with errors (Carriero et al., 2015), but the period-specific signal-to-noise ratios affect the finance-based and forecast-based indexes more than the news-based and searches-based indexes. Also, the events occurring in certain periods imply structural changes in the parameters establishing the role of uncertainty (Mumtaz and Theodoridis, 2016). Hence, the $E U R Q$ index improves our understanding of the heterogeneous nature of uncertainty.

The second aim is to establish whether the interest manifested by economic agents is driven by certain specific events, or whether given types of uncertainty generate the spontaneous interest of economic agents. The joint analysis of news-based measures of uncertainty and the $E U R Q$ suggests that distinct categories of economic and policy uncertainty entail alternative dynamic relationships between newspaper headlines and Internet activity. Topics relating to taxes, health and economic crises generate people's spontaneous, conscious interest regardless of any stimulus from the press. This suggests that uncertainty over fiscal policy may manifest its impact on economic variables at a very early stage. On the other hand, topics only affecting people's lives after changes have been made to rules/regulations and monetary/foreign policies, tend to stimulate the interest of economic agents only after the press has reported such changes and journalists have "driven" the public's general attention towards such issues. This suggests that financial shocks are amplified, and produce a more pronounced reduction in economic activity, as a consequence of the journalists' intervention and the multiplicative effect of the Internet. Extremely important issues concerning employment and terrorism, simultaneously generate the interest of both people and the press, without the one influencing the other.

\subsection{Conclusions}

Macroeconomic uncertainty comprises several unobservable components. As such, it is difficult to fully quantify using any specific measure, as such may be based on only a few of the aforesaid components. The heterogeneous nature of uncertainty is substantiated by the literature, which proposes a variety of different indicators: finance-based, forecast-based and news-based. In short, measuring uncertainty is a very "uncertain" activity. Moreover, we do not know how and when people perceive uncertainty, and which components of uncertainty may have a strong impact on economic agents. "The measures of uncertainty tend to combine economic uncertainty with other notions. For example, stock return volatility combines information about stock market volatility with 
economic uncertainty, and forecast disagreement could measure a divergence of opinions among forecasters rather than just the underlying uncertainty about the economy" (Scotti, 2016, p. 2). Moreover, "Agents base decisions on their perceived uncertainty rather than on an objective uncertainty that they do not observe" (Scotti, 2016, p. 16).

Our EURQ index delivers patterns that, in the context of uncertainty measurement, are both interesting and useful. Provided that the "appropriate" set of queries is posed, the $E U R Q$ index is based on large-scale data from a freely available survey delivering updated monthly information on people's moods. We believe that the EURQ index furthers our knowledge of the dynamics of the perception of uncertainty by all economic agents, and of the specific components of uncertainty that worry economic agents the most. In the future we aim to create a series of disaggregated EURQ indexes: one based on macroeconomic queries, another based on financial queries, another based on normative queries, and a fourth one based on political queries. This disaggregation may help deal with measurement errors and the endogeneity of the mainstream uncertainty indexes proposed in the literature (for a recent example of estimates of the impact of different types of uncertainty on the US economy, see Mumtaz and Surico, 2018). We also shed some light on the miscellanea of empirical results in other papers (Angelini et al., 2017, Ludvigson et al., 2017, and Shin and Zhong, 2016), and offer new interpretations encompassing the recent statistical and economic views of Carriero et al. (2016), Mumtaz and Theodoridis (2016), and Scotti (2016).

\section{References}

Alexopoulos, M. and J. Cohen (2015), "The power of print: uncertainty, markets, and the economy", International Review of Economics and Finance, Vol. 40, pp. 8-28.

Algan, Y., E. Beasley, F. Guyot, K. Higa, F. Murtin and C. Senik (2016), "Big data measures of well-being: Evidence from a Google well-being index in the US", OECD Statistics Working Paper, No. 3.

Angelini, G., E. Bacchiocchi and L. Fanelli (2017), "Uncertainty across volatility regimes", mimeo.

Bachmann, R, S. Elstner and E. R. Sims (2013), "Uncertainty and the economic activity: evidence from business survey data", American Economic Journal: Macroeconomics, Vol. 5, No. 2, pp. 217-249.

Baker, S. R., N. Bloom and S. J. Davis (2016), "Measuring economic policy uncertainty", The Quarterly Journal of Economics, Vol.131, No. 4, pp. 1593-1636.

Baker, S. R. and A. Fradkin (2017), "The impact of unemployment insurance on job search: evidence from Google search data", mimeo downloadable: http://andreyfradkin.com/assets/FullTexasJobSearch.pdf

BBVA (2012), "Uncertainty: models and impacts", Economic Watch https://www.bbvaresearch.com/KETD/fbin/mult/120321_EconomicWatchEEUU_155_tcm348297922.bbvapdf

Beetsma, R. and M. Giuliodori (2012), "The changing macroeconomic response to stock market volatility shocks", Journal of Macroeconomics, Vol. 34, pp. 281-293.

Bekaert, G., M. Hoerova and M. Lo Duca (2013), "Risk, uncertainty and monetary policy", Journal of Monetary Economics, Vol. 60, No. 7, pp. 771-788.

Bloom, N. (2009), "The Impact of uncertainty shocks", Econometrica, Vol. 77, No. 3, pp. 623-685. 
Bloom, N. (2014), "Fluctuations in uncertainty", Journal of Economic Perspectives, Vol. 28, No. 2, pp. 153176.

Bouri, E and R. Gupta (2019), "Predicting Bitcoin returns: comparing the roles of newspaper- and internet search-based measures of uncertainty", https://www.up.ac.za/media/shared/61/WP/wp_2019_55.zp177350.pdf

Bulut, L. (2018), "Google Trends and the forecasting performance of exchange rate models", Journal of Forecasting, Vol.37, pp. 303-315.

Caggiano, G., E. Castelnuovo and N. Groshenny (2014), "Uncertainty shocks and unemployment dynamics in US recessions", Journal of Monetary Economics, Vol. 67, pp. 78-92.

Caggiano, G., E. Castelnuovo and N. Groshenny (2017), "Economic policy uncertainty and unemployment in the United States: a nonlinear approach”, Economics Letters, Vol. 151, pp. 31-34.

Carrière-Swallow Y. and F. Labbé (2013), “Nowcasting with Google Trends in an Emerging Market”, Journal of Forecasting, Vol. 32, pp. 289-298.

Carriero, A., H. Mumtaz, K. Theodoridis and A. Theophilopoulou (2015), "The impact of uncertainty shocks under measurement error: a proxy SVAR approach", Journal of Money, Credit and Banking, Vol. 47, No. 6, pp. 1223-1238.

Carriero, A., T. E. Clark and M. Marcellino (2018), "Endogenous Uncertainty", Federal Reserve Bank of Cleveland, Working Paper No. 18-05.

Carroll, C. D. (2003), Macroeconomic expectations of households and professional forecasters", The Quarterly Journal of Economics, Vol. 118, No. 1, pp. 269-298.

Castelnuovo, E. and T. D. Tran (2017), "Google It Up! A Google Trends-based Uncertainty index for the United States and Australia", Economics Letters, Vol. 161, pp. 149-153.

Chicago Board Options Exchange, (2009), "The CBOE Volatility Index- VIX", CBOE White Paper.

Choi, S. (2013), "Are the effects of Bloom's uncertainty shock robust?", Economics Letters, Vol. 199, pp. 216220.

Christiano, L. J., M. Eichenbaum and C. L. Evans (2005), "Nominal rigidities and the dynamic effects of a shock to monetary policy", Journal of Political Economy, Vol. 113, No. 1, pp. 1-45.

Clarida, R., J. Galì and M. Gertler (2000), "Monetary policy rules and macroeconomic stability: evidence and some theory", The Quarterly Journal of Economics, Vol. 115, No. 1, pp. 147-180.

Cogley, T., G. E. Primiceri and T. J. Sargent (2010), "Inflation-gap persistence in the US", American Economic Journal: Macroeconomics, Vol. 2, pp. 43-69.

Coibion, O. and Y. Gorodnichenko (2015), "Information rigidity and the expectations formation process: a simple framework and new facts", American Economic Review, Vol. 105, No. 8, pp. 2644-2678.

Da Z., J. Engelberg and P. Gao (2011), "In Search of Attention", The Journal of Finance, vol. 66, No. 5, pp. 1461-1499.

Da Z., J. Engelberg and P. Gao (2015), "The Sum of All FEARS Investor Sentiment and Asset Prices", Review of Financial Studies, vol. 28, No. 1, pp. 1-32.

D'Amuri, F. and J. Marcucci (2017), "The predictive power of Google searches in forecasting unemployment", International Journal of Forecasting, Vol. 33, pp. 801-816.

Das, A., K. Lahiri and Y. Zhao (2019), "Inflation expectations in India: Learning from household tendency surveys", International Journal of Forecasting, Vol. 35, pp. 980-993.

Der Kiureghian, A and O. Ditlevsen (2009), "Aleatory or epistemic? Does it matter?", Structural Safety, Vol. 31, No. 2, pp. 105-112.

Donadelli, M. (2015), "Google search-based metrics, policy-related uncertainty and macroeconomic conditions", Applied Economic Letters, Vol. 22, No. 10, pp. 801-807. 
Donadelli, M. and L. Gerotto (2018), "Non-macro-based Google searches, uncertainty and real economic activity", Research in International Business and Finance, forthcoming.

Drake M. S., D. T. Roulstone and J. R. Thornock (2012) "Investor Information Demand: Evidence from Google Searches Around Earnings Announcements", Journal of Accounting Research, Vol. 50, No. 4, pp. 1001-1040.

Dzielinski, M. (2012), "Measuring economic uncertainty and its impact on the stock market", Finance Research Letters, Vol. 9, pp. 167-175.

Eberth, J. M., K. N. Kline, D. A. Moskowitz, J. R. Montealegre and M. E. Scheurer (2014), "The role of media and the internet on vaccine adverse event reporting: a case study of human papillomavirus vaccination", Journal of Adolescent Health, Vol. 54, pp. 289-295.

Fernandez-Villaverde, J., P. Guerron-Quintana, K. Kuester and J. Rubio-Ramirez (2015), "Fiscal volatility shocks and economic activity", American Economic Review, Vol. 105, No. 11, pp. 3352-3384.

Gilchrist, S., J. W. Sim and E. Zakrajsek (2014), "Uncertainty, financial frictions and investment dynamics", NBER Working Papers Series, No. 20038.

Gotz, T. B. and T. A. Knetsch (2019), "Google data in bridge equation models for German GDP", International Journal of Forecasting, Vol. 35, pp. 45-66.

Harmanec, D. (1999), "Measures of uncertainty and information", Documentation Section, Society for Imprecise Probability Theory and Applications, http://www.sipta.org/

Henzel, S. R. and M. Rengel (2014), "Dimensions of macroeconomic uncertainty: a common factor analysis", CESifo Working Papers, No. 4991.

Jetter, M. (2019), "The inadvertent consequences of al-Qaeda news coverage", European Economic Review, Vol. 119, pp. 391-410.

Johansen, S. (1995), Likelihood-based Inference in Cointegrated Vector Autoregressive Models, Oxford University Press.

Julio, B. and Y. Yook (2012), "Political Uncertainty and Corporate Investment Cycles", The Journal of Finance, Vol. 67, pp. 45-83.

Jurado, K., S.C. Ludvingson and S. Ng (2015), "Measuring uncertainty", American Economic Review, Vol. 105, No. 3, pp. 1177-1216.

Knotek, E. S. and S. Khan (2011), "How do households respond to uncertainty shocks?", Economic Review of the Federal Reserve Bank of Kansas City, Second Quarter, pp. 5-34.

Kupfer, A. and J. Zorn (2019), "A language-independent measurement of economic policy uncertainty in eastern European countries", Emerging Markets Finance and Trade, forthcoming

Lahiri, K. and X. Sheng (2010), "Measuring forecast uncertainty by disagreement: The missing link", Journal of Applied Econometrics, Vol.25, pp. 514-538.

Lahiri, K. and Y. Zhao (2017), "Determinants of consumer sentiment over business cycles: evidence from the US Survey of Consumers", Journal of Business Cycle Research, Vol. 12, No. 2, pp. 187-2015.

Leduc, S. and Z. Liu (2016), "Uncertainty shocks are aggregate demand shocks", Journal of Monetary Economics, Vol. 82, pp. 20-35.

Lemieux, J. and R. A. Peterson (2011), "Purchase deadline as a moderator of the effects of price uncertainty on search duration", Journal of Economic Psychology, Vol. 32, pp. 33-44.

Ludvigson, S. C., S. Ma and S. Ng (2017), "Uncertainty and business cycles: exogenous impulse or endogenous response?", NBER Working Paper, No. 21803, revised.

Ludvigson, S. C. and S. Ng (2017), "Appendix for updates of uncertainty data", downloadable at the web site https://www.sydneyludvigson.com/s/uncertainty_data_appendix_2017MAR_update.pdf

Manski, C. F. (2015), "Communicating uncertainty in official economic statistics: an appraisal fifty years after Morgenstern", Journal of Economic Literature, Vo. 53, No. 3, pp. 631-653. 
Meinen, P. and O. Roehe (2017), "On measuring uncertainty and its impact on investment: Cross-country evidence from the euro area", European Economic Review, Vol. 92, pp. 161-179.

Mumtaz, H. and K. Theodoridis (2016), "The changing transmission of uncertainty shocks in the US: An empirical analysis", Journal of Business \& Economic Statistics, doi: 10.1080/07350015.2016.1147357

Mumtaz, H and P. Surico (2018), "Policy uncertainty and aggregate fluctuations". Journal of Applied Econometrics, https://doi.org/10.1002/jae.2613

Pew Research Center (2016), "The modern news consumer: News attitudes and practices in the digital era", downloadable at http://www.journalism.org/2016/07/07/the-modern-news-consumer/

Ramey, V. A. (2011), "Identifying government shocks: it's all in the timing", The Quarterly Journal of Economics, Vol. 126, No. 1, pp. 1-50.

Reis, R. (2006), "Inattentive producers", Review of Economic Studies, Vol. 73, pp. 793-821.

Repetto, L. (2018), "Political budget cycles with informed voters: evidence from Italy", The Economic Journal, forthcoming.

Rich, R and J. Tracy (2010), "The relationships among expected inflation, disagreement, and uncertainty: evidence from matched point and density forecasts", The Review of Economics and Statistics, Vol. 92, No. 1, pp. 200-207

Romer, C. D. (1990), "The great crash and the onset of the great depression", Quarterly Journal of Economics, Vol. 105, No. 3, pp. 597-624.

Romer, C. D. and D. H. Romer (2004), "A new measure of monetary shocks: derivation and implications", American Economic Review, Vol. 94, No. 4, pp. 1055-1084.

Rossi, B. (2006), "Are exchange rates really random walks? Some evidence robust to parameter instability", Macroeconomic Dynamics, Vol. 10, No. 1, pp. 20-38.

Rossi, B and T. Sekhposyan (2015), "Macroeconomic Uncertainty Indices Based on Nowcast and Forecast Error Distributions", American Economic Review, Vol. 105, No. 5, pp. 650-655.

Schaal, E. (2015), “Uncertainty and unemployment”, mimeo downloadable from author's website: https://sites.google.com/site/edouardschaal/research

Scotti, C. (2016), "Surprise and uncertainty indexes: real-time aggregation of real-activity macro surprises", Journal of Monetary Economics, Vol. 82, pp. 1-19.

Segal, G., I. Shaliastovich and A. Yaron (2015), "Good and bad uncertainty: macroeconomic and financial market implications", Journal of Financial Economics, Vol. 117, No. 2, pp. 369-397.

Sims, C. A. (2012), "Comment by", Brookings Papers on Economic Activity, Spring, pp. 141-148.

Sirotkin P. (2012), Metrics On Search Engine Evaluation, PhD Thesis, Heinrich-Heine-Universität Düsseldorf, April 2012

Shin, M. and M. Zhong (2016) "A new approach to identifying the real effects of uncertainty shocks", Finance and Economics Discussion Series, No. 2016-040. http://dx.doi.org/10.17016/FEDS.2016.040

Stock, J. H. and M. W. Watson (2007), "Why has US inflation become harder to forecast?", Journal of Money, Credit and Banking, Vol. 39, No. 1, pp. 3-33.

Stock, J. H. and M. W. Watson (2012), "Disentangling the channels of the 2007-09 recession", Brookings Papers on Economic Activity, Spring, pp. 81-135.

Toda, H. Y. and T. Yamamoto (1995), "Statistical inference in vector autoregressions with possibly integrated processes", Journal of Econometrics, Vol. 66, pp. 225-250.

Tsay, R. S. (1987), "Conditional heteroscedastic time series models", Journal of the American Statistical Association, Vol. 82, No. 398, pp. 590-604.

Vosen S. and T. Schmidt (2011), "Forecasting private consumption: survey-based indicators vs. Google trends", Journal of Forecasting, Vol. 30, pp. 565-578. 
Whaley, R. (2000), "The Investor Fear Gauge", Journal of Portfolio Management, Vol. 26, pp. 12-17. 
Tab. 1 - Univariate analysis of uncertainty proxies over EURQ sample 2004m1-2014m12

\begin{tabular}{|c|c|c|c|c|c|c|}
\hline & VIX & SPREAD & PREDICT1 & FDISP & HNEWS & EURQ \\
\hline \multicolumn{7}{|l|}{ Summary statistics } \\
\hline Mean, $\mu$ & 19.6 & 1.921 & 0.701 & 0.685 & 166.9 & 112.0 \\
\hline Median & 16.7 & 1.655 & 0.662 & 0.689 & 153.5 & 111.9 \\
\hline Maximum & 62.6 & 5.560 & 1.129 & 0.828 & 309.5 & 150.8 \\
\hline Minimum & 10.8 & 1.170 & 0.589 & 0.474 & 90.5 & 88.0 \\
\hline Std. Dev., $\sigma$ & 9.4 & 0.821 & 0.118 & 0.064 & 46.0 & 12.8 \\
\hline Coeff. Variation, $\sigma / \mu$ & 0.477 & 0.427 & 0.168 & 0.094 & 0.276 & 0.115 \\
\hline Skewness & 2.324 & 2.766 & 2.085 & -0.458 & 0.931 & 0.543 \\
\hline Kurtosis & 9.401 & 10.667 & 6.941 & 3.996 & 3.493 & 2.764 \\
\hline $\mathrm{T}^{a}$ & 132 & 132 & 132 & 132 & 132 & 132 \\
\hline \multicolumn{7}{|l|}{ Cyclicality } \\
\hline Downturn/upturn $\boldsymbol{\mu}$ ratios & 2.022 & 2.126 & 1.430 & 1.126 & 0.992 & 1.058 \\
\hline Downturn/upturn $\sigma$ ratios & 2.564 & 4.264 & 2.479 & 0.989 & 0.771 & 0.999 \\
\hline \multicolumn{7}{|l|}{ Persistence testing and measures } \\
\hline \multicolumn{7}{|l|}{ Through unit-root tests $\left({ }^{a}\right)$} \\
\hline - augmentation, $k$ & 2 & 2 & 2 & 8 & 8 & 11 \\
\hline - tests' p-values & 0.089 & 0.109 & 0.159 & 0.334 & 0.358 & 0.584 \\
\hline - speed of adjustment, $\pi$ & -0.108 & -0.056 & -0.021 & -0.197 & -0.162 & -0.190 \\
\hline - half-life months, $m\left({ }^{b}\right)$ & 6 & 12 & 32 & 3 & 4 & 3 \\
\hline - ARCH(1) test, p-values $\left({ }^{c}\right)$ & 0.302 & 0.432 & 0.000 & 0.064 & 0.456 & 0.113 \\
\hline \multicolumn{7}{|l|}{ Through fractional integration $\left({ }^{d}\right)$} \\
\hline - $d$ estimate & 0.305 & 0.460 & 0.464 & 0.226 & 0.368 & 0.463 \\
\hline - highest AR root & 0.70 & 0.85 & 0.91 & 0.82 & 0.20 & - \\
\hline - highest MA root & - & 0.35 & -0.39 & - & - & 0.86 \\
\hline - half-life impulse-response, $m$ & 6 & 34 & 97 & 4 & 3 & 2 \\
\hline - ARCH(1) test (p-values) ${ }^{(c)}$ & 0.263 & 0.437 & 0.000 & 0.003 & 0.393 & 0.252 \\
\hline
\end{tabular}

$\left(^{a}\right)$ Dickey and Fuller (1979) test equation: $\Delta y_{t}=c+\pi y_{t-1}+\sum_{i=1}^{k} \gamma_{i} \Delta y_{t-1}+u_{t}$ where $k$ is selected by using the MAIC criterion of Ng and Perron (2001) starting from a given maximum number of lags $\left(k_{M A X}\right)$. The clear unit root evidence for FDISP, HNEWS and EURQ is probably due to the short sample, as the estimates of the persistence indicators $m$ and $d$ sub $\left({ }^{b}\right)$ and $\left({ }^{d}\right)$ suggest stationarity. $\left(^{b}\right)$ Months for closing $50 \%$ of the disequilibria. In general, $m=\ln (1-p) / \ln (1+\pi)$, where $p$ is the part of the initial gap to be closed between actual $y_{t}$ and its long run forecast (if $y_{t}$ is stationarity, it is its unconditional mean), and $\pi$ is the speed of adjustment (see above). Here, $p=0.50$, i.e. $50 \%$.

${ }^{(c)}$ Significant ARCH tests highlight residuals' conditional heteroscedasticity of the first order for the estimated ARMA/ARFIMA model.

$\left({ }^{d}\right)$ The first row reports the ML estimate of the fractional integration parameter $d$ in the ARFIMA (p, $d$, q) model: $\rho(L)(1-L)^{d}\left(y_{t}-\mu\right)=\vartheta(L) \varepsilon_{t}$ which is covariance stationary for $|d|<1 / 2$; the second/third rows respectively report the highest roots of the $\rho(L)$ and $\vartheta(L)$ polynomials (to check for stationary and invertible ARMA processes); the fourth row reports the number of months $m$ required for $50 \%$ of the initial impulse to accumulate. 

the right: query-driven, news-pooled and with no Granger-causality categories. 
Fig. 1 - EURQ: annotated chart

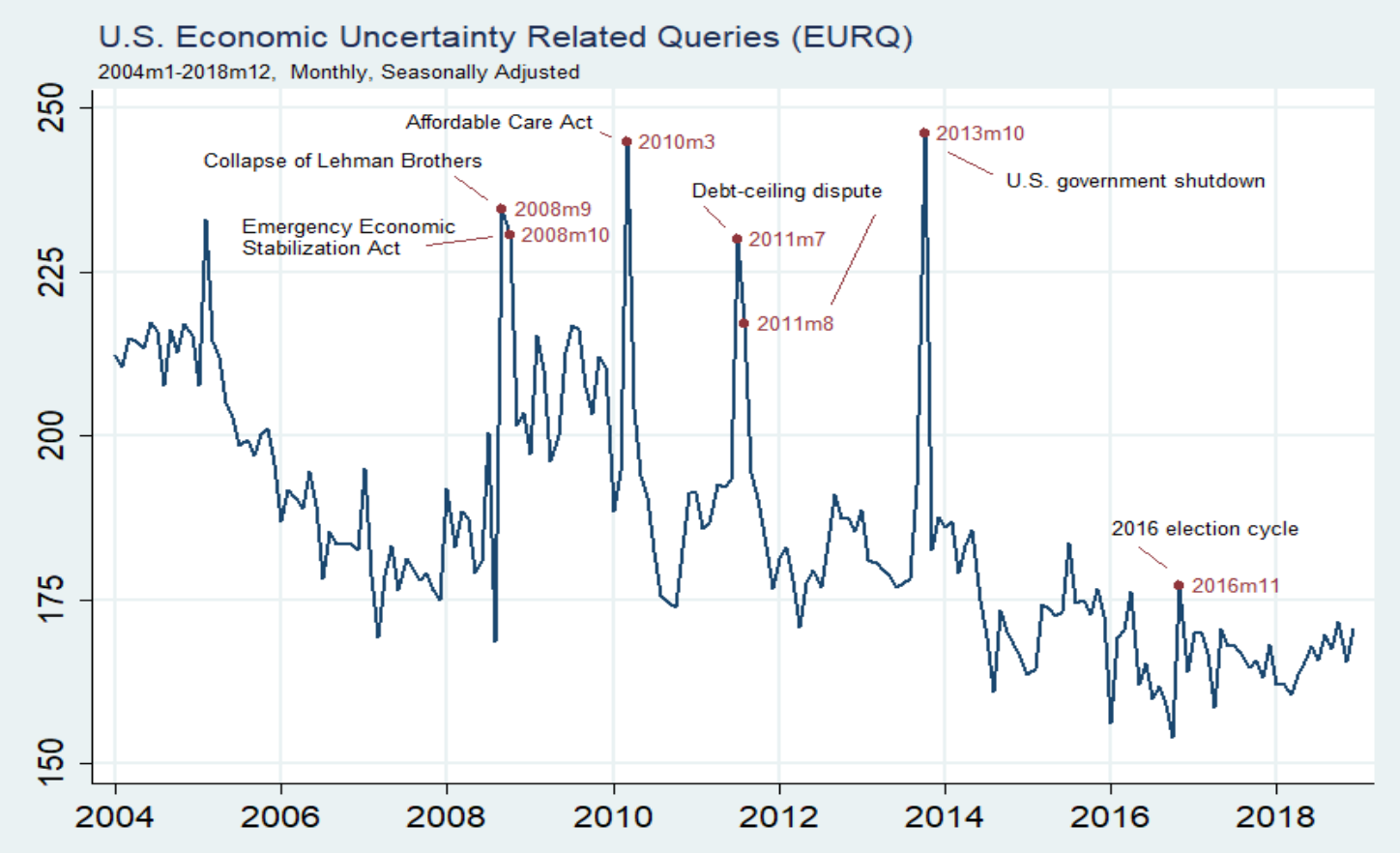

Fig. 2 - Alternative uncertainty measures over the common 2004m1-2014m12 period $\left(^{a}\right)$
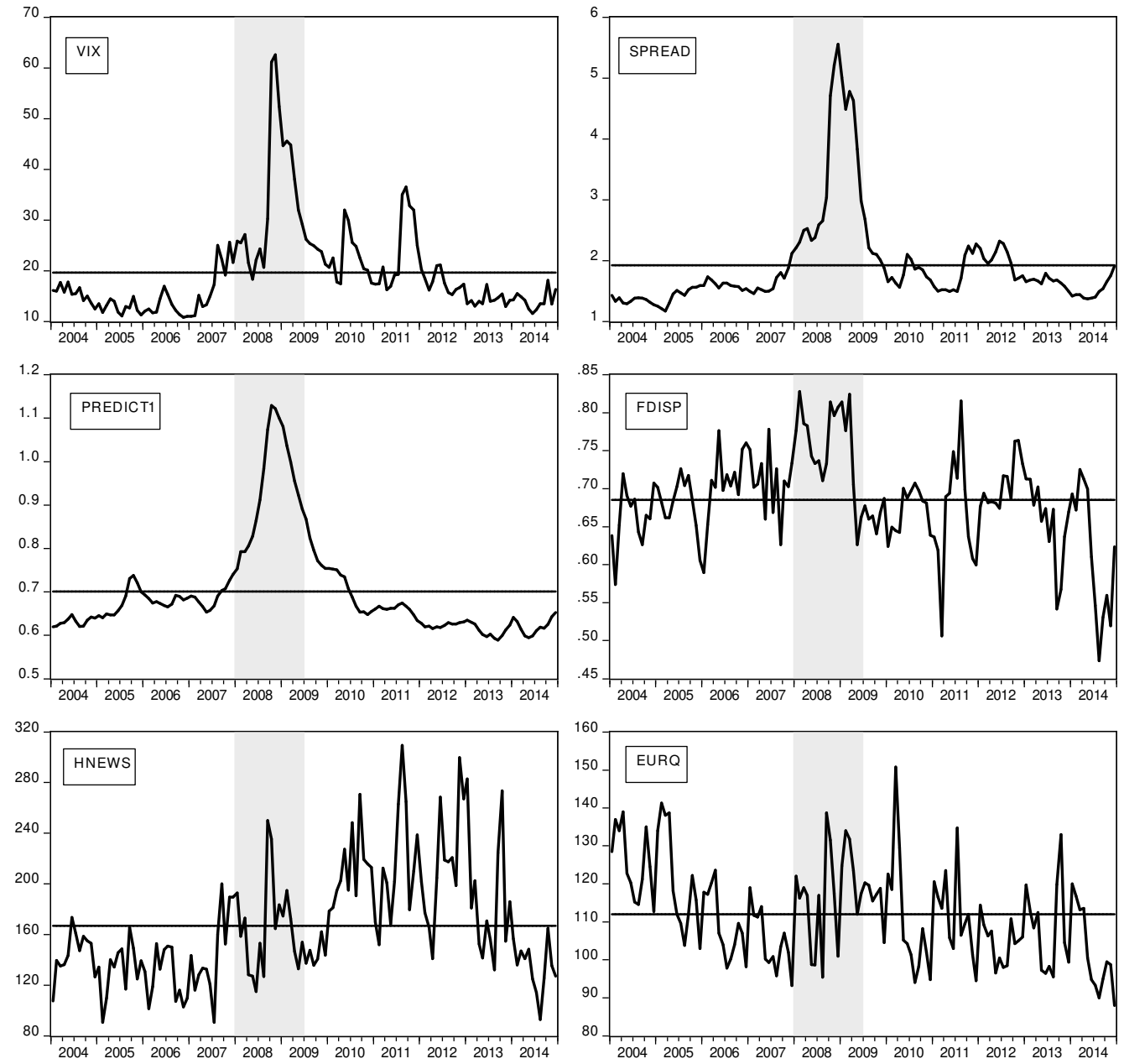

$\left.{ }^{(a}\right)$ Shaded areas denote NBER downturn phases. Horizontal lines measure the sample averages. 


\section{Fig. 3 - Impulse response of production (IPMAN) from the estimation of 5-variable VARs with alternative uncertainty measures}
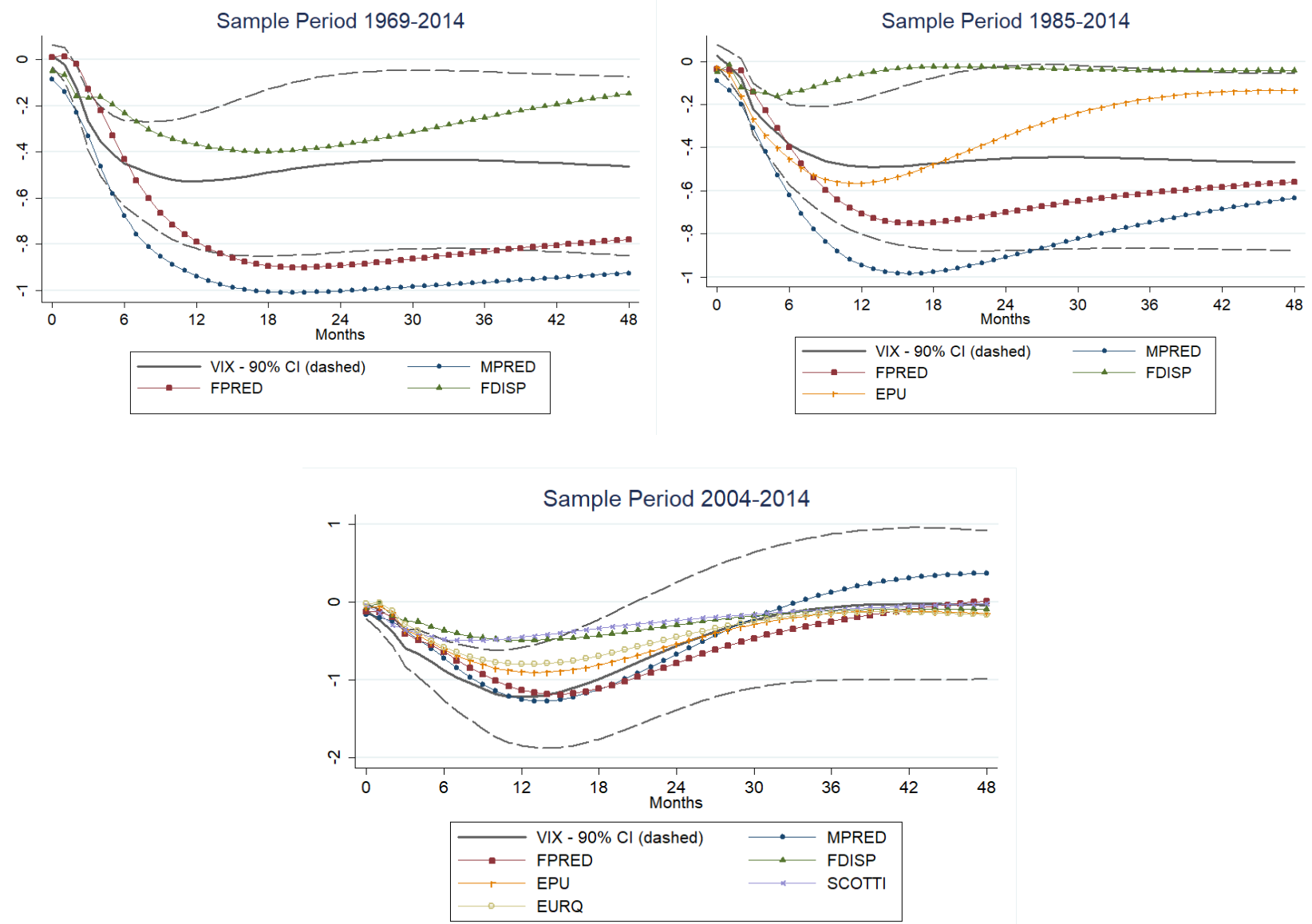

Response of log manufacturing production to Cholesky one s.d. impulse in MPRED (seasonally adjusted), FPRED (seasonally adjusted), $\log (V I X), \log (F D I S P), \log (E P U), S C O T T I$ and $\log (E U R Q$ - seasonally adjusted) for different estimation sample periods: (1) 1969 - 2014, (2) 1985 - 2014, (3) 2004 - 2014. The indexes are used according to their availability in the different subsamples. Identification is based on a 5 -variables $\operatorname{VAR}(\mathrm{p})$, ordered as: uncertainty, $\log (\mathrm{SP} 500), \log (1+\mathrm{Fed}$ funds effective rate/100), $\log$ manufacturing employment, log manufacturing industrial production. The order $\mathrm{p}$ is set as follow:

Sample (1): MPRED $=6, F P R E D=6, \log (V I X)=5, \log (F D I S P)=6$

Sample (2): MPRED $=4, F P R E D=4, \log (V I X)=4, \log (F D I S P)=4, \log (E P U)=4$

Sample (3): $M P R E D=5, F P R E D=5, \log (V I X)=5, \log (F D I S P)=4, \log (E P U)=4$, SCOTTI $=3, E U R Q=4$

Estimations on the 2004-2014 sample are performed with a small-sample degree-of-freedom adjustment. Dashed lines represent $90 \%$ standard error bands obtained from the system using $\log (V I X)$ as the uncertainty measure. 


\section{Fig. 4 - Impulse response of production (IPMAN) from the estimation of 5-variableVARs with alternative uncertainty measures and normalized sizes of the shocks}
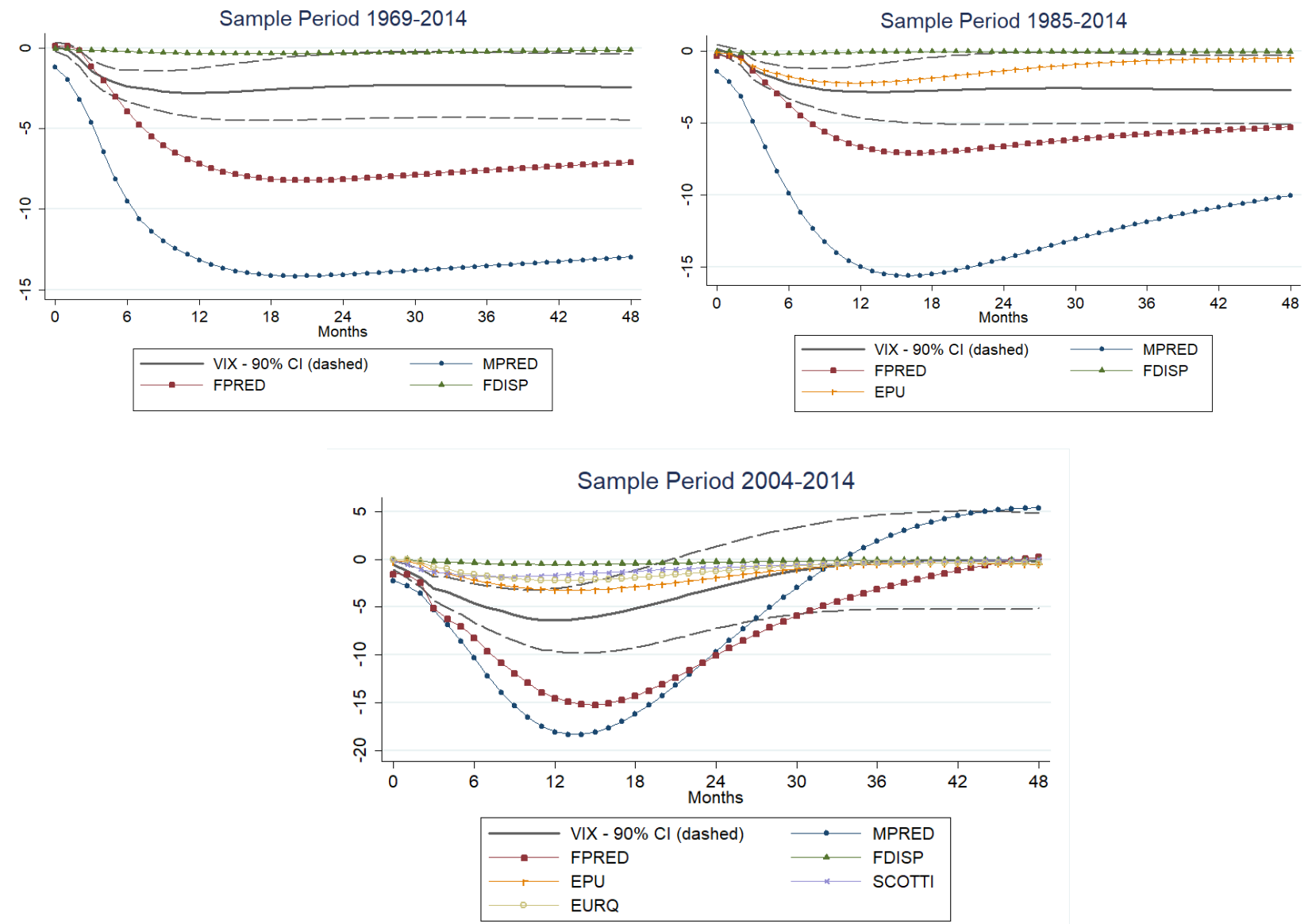

Response of log manufacturing production to Cholesky one s.d. impulse in MPRED (seasonally adjusted), FPRED (seasonally adjusted), $\log (V I X), \log (F D I S P), \log (E P U), S C O T T I$ and $\log (E U R Q$ - seasonally adjusted) for different estimation sample periods: (1) 1969 - 2014, (2) 1985 - 2014, (3) 2004 - 2014. The indexes are used according to their availability in the different subsamples. Identification is based on a 5 -variables $\operatorname{VAR}(\mathrm{p})$, ordered as: uncertainty, $\log (\mathrm{SP} 500), \log (1+\mathrm{Fed}$ funds effective rate/100), $\log$ manufacturing employment, log manufacturing industrial production. The order $\mathrm{p}$ is set as follow:

Sample (1): MPRED = 6, FPRED $=6, \log (V I X)=5, \log (F D I S P)=6$

Sample (2): $M P R E D=4, F P R E D=4, \log (V I X)=4, \log (F D I S P)=4, \log (E P U)=4$

Sample (3): $M P R E D=5, F P R E D=5, \log (V I X)=5, \log (F D I S P)=4, \log (E P U)=4, S C O T T I=3, E U R Q=4$

Estimations on the sample 2004-2014 are performed with a small-sample degree-of-freedom adjustment. Dashed lines represent $90 \%$ standard error bands obtained from the system using $\log (V I X)$ as the uncertainty measure. For each uncertainty proxy the size of the shock is set equal to the increase from the average value in June-August 2008 to the average in September-November 2008. 
Fig. 5 - EURQ for Italy: annotated chart

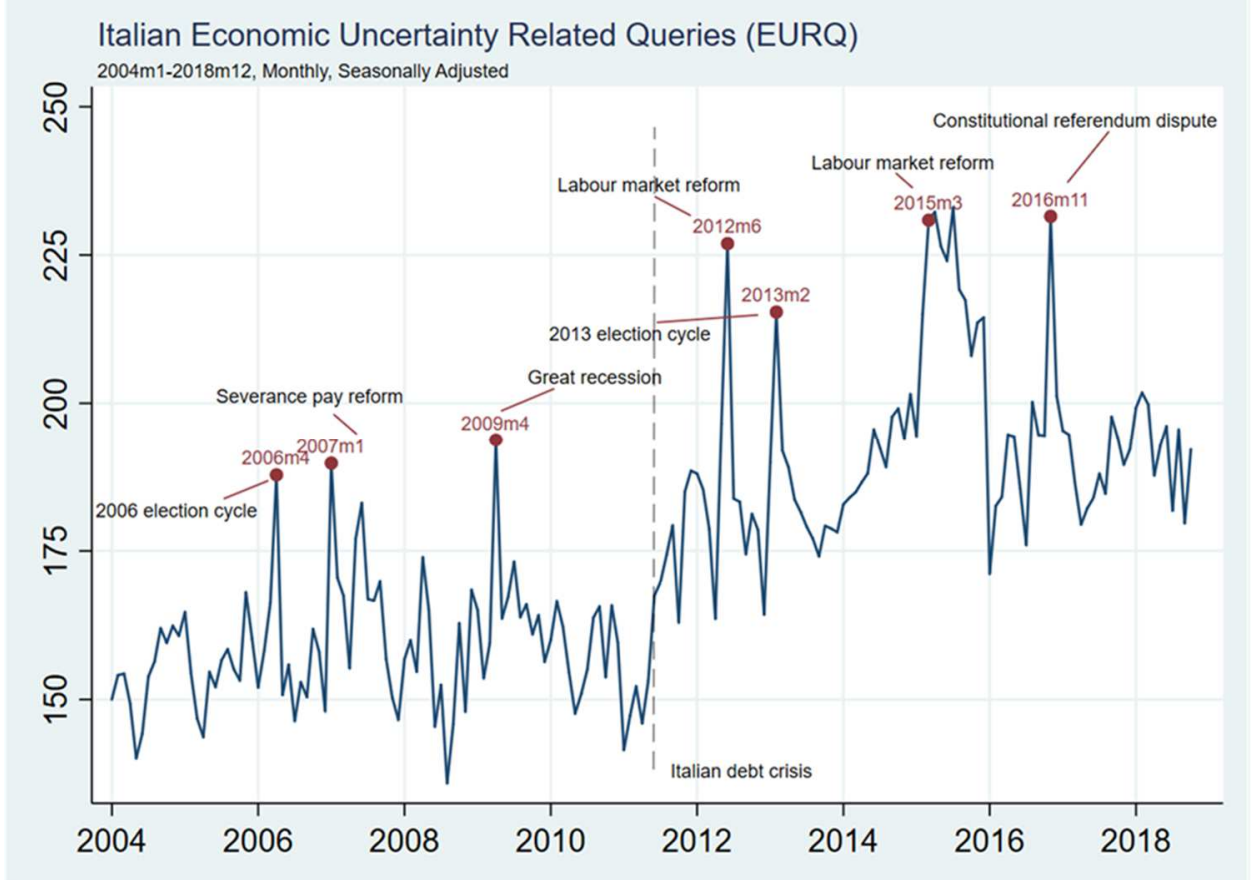

Fig. 6 - EURQ and finance-, forecast- and news-based indexes for Italy EURQ

NEWS
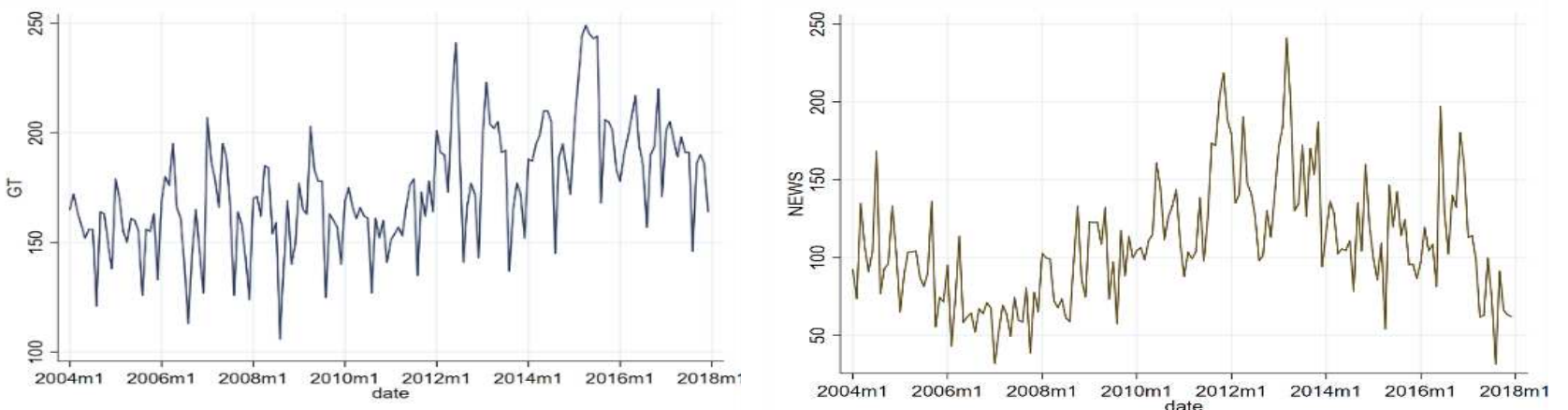

MUI

SVOL
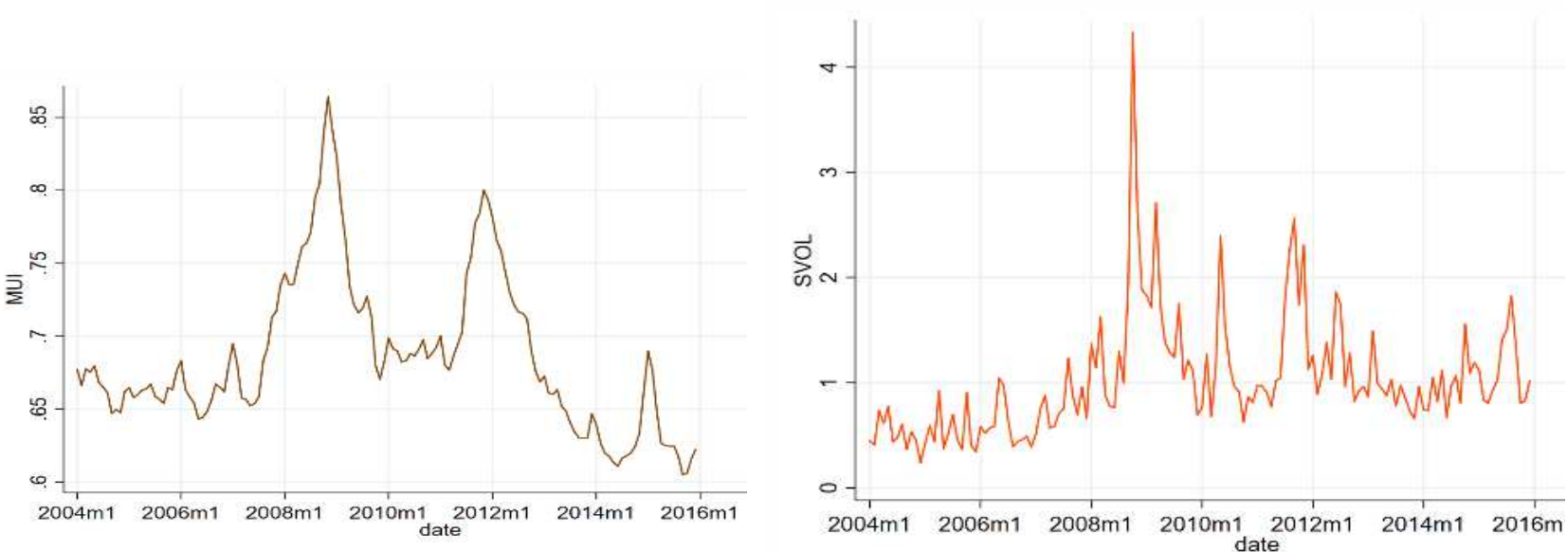
Fig. 7 - EURQ and competing search-based indexes for Italy

EURQ

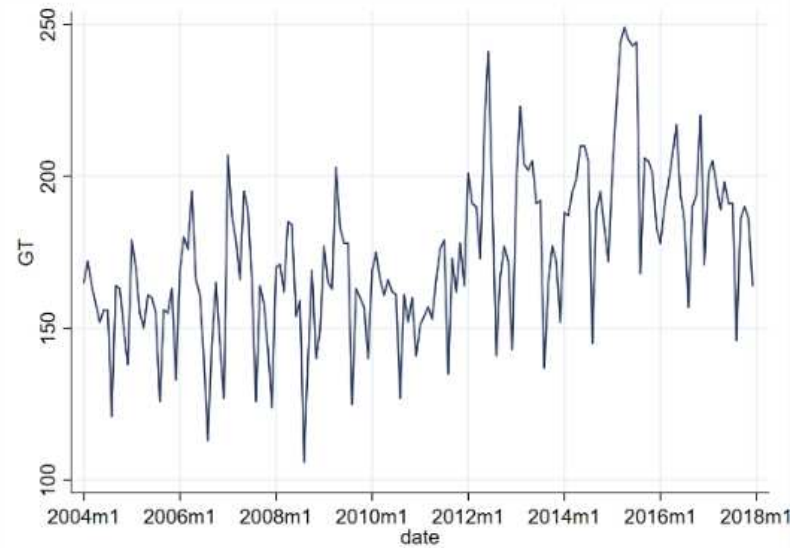

ECON

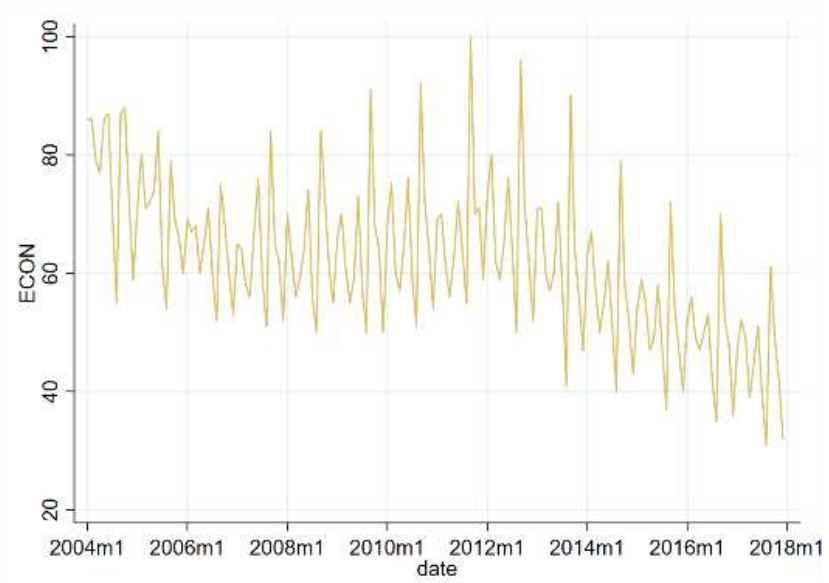

EPUGT

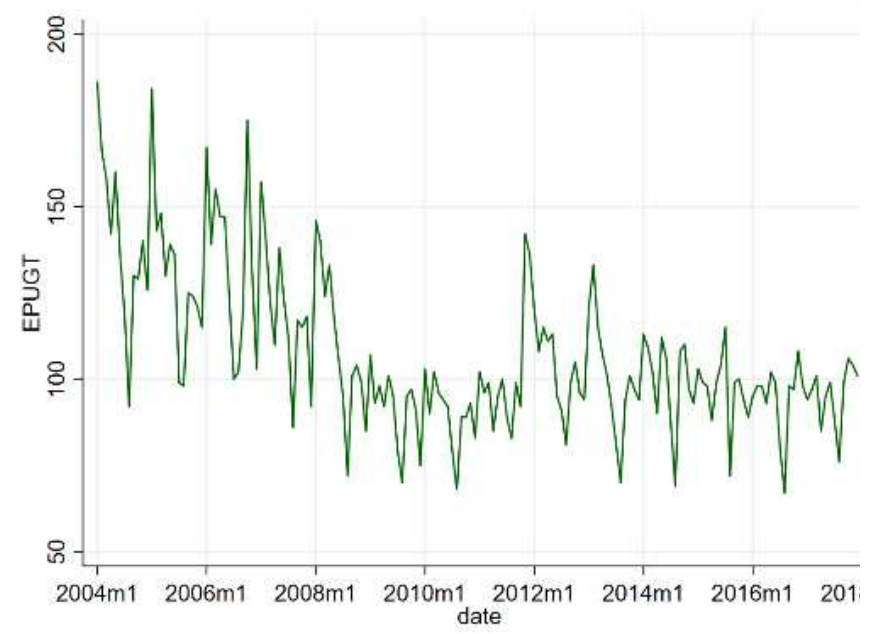

GSI

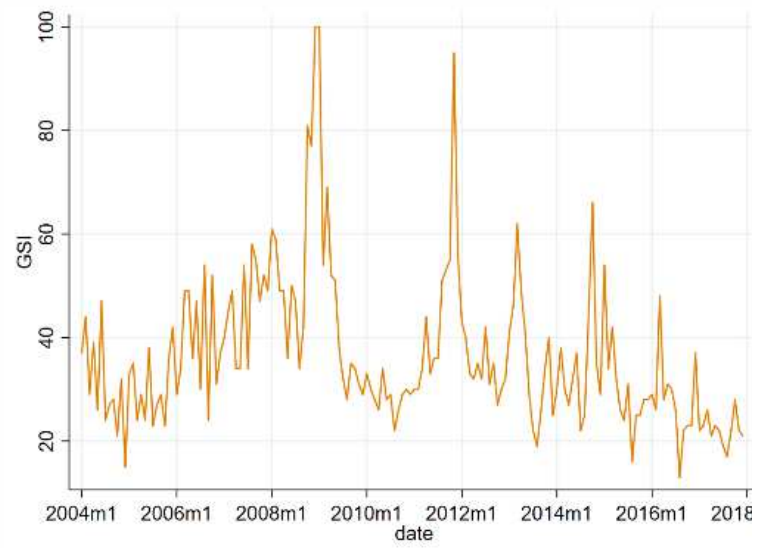

UI

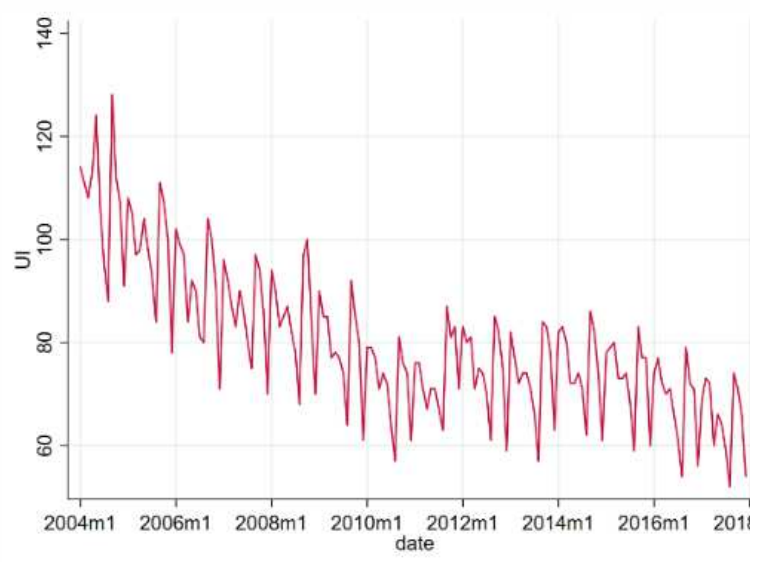




\section{Fig. 8 - Impulse-response functions for Italy}

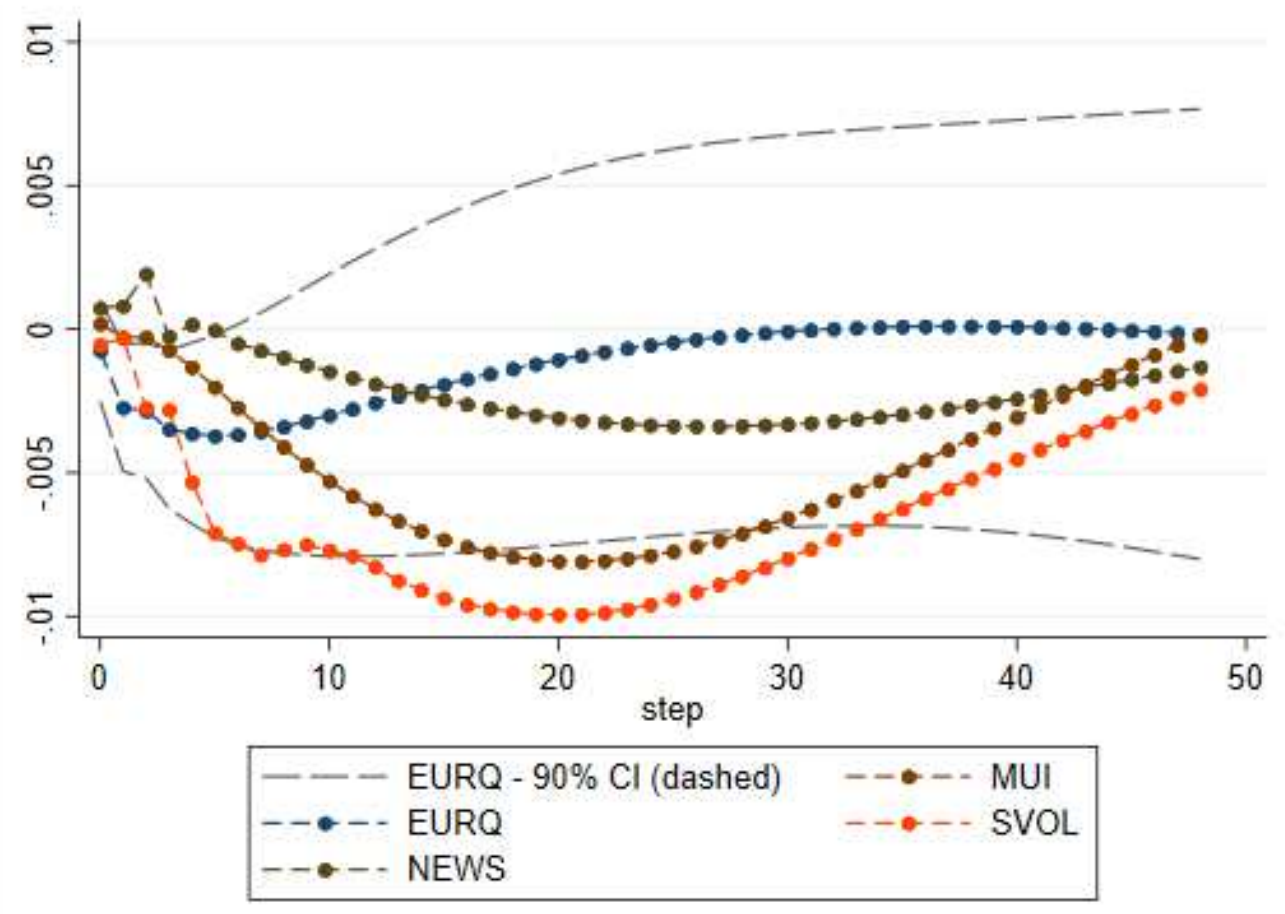

Response of the $\log$ (industrial production, excluded the construction industry) to Cholesky one s.d. impulse in $\log (E U R Q$ - seasonally adjusted $), \log (N E W S), \log (M U I$ - seasonally adjusted), $\log (S V O L)$. Estimated periods: $2004 \mathrm{~m} 1-2017 \mathrm{~m} 12$ for EURQ and NEWS; 2004m1 - 2015m12 for MUI and SVOL. Identification is based on a 5-variables $\operatorname{VAR}(p)$, ordered as: uncertainty, $\log ($ FTSE-MIB) that is the benchmark Italian Stock Exchange index, $\log (1+$ one-month Euribor), $\log$ (employment), $\log$ (industrial production). The number $p$ of lags in the VAR is set according to the AIC criterion: $E U R Q=2 ; N E W S=3 ; M U I=2 ; S V O L=4$. Estimations are performed with a small-sample degree-of-freedom adjustment. Dashed lines represent the $90 \%$ standard error bands obtained from the system using $\log (E U R Q)$ as the uncertainty measure. 


\section{$\underline{\text { Appendices with detailed results }}$}

Appendix A1 - Uncertainty episodes and Google searches spikes 42

Appendix A2 - The technical implementation of our Google Trends indexes, EURQ ............................... 46

A2.1 - How to use Google correlate to find search terms and main results .................................................. 50

A2.2 - How each single BBD search term is obtained and validated...................................................... 51

A2.3 - The possibly changing nature of search and internet use: detailed evidence .................................... 52

A2.4 - EURQ data replicability: vintages and data revisions .................................................................... 56

A2.5 - Robustness of $E U R Q$ to the presence or absence of subsets of search terms..................................... 57

Appendix A3 - The sum of the 184 series into sub-groups, policy categories and the EURQ .................... 59

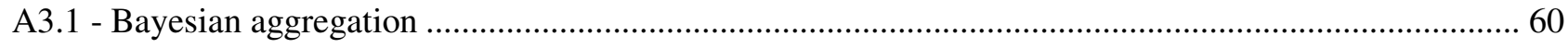

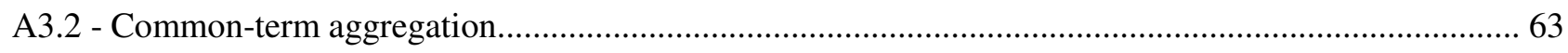

Appendix A4 - Internet and news comparison of "government shutdown" and "debt ceiling"..................... 64

Appendix A5 - The measurement of the "fantastic five" $(F F)$ : further details............................................ 67

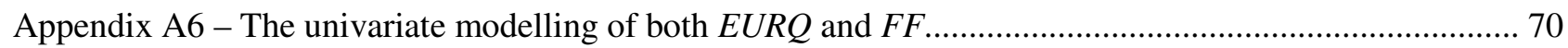

A6.1 - Univariate analysis of $F F$ over the large sample 1970m1-2014m12 ............................................... 70

A6.2 - The ARMA/GARCH and ARMA-with-breaks modelling of uncertainty indicators......................... 72

Appendix A7 - The methodology of the alternative univariate models........................................................ 77

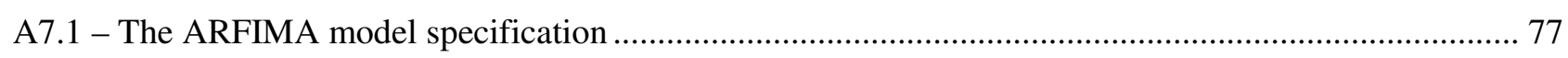

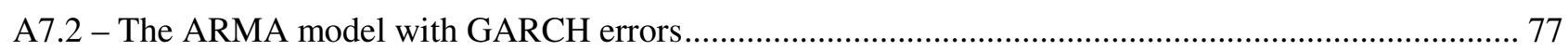

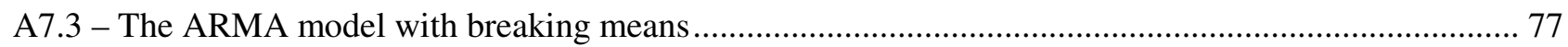

Appendix A8 - Modelling residuals in the multivariate VAR setting ……................................................. 78

A8.1 - VAR modelling of ARMA/GARCH residuals over alternative samples ............................................ 78

A8.2 - VAR modelling of ARMA-with-breaks residuals .......................................................................... 79

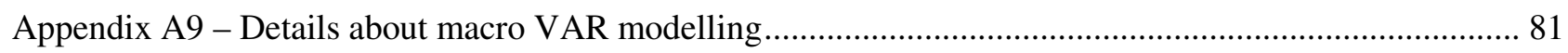

A9.1 - Tests of seasonal adjustment of all the uncertainty measures.......................................................... 81

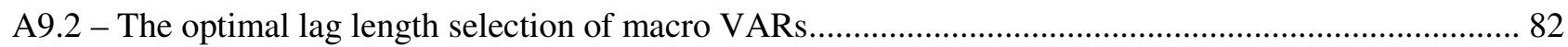

Appendix A10 - The making of EURQ for Italy: technical details............................................................ 83

A10.1 - The technical implementation of the $E U R Q$ index for Italy ........................................................... 83

A10.2 - Specific search used for alternative Google Trends-based indices................................................. 86

A10.3 - Univariate and multivariate analysis of EURQ for Italy ............................................................... 87

Appendix A11 - Newsbank and EURQ VARs by category, sub-group and search terms: detailed results.... 89

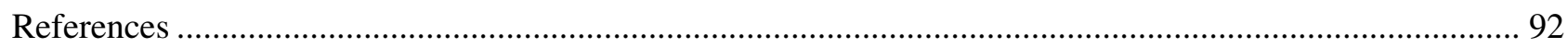




\section{Appendix A1 - Uncertainty episodes and Google searches spikes}

Direct evidence supporting of the economic (not spurious) content of the collective spikes can be found by examining whether significant uncertainty events resulted in a significant increase in Google searches for keywords related to such events.

As a preliminary example of direct evidence, Figure A1.1 displays screenshots of Google Trends charts showing search volumes for "interest rates", "fiscal stimulus" and "tarp" (Troubled Asset Relief Program) over the period between January 2004 and December 2014. The graphs lend support to our hunch. For example, Google Trends for "tarp" clearly denote a sudden, rapid increase in Internet search activity during the TARP debate, when the degree of policy uncertainty was high. In fact, the queries start to increase in late 2008, when TARP legislation was passed, then remained at a constant elevated level until April 2009. No other peaks are evident. Of course, the quantity of searches for the term "tarp" based on other factors besides economic and policy uncertainty, such as an interest in tarp (tarpaulin) tents, does not compromise identification of the episodes of uncertainty.

\section{Fig. A1.1 - Screenshots from Google Trends}

Search volume index for the term "Interest Rate"

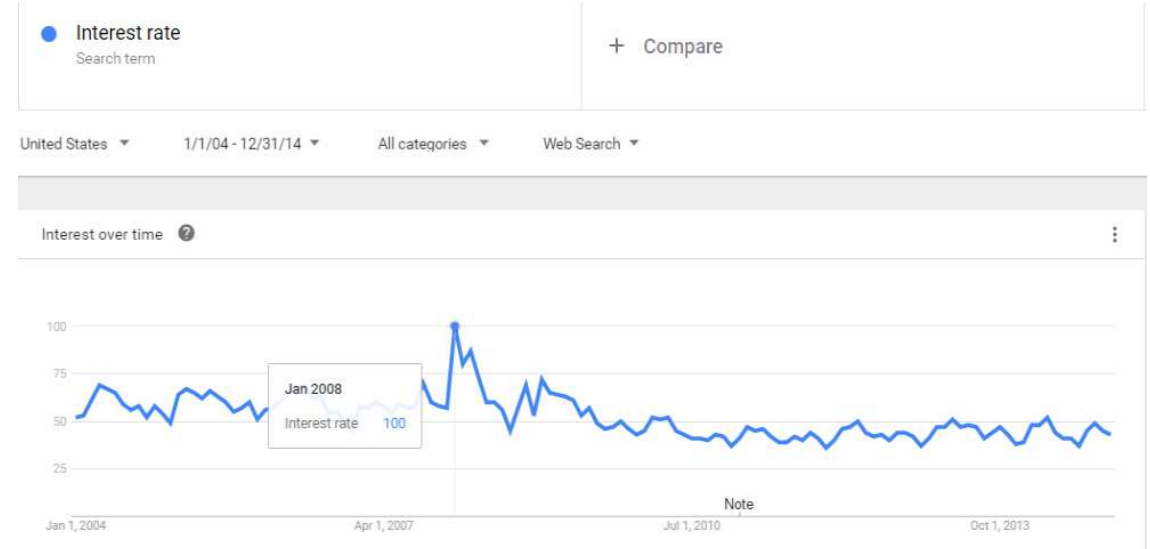

Search volume index for the term "Fiscal Stimulus"

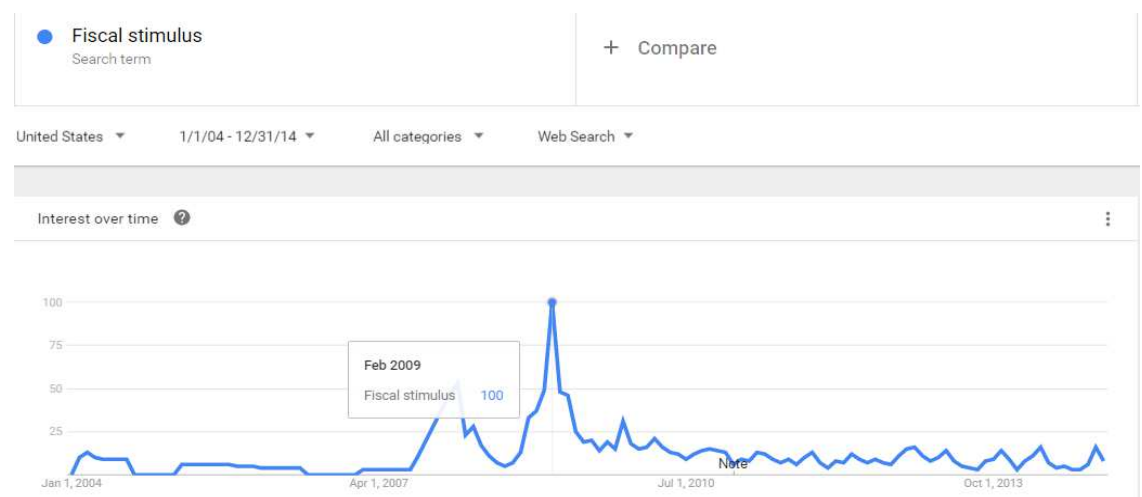




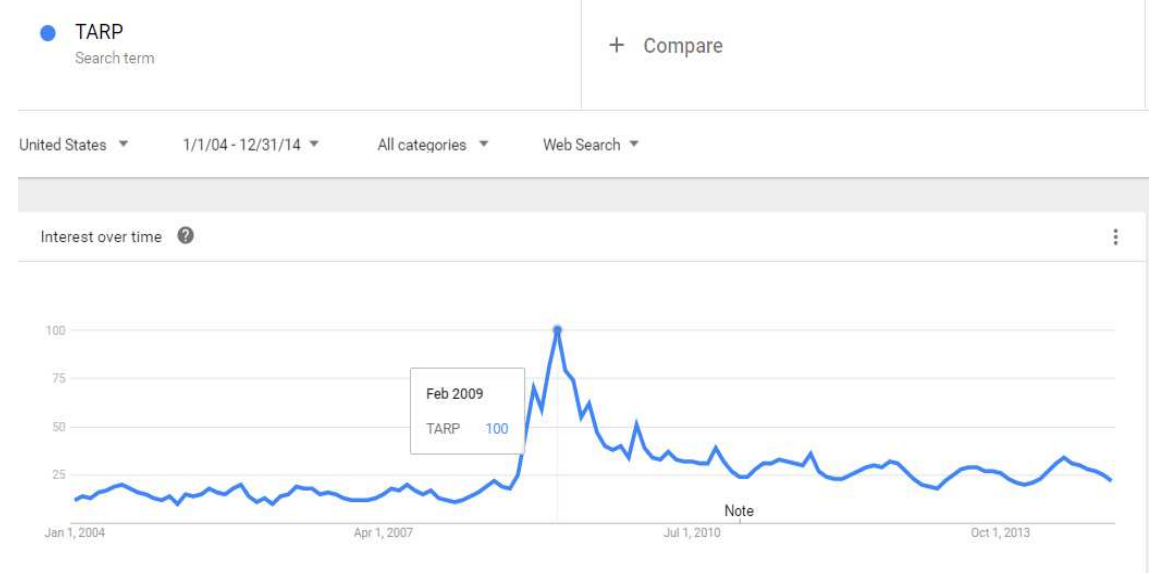

The index measures the monthly volume of Google searches from the United States for a specific search term divided by the total number of Google searches in the same region and month. The index is peak normalized, so a value of 100 is assigned to the maximum value of this ratio over the specified period. The data range is from $2004 \mathrm{~m} 1$ to $2014 \mathrm{~m} 12$.

In a more systematic way, Table A1.1 reports peaks in Google searches for specific terms linked to the major uncertainty episodes listed in Moore (2016), or that are usually cited as of importance in the uncertainty literature, and which occurred between January 2004 and December 2014. Internet search volumes clearly tend to rise during all such periods of uncertainty. For example, searches for "election" spike during election years, in the case of both presidential and midterm elections. Similarly, when financial uncertainty shocks hit the economy (such as the bailout of Bear Stearns or the collapse of Lehman Brothers), searches for related items rise. Significant tax policy problems increase people's appetite for information as well (see, for example, the TARP in 2008, the Stimulus Debate in 2009, or the Fiscal Cliff controversy in 2012). The same finding holds for both monetary policy shocks, such as the aggressive interest rate cuts in late 2008, and other uncertainty shocks originating from outside the USA, such as the Eurozone crisis.

Tab. A1.1 - Peaks in search volumes for queries linked to major economic uncertainty events

\begin{tabular}{|l|l|l|l|} 
Date & Event $\left(^{\boldsymbol{a}}\right)$ & Google Trends query & Peaks in search volumes $\left.\boldsymbol{(}^{\boldsymbol{b}}\right)$ \\
\hline $\begin{array}{l}\text { November 2004 (Presidential) } \\
\text { November 2006 (midterm) }\end{array}$ & & & $2004 \mathrm{~m} 10$ \\
November 2008 (Presidential) & Election cycle & Election & $\mathbf{2 0 0 4 m 1 1 *}$ \\
November 2010 (midterm) & & & $2006 \mathrm{~m} 11$ \\
November 2012 (Presidential) & & & $\mathbf{2 0 0 8 m 1 1}$ \\
November 2012 (midterm) & & & $\mathbf{2 0 1 0 m 1 1}$ \\
& & & $2014 \mathrm{~m} 11$ \\
\hline & & & $2004 \mathrm{~m} 4$ \\
January 2008 & Interest rate & Interest rate & $2006 \mathrm{~m} 6$ \\
& cuts & & $\mathbf{2 0 0 8 m 1} *$ \\
& & & $2008 \mathrm{~m} 2$ \\
& & $\mathbf{2 0 0 8 m 3}$ \\
& & & $2008 \mathrm{~m} 4$ \\
\hline
\end{tabular}




\begin{tabular}{|c|c|c|c|}
\hline & & & $\begin{array}{l}2008 \mathrm{~m} 10 \\
2008 \mathrm{~m} 12 \\
\end{array}$ \\
\hline 2008 (signed in February 2008) & $\begin{array}{l}\text { Economic } \\
\text { Stimulus Act }\end{array}$ & Economic Stimulus & $\begin{array}{l}2008 \mathrm{~m} 2 \\
2008 \mathrm{~m} 3 \\
\mathbf{2 0 0 8 m 4} 4 \\
\mathbf{2 0 0 8}^{*} \text { * } \\
2008 \mathrm{~m} 6 \\
\mathbf{2 0 0 9 m} \mathbf{m}\end{array}$ \\
\hline March 2008 & $\begin{array}{l}\text { Bear Stearns } \\
\text { Rescue }\end{array}$ & Bear Stearns & $\begin{array}{l}\text { 2008m3* } \\
2008 \mathrm{~m} 4\end{array}$ \\
\hline September 2008 & $\begin{array}{l}\text { Lehman } \\
\text { Brother } \\
\text { Bankruptcy }\end{array}$ & Lehman Brother & $\begin{array}{l}\text { 2008m9* } \\
2008 \mathrm{~m} 10\end{array}$ \\
\hline October 2008 & $\begin{array}{l}\text { Emergency } \\
\text { Economic } \\
\text { Stabilization } \\
\text { Act }\end{array}$ & Economic Stabilization & $\begin{array}{l}\text { 2008m9 } \\
\text { 2008m10* } \\
2008 \mathrm{~m} 11\end{array}$ \\
\hline Late 2008 & $\begin{array}{l}\text { TARP } \\
\text { legislation }\end{array}$ & TARP & $\begin{array}{l}2008 \mathrm{~m} 11 \\
2008 \mathrm{~m} 12 \\
\mathbf{2 0 0 9 m 1} \\
\mathbf{2 0 0 9 m 2 *} \\
\mathbf{2 0 0 9 m 3} \\
\mathbf{2 0 0 9 m 4} \\
2009 \mathrm{~m} 5 \\
2009 \mathrm{~m} 6 \\
2009 \mathrm{~m} 12 \\
\end{array}$ \\
\hline 2009 & $\begin{array}{l}\text { The Stimulus } \\
\text { Debate }\end{array}$ & Fiscal stimulus & $\begin{array}{l}\text { 2008m1 } \\
2008 \mathrm{~m} 2 \\
2008 \mathrm{~m} 11 \\
2008 \mathrm{~m} 12 \\
2009 \mathrm{~m} 1 \\
\mathbf{2 0 0 9 m 2 *} \\
2009 \mathrm{~m} 3 \\
\mathbf{2 0 0 9 m 4} \\
2009 \mathrm{~m} 11 \\
\end{array}$ \\
\hline 2010 & $\begin{array}{l}\text { Patient } \\
\text { Protection and } \\
\text { Affordable } \\
\text { Care Act }\end{array}$ & $\begin{array}{l}\text { Patient Protection and } \\
\text { Affordable Care Act }\end{array}$ & $\begin{array}{l}\mathbf{2 0 1 0 m 3} \\
\text { 2010m4* } \\
2010 \mathrm{~m} 5 \\
2010 \mathrm{~m} 6 \\
2010 \mathrm{~m} 7 \\
2010 \mathrm{~m} 9 \\
2010 \mathrm{~m} 10 \\
2010 \mathrm{~m} 11 \\
2012 \mathrm{~m} 6 \\
2012 \mathrm{~m} 7 \\
2012 \mathrm{~m} 11 \\
2013 \mathrm{~m} 10 \\
\end{array}$ \\
\hline April 2010 & $\begin{array}{l}\text { Greece's } \\
\text { request for } \\
\text { financial } \\
\text { assistance }\end{array}$ & \multirow{2}{*}{ Greek crisis } & $\begin{array}{l}\text { 2010m4 } \\
\text { 2010m5* } \\
\text { 2011m6 } \\
2011 \mathrm{~m} 9 \\
2011 \mathrm{~m} 10\end{array}$ \\
\hline March 2012 & $\begin{array}{l}\text { Greece's Debt } \\
\text { Restructuring }\end{array}$ & & $\begin{array}{l}\text { 2011m11 } \\
\text { 2012m2 } \\
2012 \mathrm{~m} 5 \\
2012 \mathrm{~m} 6 \\
\end{array}$ \\
\hline 2010 & $\begin{array}{l}\text { Sovereign } \\
\text { debt crisis in } \\
\text { the Eurozone } \\
\text { area }\end{array}$ & Eurozone crisis & $\begin{array}{l}2011 \mathrm{~m} 9 \\
2011 \mathrm{~m} 10 \\
\text { 2011m11* } \\
\text { 2011m12 } \\
2012 \mathrm{~m} 1\end{array}$ \\
\hline
\end{tabular}




\begin{tabular}{|c|c|c|c|}
\hline & & & $\begin{array}{l}2012 \mathrm{~m} 2 \\
\mathbf{2 0 1 2} \mathbf{m 5} \\
\mathbf{2 0 1 2} \mathbf{6} 6 \\
2012 \mathrm{~m} 7 \\
2012 \mathrm{~m} 9 \\
2012 \mathrm{~m} 10 \\
2012 \mathrm{~m} 11\end{array}$ \\
\hline July 2011 & $\begin{array}{l}\text { Debt Ceiling } \\
\text { Standoff }\end{array}$ & Debt ceiling & $\begin{array}{l}2011 m 7 * \\
2011 m 8 \\
2013 m 10 \\
\end{array}$ \\
\hline Late 2012 & Fiscal Cliff & Fiscal Cliff & $\begin{array}{l}2012 \mathrm{~m} 11 \\
2012 \mathrm{~m} 12 * \\
2013 \mathrm{~m} 1\end{array}$ \\
\hline October 2013 & $\begin{array}{l}\text { Federal } \\
\text { government } \\
\text { shutdown }\end{array}$ & Government shutdown & $\begin{array}{l}2011 \mathrm{~m} 4 \\
2013 \mathrm{~m} 10^{*}\end{array}$ \\
\hline
\end{tabular}

( $\left.{ }^{a}\right)$ Selected Uncertainty episodes are those reported either in Table 4 of Moore (2016), or usually cited as relevant in the literature on economic uncertainty.

$\left({ }^{b}\right)$ This column reports those dates when the corresponding Google's Search Volume Index is more than 1.5 standard deviations above the average (in bold, when they are more than 3 standard deviations). An asterisk denotes the global maximum of Google's SVI (Search Volume Index).

Overall, the empirical evidence offered by Google Trends directly supports the view that uncertainty prevails over idiosyncratic interest in driving the aggregate search volumes of specific terms, provided that such terms are identified.

In this context, one could argue that, if we make the same exercise for movie titles instead of for e.g. the TARP program, the spikes around releases are not uncertainty about that movie. However, a collective spike about that title could inform the interest in knowing more about movie's plot to solve the uncertainty about where to go to cinema next time. Again, the choice of the search term is fundamental to qualify the kind of information that is collected by the search volumes. 


\section{Appendix A2 - The technical implementation of our Google Trends indexes, EURQ}

Taking the original list of 210 search terms of Baker et al. (2016, henceforth $B B D$ ) as our starting point, below we classify our selected 184 queries $(S j, j=1, . ., 184)$ in 8 policy areas $(c=1, \ldots$, $8)$. We used only 184 terms of the 210 ones of $B B D$ : of the 26 dropped terms, 8 of them were repeated several times in the list, while the other 18 never reached the minimum popularity threshold.

\section{4 included queries of BBD}

(1) Fiscal policy, FP (16 queries)
1. "taxes rates"
2. "tax rate"- "calculator"
3. "taxation"
4. "taxed"
5. "government spending"
6. "us federal budget"
7. "budget battle"
8. "balanced budget"
9. "fiscal stimulus"
10. "us budget deficit"
11. "federal debt"
12. "national debt"
13. "Gramm Rudman"
14. "debt ceiling"
15. "government deficits"
16. "balance the budget"

(2) Monetary Policy, MP (25 queries)

17. "the federal reserve"

18. "the fed"

19. "money supply"

20. "open market operations"

21. "quantitative easing"

22. "monetary policy"

23. "fed funds rate"

24. "Bernanke"

25. "Paul Volcker"

26. "Alan Greenspan" - "Mitchell" -"wife"

27. "the central bank"

28. "interest rates" - "calculator" - "best"

29. "fed chairman"

30. "fed chair"

31. "lender of last resort"

32. "fed discount window"

33. "European Central Bank"

34. "ECB bank"

35. "Bank of England"

36. "Bank of Japan"

37. "BOJ" - "xem" - "anglers" - "jamaica"

38. "Bank of China"

39. "Bundesbank"

40. "Bank of France"
41. "Bank of Italy"

(3) Health care, HC (15 queries)

42. "health care reform"

43. "Medicaid program"

44. "Medicare program"

45. "health insurance reform"

46. "malpractice tort reform"

47. "malpractice reform"

48. "prescription drug program"

49. "drug policy" - "nfl"

50. "food and drug administration"

51. "FDA regulation"

52. "medical malpractice law"

53. "liability reform"

54. "Medicare Part D" - "humana" - "aarp"

55. "affordable care act"

56. "Obamacare law"

(4) National security and war, NS (15 queries)

57. "national security strategy"

58. "us war"

59. "military conflict"

60. "terrorism"

61. "war on terror"

62. "after 9/11"

63. "defence spending"

64. "military spending"

65. "police action"

66. "us armed forces" -"ranks"

67. "military base closure"

68. "saber rattling"

69. "naval blockade"

70. "no-fly zone"

71. "military invasion"

(5) Regulation, RE (65 queries)

72. "federal regulation"

73. "banking supervision"

74. "Glass Steagall"

75. "tarp program"

76. "thrift supervision"

77. "Dodd frank" - "form" - "certification"

78. "financial reform"

79. "commodity futures trading commission"

80. "cftc" 
81. "house financial services committee"

82. "Basel Accord"

83. "capital requirement" - "working capital"

84. "Volcker rule"

85. "bank stress test"

86. "securities and exchange commission"

87. "us sec"

88. "deposit insurance"

89. "fdic" - "jobs"

90. "fslic"

91. "office of thrift supervision"

92. "Office of the Comptroller of the Currency"

93. "firrea"

94. "truth in lending"

95. "union rights"

96. "union card check"

97. "collective bargaining law"

98. "national labor relations board"

99. "minimum wage"

100. "living wage" - "calculator"

101. "right to work"

102. "closed shop"

103. "wages and hours"

104. "workers compensation law"

105. "affirmative action"

106. "at-will employment"

107. "trade adjustment assistance"

108. "davis bacon"

109. "equal employment opportunity"

110. "eeo laws"

111. "osha safety"

112. "antitrust"

113. "competition policy"

114. "monopoly power"

115. "patent law" - "firm" - "firms" - "school" - "schools" - "lawyer" - "attorney" -

"group" - "bar" -"jobs"

116. "copyright law"

117. "federal trade commission"

118. "the ftc" - "complaint"

119. "unfair business practice"

120. "competition law"

121. "price fixing" - "adm" - "apple"

122. "class action law"

123. "healthcare lawsuit"

124. "tort reform"

125. "punitive damages" - "punitive definition" - "definition of punitive"

126. "energy policy"

127. "energy tax"

128. "carbon tax"

129. "cap and trade"

130. "cap and tax"

131. "offshore oil drilling"

132. "clean air act"
133. "clean water act"

134. "environmental protection agency"

135. "the epa" - "jobs"

136. "immigration policy"

(6) Foreign sovereign debt and currency crisis, SDCC (14 queries)

137. "sovereign debt"

138. "currency crisis"

139. "currency devaluation"

140. "currency revaluation"

141. "currency manipulation"

142. "euro crisis"

143. "Eurozone crisis"

144. "European financial crisis"

145. "European debt"

146. "Asian financial crisis"

147. "Asian crisis"

148. "Russian financial crisis"

149. "Russian crisis"

150. "exchange rate policy"

(7) Entitlement programs, EP (20 queries)

151. "entitlement program"

152. "entitlement spending"

153. "government entitlements"

154. "social security" - "office" - "number" "my" - "calculator" - "online" - "jobs"

155. "government welfare"

156. "welfare reform"

157. "unemployment insurance"

158. "unemployment benefits" - "online"

159. "food stamps" - "application" - "online"

160. "afdc"

161. "tanf program"

162. "wic program"

163. "state disability insurance"

164. "oasdi"

165. "Supplemental Nutrition Assistance Program"

166. "Earned Income Tax Credit"

167. "eitc tax"

168. "head start program" - "jobs"

169. "public assistance" - "application" "apply"

170. "government subsidized housing"

(8) Trade policy, TP (14 queries)

171. "import tariffs"

172. "import duty" - "calculator"

173 "government subsidies"

174 "government subsidy"

175 "wto" - "howto"

176 "world trade organization"

177 "trade treaty"

178 "trade agreement"

179 "trade policy" 
180 "trade act"

181 "doha round"

182 "uruguay round"

183 "gatt" -"joseph" - "josh" - "stefan"

184 "anti dumping"

\section{6 excluded queries of $B B D$}

Fiscal policy:

1. "defence spending" $\rightarrow$ Already included in "National Security and War"

2. "military spending" $\rightarrow$ Already included in "National Security and War"

3. "entitlement spending" $\rightarrow$ Already included in "Entitlement programs"

4. "fiscal footing" $\rightarrow$ Not enough search volume to show graphs.

\section{Monetary Policy:}

5. "overnight lending rate" $\rightarrow$ Not enough search volume to show graphs.

6. "the fed" $\rightarrow$ Already included in "Monetary Policy"

\section{Health care:}

7. "prescription drug act" $\rightarrow$ Not enough search volume to show graphs.

8. "medical insurance reform" $\rightarrow$ Not enough search volume to show graphs.

\section{National security and war:}

9. "military procurement" $\rightarrow$ Not enough search volume to show graphs.

10. "military embargo" $\rightarrow$ Not enough search volume to show graphs.

\section{Regulation:}

11. "bank supervision" $\rightarrow$ Not enough search volume to show graphs.

12. "nlrd" $\rightarrow$ Not enough search volume to show graphs.

13. "advance notice requirement" $\rightarrow$ Not enough search volume to show graphs.

14. "overtime requirements" $\rightarrow$ Not enough search volume to show graphs.

15. "merger policy" $\rightarrow$ Not enough search volume to show graphs.

16. "cartel" $\rightarrow$ Not possible to find an alternative query with enough search volume to show graphs.

17. "tort policy" $\rightarrow$ Not enough search volume to show graphs.

18. "medical malpractice" $\rightarrow$ Already included in "Health Care".

19. "drilling restrictions" $\rightarrow$ Not enough search volume to show graphs.
20. "pollution controls" $\rightarrow$ Not enough search volume to show graphs.

21. "environmental restrictions" $\rightarrow$ Not enough search volume to show graphs.

\section{Foreign sovereign debt and currency crisis}

22. "currency crash" $\rightarrow$ Not enough search volume to show graphs.

\section{Entitlement programs:}

23. "Medicaid" $\rightarrow$ Already included in "Health Care".

24. "medicare" $\rightarrow$ Already included in "Health Care".

25. "part d" $\rightarrow$ Already included in "Health Care".

Trade policy:

26. "import barrier" $\rightarrow$ Not enough search volume to show graphs. 
Google Trends provides an index of the volume of Google searches, which is freely available, measured at high frequency and released early (almost in real time). This index is called the Search Volume Index - in symbols $S V I_{s t}$ - and it measures the volume of searches for a generic term (or group of terms) $s$ in each region (in our case the USA) at time $t$ :

$$
S V I_{s t}=\frac{s v_{s t}}{s v_{G t} \times M S V_{[o, T]}} \times 100=\frac{s v_{s t}}{s v_{G t} \times \max _{t=[0, T]}\left\{s v_{s t} / s v_{G t}\right\}} \times 100
$$

where $s v_{s t}$ is the number of searches for $s$ within period $t$. In our extraction period, 2004m1$2014 \mathrm{~m} 12$, the frequency of Google Trends series was weekly, and we converted this to a monthly frequency by averaging based on the month in which the week begins. ${ }^{28}$

The division by $s v_{G t}$ - the total number of Google searches within the same period $t$ - should prevent the $S V I_{s t}$ from being significantly affected by the extensive margin in Internet searches. Moreover, $S V I_{s t}$ series are bounded between 0 and 100, since they are scaled by the maximum value of $s v_{s t} / s v_{G t}$ from 0 to $T$ (i.e. over the entire time span), and then multiplied by 100 . Being peaknormalized, the $S V I s^{\prime}$ sensitivity to extreme values is per sé sharply reduced, as this avoids the use of various methods of treating extreme values (such as outlier-trimming) that could bias the genuine data structure. However, differences in $S V I_{s t}$ are consequently independent of the relative relevance of $s$ over total Google traffic: an increase in the required information about term $s$ is not measured as an increase in its share, but rather as an increase in its level towards 100 . Therefore, $S V I_{s t}$ indexes are short-term indicators, measuring how close the need for information about $s$ at time $t$ is to its highest point, rather than being indicators of the most searched-for terms. Because of SVI normalization, aggregation of the search terms is achieved by means of the "compare" function of Google Trends, which computes the relative relevance of different queries. In fact, by comparing each of our search terms with the same individual query, we can simply aggregate them by summing or averaging comparable-scale observations, since the measures with "compare" account for the relative relevance of the whole Google traffic. ${ }^{29}$

Of course, SVI indicators are subject to sampling variability, since it is impossible to exactly replicate the search volumes that differ slightly from one download to the next, by using a completely

\footnotetext{
${ }^{28}$ Google Trends only provides SVIst observations for those search terms exceeding a minimum threshold of popularity in period $t$, otherwise they are set to zero; therefore, zero SVIst indicates either no searches, or insignificant searches, for $s$ at time $t$.

${ }^{29}$ A detailed description of the "compare" function is below in Appendix A3.2. An alternative SVI aggregation procedure with Bayesian techniques is described in Appendix A3.1; it has the advantage of listing the most relevant search terms within the same category. We will exploit this information in the comparisons at the end of the paper.
} 
undocumented process of data review. ${ }^{30}$ However, by focusing on the aggregate EURQ index obtained from multiple downloads of our search terms on different days one year after the first download, we concluded that the effect on our findings of both sampling variation and data reviews, was negligible. ${ }^{31}$

\section{A2.1 - How to use Google correlate to find search terms and main}

\section{results}

In adopting the "correlate approach", we can use Google Correlate, a tool that allows us to identify those terms whose search volumes are correlated with either another search term or a time series uploaded by the user, as in our case. In this way, we can list those search terms that are correlated to the greatest degree with the uncertainty indexes proposed by the literature (the "fantastic five", $F F$, discussed in Appendix A5). This should give us a list of those words that people use more frequently to find information on the Internet when they are uncertain about important economic and policy issues, in the light of the five uncertainty indexes most frequently used by the media and in the literature.

To assess which queries are stable over time, and so are likely to persist in the future, we split the sample into two parts: the first part extends from January 2004 (when the Google series started) through to December 2009, while the second part extends from January 2010 to December 2014. The results are clear cut: most search terms are spuriously correlated with economic uncertainty indicators, as only about 10\% of the top 100 listed terms (such as "Dow future", "recession proof", "Austrian economics", or "Krugman blog") are related to economic concepts. Moreover, results are not the same over sub-periods, suggesting that the use of few, broad search terms fails to encompass all the various events determining economic uncertainty over time.

The full list of search terms from Google Correlate is in Table A2.1.

Tab. A2.1 - Top 10 queries of Google Correlate related with popular uncertainty indicators ${ }^{a}$

\begin{tabular}{|c|c|c|c|}
\hline & $\begin{array}{l}\text { Sample period: } \\
\text { 2004m1-2009m12 }\end{array}$ & $\begin{array}{l}\text { Sample period: } \\
\text { 2010m1-2014m12 }\end{array}$ & $\begin{array}{c}\text { Search terms common to } \\
\text { both subsamples }\end{array}$ \\
\hline VIX & $\begin{array}{l}0.9678 \text { proshares ultra } \\
0.9663 \text { ultra etf } \\
0.9651 \text { proshares ultrashort } \\
0.9619 \text { un party } \\
0.9573 \text { money futures }\end{array}$ & $\begin{array}{l}\text { 0.8241 market drop } \\
0.8186 \text { dow jones drop } \\
0.8158 \text { stock market fall } \\
0.8158 \text { dow drop } \\
0.8146 \text { dow jones crash }\end{array}$ & dow future \\
\hline
\end{tabular}

\footnotetext{
30 Regarding this point, we noticed even intra-day changes.

${ }^{31}$ Confirming Da et al. (2011), who report that correlation is usually greater than 0.97 for series downloaded several times, we found that the SVIS for a search term change very slightly from one download to another, especially when considering highly popular terms. In addition, we computed univariate statistics, sample correlations and the core macroeconomic results from our multiple downloads of $E U R Q$ series; Appendix A2.4 reports these outcomes.
} 


\begin{tabular}{|c|c|c|c|}
\hline & $\begin{array}{l}0.9546 \text { xkcd youtube } \\
0.9542 \text { bloons } 3 \\
0.9536 \text { her own } \\
0.9533 \text { recession proof business } \\
0.9510 \text { 经济危机 }\end{array}$ & $\begin{array}{l}0.8109 \text { stock market decline } \\
0.8025 \text { stocks tumble } \\
0.7998 \text { stock market drop } \\
0.7930 \text { short vix } \\
0.7914 \text { dow drops }\end{array}$ & \\
\hline SPREAD & $\begin{array}{l}0.9745 \text { ixenland } \\
0.9697 \text { tan her hide } \\
0.9658 \text { nfm omaha } \\
0.9619 \text { recession proof } \\
0.9619 \text { dnschanger } \\
0.9617 \text { vietcungvui } \\
0.9609 \text { baby names } 2008 \\
0.9602 \text { return the favor } \\
0.9599 \text { alltel phones } \\
0.9595 \text { saving abel } 18 \text { days } \\
\end{array}$ & $\begin{array}{l}0.8435 \text { samsung txt } \\
0.8374 \text { how to edit friends on facebook } \\
0.8352 \text { forgotten lands } \\
0.8339 \text { t mobile samsung phones } \\
0.8320 \text { edit friends on facebook } \\
0.8277 \text { university hotel minneapolis } \\
0.8268 \text { swap clips } \\
0.823312 \text { web } \\
0.8203 \text { edit friends } \\
0.8176 \text { fifa } 12 \text { ipad }\end{array}$ & - \\
\hline PREDICT1 & $\begin{array}{l}0.9787 \text { top bun } \\
0.9759 \text { zebra default layouts } \\
0.9733 \text { calle vip } \\
0.9706163 \text { com } \\
0.9692 \text { mx850 } \\
0.9681 \text { yours lyrics } \\
0.9680 \text { muyes } \\
0.9678 \text { vmware } 2.0 \\
0.9677 \text { dangon } \\
0.9671 \text { the shack book } \\
\end{array}$ & $\begin{array}{l}0.9457 \text { download.com } \\
0.9447 \text { cell phones without plans } \\
0.9447 \text { post.com } \\
0.9444 \text { disk partition } \\
0.9436 \text { lyrics metro station } \\
0.9432 \text { sms messages } \\
0.9431 \text { palm.com } \\
0.9431 \text { piloto cannabis lyrics } \\
0.9430 \text { puzzle games online } \\
0.9430 \text { i seem to be struck by you lyrics }\end{array}$ & - \\
\hline FDISP & $\begin{array}{l}0.7477 \text { first aid } 150 \\
0.7334 \text { fort lauderdale grande hotel } \\
0.7297 \text { fort lauderdale grande } \\
0.7229 \mathrm{ft} \text { lauderdale grande hotel } \\
0.7215 \mathrm{free} \text { death record search } \\
0.7154 \text { ガンダム oo } \\
0.7145 \mathrm{ft} \text { lauderdale grande } \\
0.7139 \text { east valley tribune arizona } \\
0.7111 \text { mageweave bandage } \\
0.7102 \text { jazz bakery culver city } \\
\end{array}$ & $\begin{array}{l}0.7294 \text { ups address change } \\
0.7018 \text { puppies washington state } \\
0.6914 \text { rationally speaking } \\
0.6888 \text { eagle pass forum } \\
0.6793 \text { chino moreno wife } \\
0.6778 \text { 子育 } \tau \\
0.6677 \mathrm{f} \& \mathrm{~m} \text { bank tulsa } \\
0.6654 \text { aol horoscopo } \\
0.6610 \text { rmls michigan } \\
0.6590 \text { whereismypov } \\
\end{array}$ & - \\
\hline EPU & $\begin{array}{l}0.9427 \text { austrian economics } \\
0.9270 \text { mises } \\
0.9218 \text { p.c } \\
0.9177 \text { go vols xtra } \\
0.9172 \text { vols xtra } \\
0.9123 \text { austrian school } \\
0.9112 \text { debt } \\
0.9104 \text { c reature from jekyll island } \\
0.9103 \text { market ticker forum } \\
0.9099 \text { how to buy gold coins }\end{array}$ & $\begin{array}{l}0.8920 \text { krugman blog } \\
0.8593 \text { target daily deals } \\
0.8559 \text { hug smiley } \\
0.8547 \text { samsung } \text { m570 } \\
0.8542 \text { craggie brewing } \\
0.8531 \text { dora princess } \\
0.8526 \text { samsung sgh a777 } \\
0.8510 \text { infiniti of bedford } \\
0.8505 \text { green girl saloon } \\
0.8503 \text { kindleboards }\end{array}$ & krugman blog \\
\hline
\end{tabular}

$\left({ }^{a}\right)$ The "fantastic five" $(F F)$ listed in the first column.

\section{A2.2 - How each single BBD search term is obtained and validated}

The $S V I_{s t}$ (Search Volume Indexes) can measure the volume of searches for a given term or phrase (query):

- if more search terms are listed together (up to a maximum of 30 words), Google Trends counts all searches that contain those words in any order;

- if the same list of search terms is placed between quotation marks, Google Trends counts all searches that include the words in the exact order they are entered (searches including other words before or after the term or phrase in quotation marks are also considered in the count); 
- the Boolean operators “+” and "_“" can combine search terms (by considering searches that contain any of several terms separated by the "+" sign) or exclude from the search volumes those queries that have nothing to do with the target in question (by listing them after “-“).

Given that the main problem with obtaining reliable search terms is the potentially ambiguous identification of meanings that are close to the BBDs' search terms, ${ }^{32}$ each term reported in BBD needs to be validated before retrieving the corresponding search volume series. This validation procedure is made easier since, for each query entered, Google Trends also reports the "top" and "rising" related queries. This further information can help us establish whether we are referring exclusively to the actual search in question, or also to extraneous topics.

Our judgmental procedure is structured as follows. Each BBD search term (either single terms or specific phrases) is placed in quotation marks, and the corresponding list of "top" and "rising" queries is inspected. If nothing suspicious emerges, the search term is left unchanged (this happened in $64 \%$ of our cases). Otherwise, if any queries result as being suspicious, the solution to the problem depends on the number of such queries. When there are only a few of them, the Boolean "-" is used to exclude them. ${ }^{33}$ However, if there are a substantial number of such suspicious queries, we add a few words to the original BBDs' search terms to narrow results. ${ }^{34}$

The list above of our 184 queries reveals no suspicious results among the corresponding "top" or "rising" queries.

\section{A2.3 - The possibly changing nature of search and internet use: detailed evidence}

Since the beginning of Google Trends data availability (2004), Internet penetration rates in the US have been rising (the extensive margin of change) and, at the same time, also the search activity could have been increasing (the intensive margin of change) because of the increasing size of the Internet, to deepen the topic see van den Bosch et al. (2016). Although this changing nature of search and Internet use should not affect short term SVI dynamics, it might induce possible low frequency fluctuations that may jeopardise the long run signal.

\footnotetext{
${ }^{32}$ Ambiguity problems can arise when there are terms with multiple meanings not all associated with the chosen topic (for example, some of the searches for "gatt", an acronym for General Agreement on Tariffs and Trade, relate to the soccer player Joshua Gatt, or to the actor Joseph Gatt); or when the search purpose is ambiguous (for example, some searches for "interest rates" relate to searches for an interest rate calculator).

${ }^{33}$ For example, if the search terms are "interest rates"-“calculator"-“best", the results will include searches containing the words "interest rates" etc. in this precise order but will exclude searches with the words "calculator" or "best" reflecting queries related to anything other than monetary policy issues.

${ }^{34}$ For example, we often added words like "act", "law" or "program" to the original search terms.
} 
Being SVI computed as ratios over the total Google searches, we do not think that problems arise from the extensive margin of change (except for changes in the structure of Internet searchers). Oppositely, the intensive margin can affect more the long run dynamics of SVI because of the increase over time in the Internet coverage of potential users. For example, at the beginning of 2004, Facebook's memberships were allowed to the Harvard students and shortly later expanded to colleges in the Boston area. Then, since 2006, anyone aged 13 and older has been allowed to become a registered Facebook user. The SVI of the "Facebook" query is plotted in Figure A2.1. Although scaled over the total number of Google searches, its share rapidly increased over the 2007-2011 period, denoting a strongly growing interest.

Before 2006, when Facebook users were not significant, the searches for the other terms did not have such a strong competitor while, after it grew so strongly, it could have structurally dampened the relevance of the pre-existing queries, including those of our 184 search terms related to uncertainty.

To deepen this point, Figure A2.2 reports the SVIs for the search terms "baseball" (panel A) and "gardening", (panel B) which are typical searches that we expect to be stable over time, apart some obvious seasonal effects.

The plot of the "baseball" SVI denotes, as expected, high stability over time with seasonal fluctuations. While, the "gardening" SVI would surprisingly suggest a decreasing trend in its interest as time passes. Given that the denominator of both SVIs is the same, this mixed evidence suggests that the actual interest of people for one of them is not stable over time. Then, the increase of Internet use (due to e.g. the advent of Facebook) did induce a break as it seems for "gardening" SVI, or was it negligible as it seems for "baseball" SVI?

Fig. A2.1 - Facebook's SVI over time (peak = 100 in December 2010)

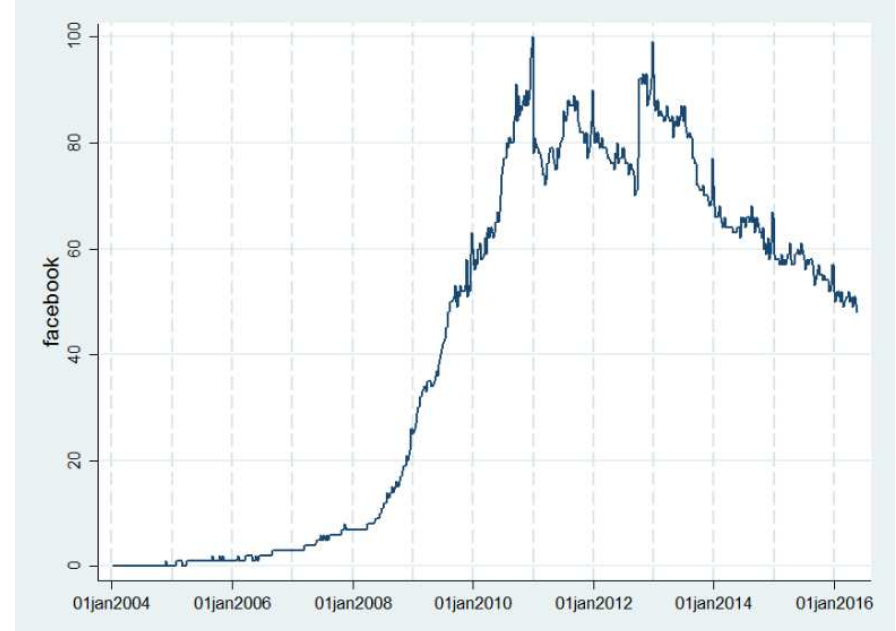


Fig. A2.2 - Alternative $S V I$ patterns expected to be stable over time

Panel A -search term: "baseball" (peak = 100 in May 2016)

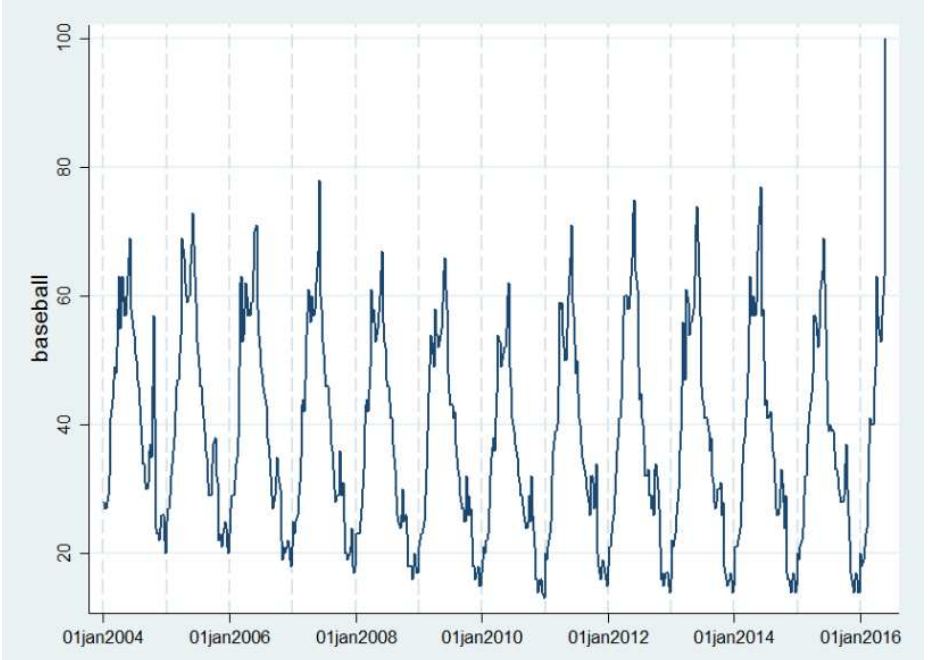

Panel B - search term: "gardening" (peak = 100 in April 2004)

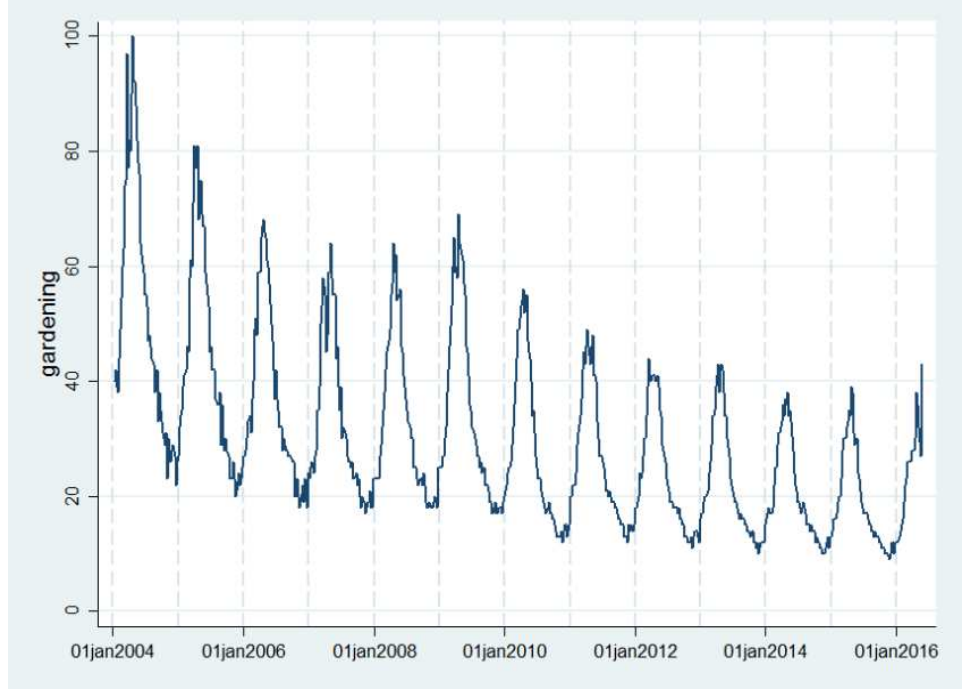

To assess the extent of this possible "Facebook effect" on the 184 SVIs collected here, Figure A2.3 reports, for each month, the counts of queries with a value above their third quartile (over75) and below their first quartile (below25). If the "Facebook effect" prevail over the uncertainty dynamics we expect to find larger over75 counts at the beginning of the sample (as for gardening), while if it does not bias in a fundamental way our uncertainty indicators, the mid-period (about in 2008-2010) over75 counts should be at their highest levels because uncertainty indicators usually show elevated levels during the Great Recession. The opposite should occur for the below25 line.

Several points emerge.

First, virtually there are no SVIs showing values below their first quartile over the Great Recession period. Conversely, over the same period, many SVIs denote elevated levels (above the third quartile). This fact corroborates the choice our search terms (good news). 
Second, the counts above 75 at the beginning of the sample - which we would expect to be lower - may warn about the risk of possible overestimates of the Google-uncertainty during the 20042005 period (unwelcome news). This fact is partly offset by the similar counts of SVIs with values below their first quartile over the same period.

Third, in line with the low uncertainty measured at the end of the sample by all the other uncertainty indicators, the evidence is of high counts of SVIS with levels below their first quartiles and of almost negligible cases above the third quartiles.

Overall, evidences move towards the existence of some "Gardening" pattern in our EURQ data, although it seems not highly distortive when considering our data. In addition, since social networks break the scene around 2007-2011 and now their popularity has stabilized (see e.g. Facebook's SVI on Figure A2.1) their impact on total Google search activity is expected to lose relevance with longer spans of data.

However, given the short sample period available for this study, a careful specification of SVI dynamics is needed, to mitigate this trend evidence through persistent (almost-in-difference) autoregressive dynamics or breaks in means specification, which can deliver reliable estimates of the timing of the uncertainty shocks. Thus, when we will compare different uncertainty measures (both at macro-aggregate level and by category), we will always filter out through either residuals prewhitening or breaks in means the uncertainty inertia which is possibly coming from the facts suggested above.

\section{Fig. A2.3 - Monthly counts of SVIs above and below their third and first quartiles}

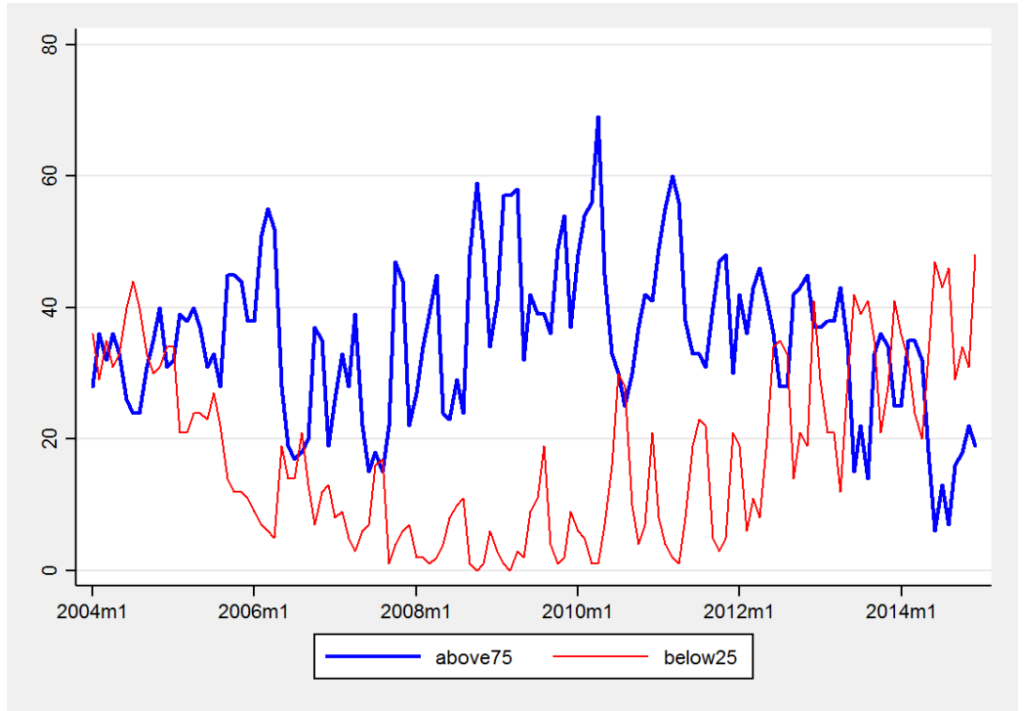




\section{A2.4 - EURQ data replicability: vintages and data revisions}

In this section we report the outcome of many statistical indicators and outcomes by using several $E U R Q$ series downloaded in 8 different days (from the 12th May 2016 to 19th May 2016) after about one year from the download of the series used in the main text of this paper. In this way, we can assess for the robustness of our results by using data which can be affected by both sampling variation and data revisions.

In the following, we use $E U R Q$ to denote the data used in the main text of this paper (downloaded the 8th June 2015), and May 12 - May 19 to denote the 8-series downloaded for conducting the robustness tests.

Tab. A2.4.1 - Descriptive statistics of different $E U R Q$ series (sample period 2004m1-2014m12)

\begin{tabular}{lccccccccc}
\hline \multicolumn{1}{c}{ Year 2016 } & EUR $\boldsymbol{Q}$ & $\begin{array}{c}\text { May } \\
\mathbf{1 2}\end{array}$ & $\begin{array}{c}\text { May } \\
\mathbf{1 3}\end{array}$ & $\begin{array}{c}\text { May } \\
\mathbf{1 4}\end{array}$ & $\begin{array}{c}\text { May } \\
\mathbf{1 5}\end{array}$ & $\begin{array}{c}\text { May } \\
\mathbf{1 6}\end{array}$ & $\begin{array}{c}\text { May } \\
\mathbf{1 7}\end{array}$ & $\begin{array}{c}\text { May } \\
\mathbf{1 8}\end{array}$ & $\begin{array}{c}\text { May } \\
\mathbf{1 9}\end{array}$ \\
Summary statistics & & & & & & & & & \\
Mean, $\boldsymbol{m}$ & 112.0 & 109.6 & 109.1 & 110.3 & 111.1 & 111.2 & 109.3 & 109.6 & 108.3 \\
Median & 111.9 & 108.9 & 108.4 & 109.6 & 110.5 & 110.9 & 108.6 & 109.0 & 107.7 \\
Maximum & 150.8 & 148.8 & 147.3 & 149.3 & 150.0 & 149.5 & 148.0 & 148.0 & 146.5 \\
Minimum & 88.0 & 86.3 & 85.5 & 86.5 & 86.5 & 86.8 & 85.0 & 85.8 & 84.3 \\
Std. Dev., $\boldsymbol{s}$ & 12.8 & 12.6 & 12.6 & 12.9 & 12.9 & 12.9 & 12.7 & 12.8 & 12.6 \\
Coeff. Variation, $\mathbf{s} \boldsymbol{m}$ & 0.115 & 0.115 & 0.116 & 0.117 & 0.116 & 0.116 & 0.116 & 0.117 & 0.117 \\
Skewness & 0.543 & 0.556 & 0.530 & 0.565 & 0.541 & 0.530 & 0.562 & 0.543 & 0.559 \\
Kurtosis & 2.764 & 2.826 & 2.738 & 2.804 & 2.801 & 2.766 & 2.840 & 2.776 & 2.807 \\
$\mathrm{~T}^{\boldsymbol{a}}$ & 132 & 132 & 132 & 132 & 132 & 132 & 132 & 132 & 132
\end{tabular}

Tab. A2.4.2 - Correlation matrix of different $E U R Q$ series (sample period 2004m1-2014m12)

\begin{tabular}{llllllllll} 
& EURQ & May 12 & May 13 & May 14 & May 15 & May 16 & May 17 & May 18 & May 19 \\
\cline { 2 - 5 } & 1.0000 & & & & & & & & \\
May 12 & 0.9955 & 1.0000 & & & & & & & \\
May 13 & 0.9960 & 0.9981 & 1.0000 & & & & & & \\
May 14 & 0.9958 & 0.9983 & 0.9984 & 1.0000 & & & & & \\
May 15 & 0.9958 & 0.9982 & 0.9983 & 0.9982 & 1.0000 & & & & \\
May 16 & 0.9955 & 0.9986 & 0.9986 & 0.9984 & 0.9989 & 1.0000 & & \\
May 17 & 0.9958 & 0.9987 & 0.9983 & 0.9988 & 0.9985 & 0.9987 & 1.0000 & & \\
May 18 & 0.9961 & 0.9982 & 0.9985 & 0.9986 & 0.9981 & 0.9986 & 0.9987 & 1.0000 & \\
May 19 & 0.9957 & 0.9985 & 0.9985 & 0.9983 & 0.9983 & 0.9985 & 0.9988 & 0.9986 & 1.0000
\end{tabular}


Fig. A2.4 - Impulse response of production (IPMAN) with alternative $E U R Q$ series (sample period $2004 \mathrm{~m} 1-2014 \mathrm{~m} 12$ )

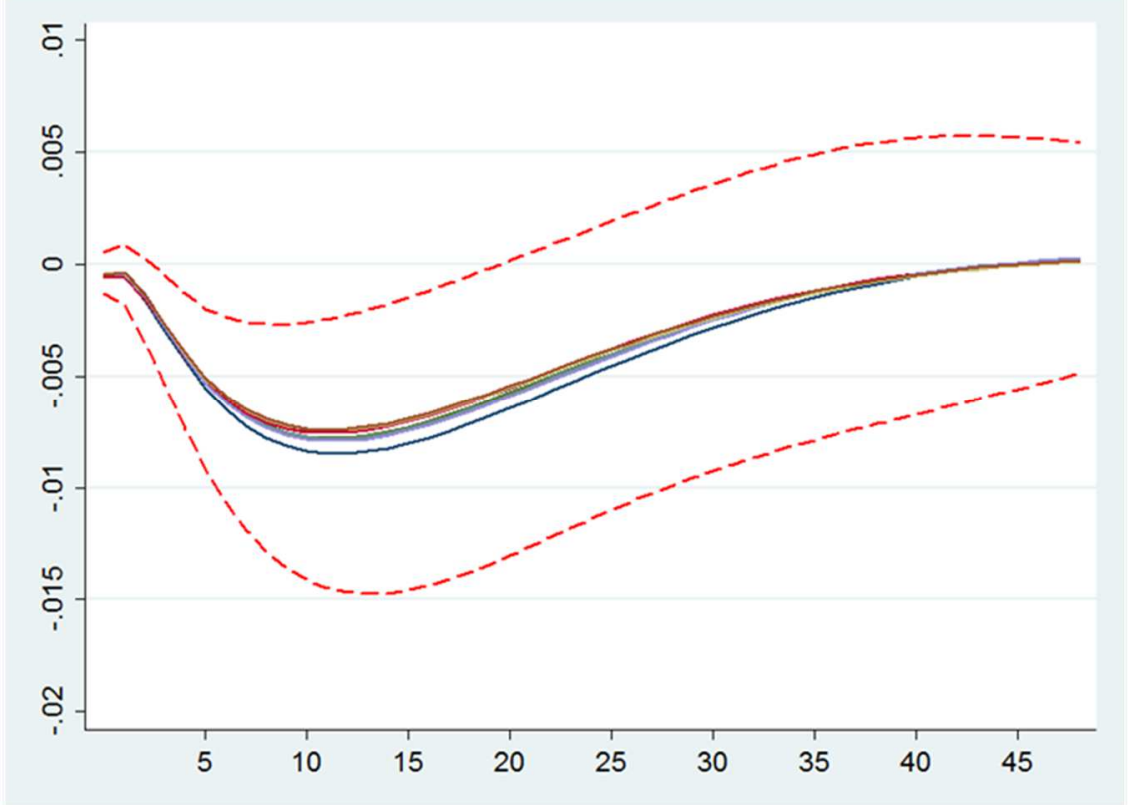

\section{A2.5 - Robustness of $E U R Q$ to the presence or absence of subsets of search} terms

In this section, we examine to which extent our aggregate index depends upon single search terms among the 184 listed in Appendix A2. This is performed by recursively excluding blocks of search terms from the computation of the aggregate index. Table A2.5 reports correlations between the indices obtained from these calculations and the original index used in the main text of this paper $(E U R Q)$. In the following, the notation $E U R Q-\left[q u e r y_{-} \boldsymbol{X}-\right.$ query_$\left._{-} \boldsymbol{Y}\right]$ refers to the version of the $E U R Q$ index computed by excluding queries from $\mathbf{X}$ to $\mathbf{Y}$ (where $\mathrm{X}$ and $\mathrm{Y}$ are the numbers associated to the search terms in the list of Appendix A2). The same information is depicted in Figure A2.5.

Tab. A2.5 - Correlation between the original EURQ index and EURQs computed by excluding block of search terms (sample period 2004m1-2014m12)

\begin{tabular}{|c|c|}
\hline $\begin{array}{c}\text { EURQ excluding block of search terms } \\
\boldsymbol{a}:\end{array}$ & Correlation with EURQ \\
\hline EURQ - [query_1 - query_8] & 0.9749 \\
\hline EURQ - [query_9 - query_16] & 0.9818 \\
\hline EURQ - [query_17 - query_24] & 0.9970 \\
\hline EURQ - [query_25 - query_32] & 0.9858 \\
\hline EURQ - [query_33 - query_41] & 0.9997 \\
\hline EURQ - [query_42 - query_49] & 0.9634 \\
\hline EURQ - [query_50 - query_56] & 0.9873 \\
\hline
\end{tabular}




\begin{tabular}{|c|c|}
\hline EURQ - [query_57 - query_64] & 0.9741 \\
\hline EURQ - [query_65 - query_71] & 1.0000 \\
\hline EURQ - [query_72 - query_80] & 0.9994 \\
\hline EURQ - [query_81 - query_89] & 0.9782 \\
\hline EURQ - [query_90 - query_98] & 0.9996 \\
\hline EURQ - [query_99 - query_107] & 0.9811 \\
\hline EURQ - [query_108 - query_114] & 0.9996 \\
\hline EURQ - [query_115 - query_118] & 0.9992 \\
\hline EURQ - [query_119 - query_126] & 0.9996 \\
\hline EURQ - [query_127 - query_136] & 0.9948 \\
\hline EURQ - [query_137 - query_143] & 1.0000 \\
\hline EURQ - [query_144 - query_150] & 1.0000 \\
\hline EURQ - [query_151 - query_157] & 0.8805 \\
\hline EURQ - [query_158 - query_164] & 0.9364 \\
\hline EURQ - [query_165 - query_171] & 0.9998 \\
\hline EURQ - [query_172 - query_178] & 0.9982 \\
\hline EURQ - [query_179 - query_184] & 0.9996 \\
\hline
\end{tabular}

Fig. A2.5 - EURQ excluding blocks of search terms (sample period 2004m1-2014m12)

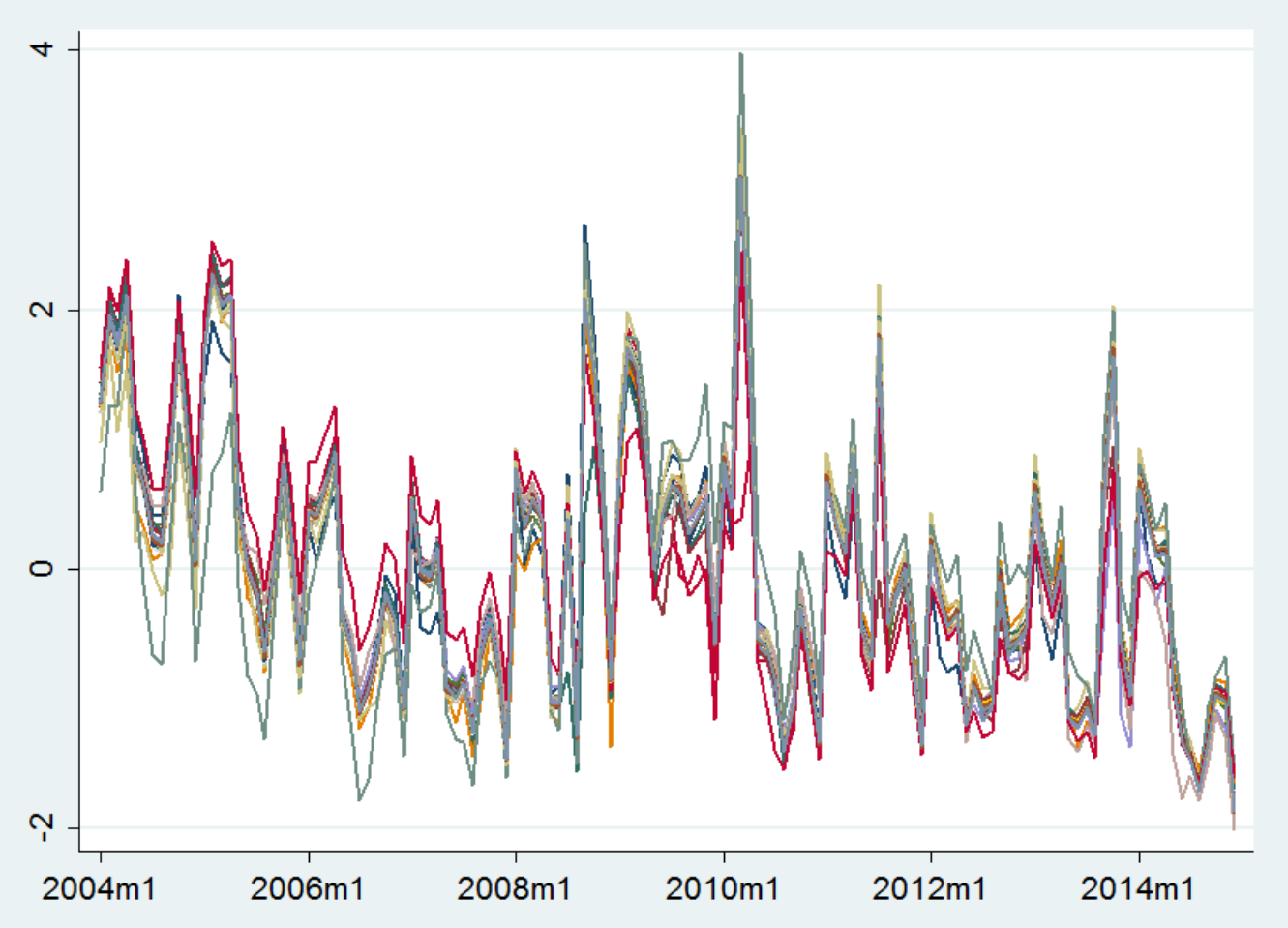

EURQ series computed by recursively excluding search terms from the computation. The blocks of search terms excluded are the same as those reported in Table A2.5. The time series are standardized by subtracting the mean and dividing by the SDs to allow for an immediate comparison 


\section{Appendix A3 - The sum of the 184 series into sub-groups, policy categories and the EURQ}

Since the 184-single series are scaled by their maximum value, each series is scaled by a different value, and thus different series cannot be directly summed into policy categories.

Ideally, we would simply merge the individual search terms listed in Appendix A2 into groups of queries to create 8 new search terms representing the combination of the individual ones, by using the Boolean "+". However, due to the Google Trends 30-word limit for each search term, the aim of replicating the 8 BBDs' policy categories using Google Trends cannot be accomplished in this way. The merging of single-series search terms is only viable if we split each of the 8 BBDs' categories into smaller sub-groups to keep the number of words in the resulting combined search terms below the upper limit of 30 . Following this route, we come to the 24 sub-groups $(G i, i=1, . ., 24)$, homogeneous in terms of the number of series within each sub-group, allocated to the 8 policy areas and listed below.

\section{(1) Fiscal policy, FP (2 sub-groups)}

1. query_1-query_8

2. query_9-query_16

(2)Monetary Policy, MP (3 sub-groups)
3. query_17 - query_24
4. query_25 - query_32
5. query_33 - query_41

(3) Health care, HC (2 sub-groups)
6. query_42-query_49
7. query_50-query_56

(4)National security and war, NS (2 sub-groups)
8. query_57 - query_64
9. query_65 - query_71

(5)Regulation, RE (8 sub-groups)

10. query_72-query_80

11. query_81 - query_89

12. query_90 - query_98

13. query_99 - query_107

14. query_108 - query_114

15. query_115 - query_118

16. query_119 - query_126

17. query_127 - query_136

(6)Foreign sovereign debt and currency crisis, SDCC (2 sub-groups)

18. query_137-query_143

19. query_144 - query_150

(7)Entitlement programs, EP (3 sub-groups)

20. query_151 - query_157 
21. query_158 - query_164

22. query_165 - query_171

\section{(8) Trade policy, TP (2 sub-groups)}

23. query_172 - query_178

24. query_179 - query_184

Obviously, the merging of individual search terms to form sub-groups prevents the insurgence of those missing data that, in specific single queries, would result from the paucity of search volumes in certain weeks/months. Furthermore, given that the peak-normalization of the search volumes' series is made at sub-group level, the relevance of each search term within its sub-group is accounted for when we extract the 24-aggregate series by sub-group. Of course, this (partial) outcome (i.e. 24 subgroups series from 184 individual search terms) still does not meet our requirement of having 8 Google Trends aggregate search volumes accounting for the weight of each search term within the category. This result can be achieved in one of two ways: Bayesian and common-term aggregation.

\section{A3.1 - Bayesian aggregation}

The first way (henceforth "Bayesian aggregation") is to shrink the number of individual search terms included in each sub-group by using the Bayesian model averaging (BMA) method. This gives us the list of the "most relevant" single search terms of those sub-groups belonging to the same category that can be successfully merged without exceeding the 30-word limit. The shrinking issue is tackled as a problem of the choice of the "best" of several explanatory variables (i.e. the single search volumes) in linear regressions where each sub-group is the dependent variable. In doing so, BMA provides a coherent method of inference of the model's parameters by taking explicit account of the uncertainty surrounding both the estimation and the steps of model selection: see, for example, Leamer (1978) and Magnus et al. (2010). ${ }^{35}$

The outcomes of the Bayesian aggregation approach are reported in Table A3.1, where the first column shows the descriptions of the sub-groups (i.e. our target variables), the second column lists the individual search terms that are parsimoniously selected by BMA, the third column reports the statistical significance of the selected search terms, and the fourth column shows the posterior inclusion probability (which must be greater than 50\%).

\footnotetext{
${ }^{35}$ To perform BMA analysis, we used the bma Stata code of De Luca and Magnus (2011). We also tried alternative model selection algorithms, such as Lars, Lasso and Least Angle algorithms, by using the lars procedure of Adrian Mander (2006). These alternative regularization methods utilize additional information to prevent overfitting; this information usually involves the introduction of a penalty for complexity, with different penalties involved by different methods; see Efron et al. (2004). The selection results of Lars, Lasso and Least Angle are not reported because they deliver outcomes that are very similar to those of BMA, albeit less parsimonious.
} 
Tab. A3.1 - List of single search terms selected by BMA

\begin{tabular}{|c|c|c|c|}
\hline SUB GROUP $(G i)$ & $\begin{array}{r}\text { SEARCH TERM }(S j) \\
\end{array}$ & $\mathbf{t}$ & PIP \\
\hline & (1)Fiscal policy, FP (16 queries) & & \\
\hline \multirow{4}{*}{ G1 } & 2. "tax rate"- "calculator" & 26.88 & 1.00 \\
\hline & 3. "taxation" & 22.07 & 1.00 \\
\hline & 5. "government spending" & 4.70 & 1.00 \\
\hline & 8. "balanced budget" & 1.15 & 0.66 \\
\hline \multirow{4}{*}{ G2 } & 11. "federal debt" & 1.57 & 0.80 \\
\hline & 12. "national debt" & 12.46 & 1.00 \\
\hline & 14. "debt ceiling" & 40.41 & 1.00 \\
\hline & (2) Monetary policy, MP (25 queries) & & \\
\hline \multirow{6}{*}{ G3 } & 17. "the federal reserve" & 4.69 & 1.00 \\
\hline & 18. "the fed" & 3.77 & 0.99 \\
\hline & 21. "quantitative easing" & 6.01 & 1.00 \\
\hline & 22. "monetary policy" & 4.03 & 1.00 \\
\hline & 23. "fed funds rate" & 6.26 & 1.00 \\
\hline & 24. "Bernanke" & 19.23 & 1.00 \\
\hline \multirow{3}{*}{ G4 } & 25. "Paul Volcker" & 4.19 & 1.00 \\
\hline & 26. "Alan Greenspan" - "Mitchell" -"wife" & 15.10 & 1.00 \\
\hline & 28. "interest rates" - "calculator" - "best" & 76.44 & 1.00 \\
\hline \multirow{4}{*}{ G5 } & 33. "European Central Bank" & 10.46 & 1.00 \\
\hline & 35. "Bank of England" & 1.84 & 0.86 \\
\hline & 36. "Bank of Japan" & 9.51 & 1.00 \\
\hline & 38. "Bank of China" & 8.40 & 1.00 \\
\hline & (3) Health care, HC (15 queries) & & \\
\hline \multirow{2}{*}{ G6 } & 42. "health care reform" & 76.15 & 1.00 \\
\hline & 49. "drug policy" - "nfl" & 3.43 & 0.99 \\
\hline \multirow{4}{*}{ G7 } & 50. "food and drug administration" & 8.52 & 1.00 \\
\hline & 54. "Medicare Part D" - "humana" - "aarp" & 18.22 & 1.00 \\
\hline & 55. "affordable care act" & 54.13 & 1.00 \\
\hline & (4) National security and war, NS (15 queries) & & \\
\hline \multirow{3}{*}{ G8 } & 60. "terrorism" & 42.30 & 1.00 \\
\hline & 61. "war on terror" & 4.77 & 1.00 \\
\hline & 63. "defense spending" & 3.49 & 0.99 \\
\hline \multirow{4}{*}{ G9 } & 66. "us armed forces" -"ranks" & 2.81 & 0.96 \\
\hline & 67. "military base closure" & 8.84 & 1.00 \\
\hline & 70. "no-fly zone" & 7.91 & 1.00 \\
\hline & (5) Regulation, $R E$ (65 queries) & & \\
\hline \multirow{5}{*}{ G10 } & 74. "Glass Steagall" & 13.97 & 1.00 \\
\hline & 76. "thrift supervision" & 12.42 & 1.00 \\
\hline & 77. "Dodd frank" - "form" - "certification" & 25.12 & 1.00 \\
\hline & 78. "financial reform" & 29.26 & 1.00 \\
\hline & 80. "cftc" & 5.57 & 1.00 \\
\hline \multirow{4}{*}{ G11 } & 84. "Volcker rule" & 3.12 & 0.98 \\
\hline & 85. "bank stress test" & 3.15 & 0.98 \\
\hline & 86. "securities and exchange commission" & 7.65 & 1.00 \\
\hline & 89. "fdic" - "jobs" & 87.01 & 1.00 \\
\hline G12 & 91. "office of thrift supervision" & 18.55 & 1.00 \\
\hline \multirow{5}{*}{ G13 } & 99. "minimum wage" & 35.60 & 1.00 \\
\hline & 100. "living wage" - "calculator" & 4.89 & 1.00 \\
\hline & 101. "right to work" & 11.26 & 1.00 \\
\hline & 105. "affirmative action" & 10.02 & 1.00 \\
\hline & 107. "trade adjustment assistance" & 1.59 & 0.81 \\
\hline G14 & 108. "davis bacon" & 9.85 & 1.00 \\
\hline
\end{tabular}




\begin{tabular}{|c|c|c|c|}
\hline & $\begin{array}{l}\text { 109. "equal employment opportunity" } \\
\text { 112. "antitrust" }\end{array}$ & $\begin{array}{c}6.62 \\
18.46\end{array}$ & $\begin{array}{l}1.00 \\
1.00\end{array}$ \\
\hline \multirow{2}{*}{ G15 } & 116. "copyright law" & 11.49 & 1.00 \\
\hline & 117. "federal trade commission" & 15.50 & 1.00 \\
\hline \multirow{3}{*}{ G16 } & 122. "class action law" & 6.05 & 1.00 \\
\hline & 124. "tort reform" & 28.89 & 1.00 \\
\hline & 126. "energy policy" & 20.72 & 1.00 \\
\hline \multirow{6}{*}{ G17 } & 127. "energy tax" & 16.23 & 1.00 \\
\hline & 128. "carbon tax" & 1.99 & 0.89 \\
\hline & 129. "cap and trade" & 25.80 & 1.00 \\
\hline & 134. "environmental protection agency" & 24.13 & 1.00 \\
\hline & 135. "the epa" - "jobs" & 5.91 & 1.00 \\
\hline & 136. "immigration policy" & 5.09 & 1.00 \\
\hline & \multicolumn{3}{|l|}{$\begin{array}{l}\text { (6) Foreign sovereign debt and currency crisis, SDCC } \\
\text { (14 queries) }\end{array}$} \\
\hline \multirow{4}{*}{ G18 } & "137. "sovereign debt" & 11.04 & 1.00 \\
\hline & 139. "currency devaluation" & 6.64 & 1.00 \\
\hline & 141. "currency manipulation" & 5.66 & 1.00 \\
\hline & 142. "euro crisis" & 8.03 & 1.00 \\
\hline \multirow[t]{2}{*}{ G19 } & 145. "European debt" & 9.96 & 1.00 \\
\hline & (7) Entitlement programs, EP (21 queries) & & \\
\hline \multirow[t]{2}{*}{ G20 } & $\begin{array}{l}\text { 154. "social security" - "office" - "number" - "my" - } \\
\text { "calculator" - "online" - "jobs" }\end{array}$ & 91.23 & 1.00 \\
\hline & 157. "unemployment insurance" & 13.12 & 1.00 \\
\hline \multirow{3}{*}{$G 21$} & 158. "unemployment benefits" - "online" & 36.49 & 1.00 \\
\hline & 159. "food stamps" - "application" - "online" & 64.23 & 1.00 \\
\hline & 162. "wic program" & 1.27 & 0.70 \\
\hline \multirow{4}{*}{ G22 } & 165. "Supplemental Nutrition Assistance Program" & 1.79 & 0.85 \\
\hline & 166. "Earned Income Tax Credit" & 14.33 & 1.00 \\
\hline & 168. "head start program" - "jobs" & 4.04 & 1.00 \\
\hline & (8) Trade policy, TP (13 queries) & & \\
\hline \multirow{5}{*}{ G23 } & 173. "government subsidies" & -3.96 & 1.00 \\
\hline & 175. "wto" - "howto" & 9.40 & 1.00 \\
\hline & 176. "world trade organization" & 4.88 & 1.00 \\
\hline & 177. "trade treaty" & 2.42 & 0.94 \\
\hline & 178. "trade agreement" & 8.83 & 1.00 \\
\hline G24 & 183. "gatt" -"joseph" - "josh" - "stefan" & 12.18 & 1.00 \\
\hline
\end{tabular}

Reported search terms $S j$ are those whose t ratio is greater, in absolute value, than one and whose posterior inclusion probability (PIP) is greater than 0.5

The outcome in Table A3.1 has the considerable advantage of delivering a limited list of the "most relevant" individual terms within each sub group: the larger is the weight of a single search term within its sub-group, the greater the likelihood it will be picked. ${ }^{36}$ However, in the BBDs' categories (2) "monetary policy", (5) "regulation" and (7) "entitlement programs" the reduced set of individual search terms is still too large to merge the individual Bayesian-selected search terms into a compound search term category of less than 30-words. Therefore, to implement a Bayesian

\footnotetext{
${ }^{36}$ This information is utilized when we will compare certain Google Trends search volumes within a category with the Newsbank categories of $B B D$.
} 
aggregation in the case of these three categories, we would need extra restrictions excluding further individual search terms.

\section{A3.2 - Common-term aggregation}

The second approach helps us and utilizes a feature of Google Trends that enables up to five different terms or groups of terms (henceforth, "common-term aggregation") to be compared. Starting from equation (1), the use of the function "compare" on Google Trends ensures that for each search term (or group of search terms) included in the comparison, we have the same scaling value, corresponding to the maximum value of over the period $0-T$, among all the single series that we are comparing. Therefore, by scaling all the series for a common term, we can easily aggregate them by summing or averaging. ${ }^{37}$

For example, considering two generic series $\{j, n\}$ included for comparison in Google Trends, and summing their SVIs, we obtain a series defined as follows:

$$
\begin{gathered}
S V I_{S U M t}=\left(\frac{s v_{j t}}{s v_{G t} \times M S V_{[o, T]}}+\frac{s v_{n t}}{s v_{G t} \times M S V_{[o, T]}}\right) \times 100= \\
=\frac{100}{M S V_{[o, T]}} \times\left(\frac{s v_{j t}+s v_{n t}}{s v_{G t}}\right)
\end{gathered}
$$

The volumes by sub-group obtained using the common-term aggregation (A3.1) are equivalent to what we would obtain by merging the single terms $j$ and $n$ in Google Trends equation (A2.1) in Appendix A2 using the Boolean operator "+", except for minor differences due to rounding and the fixed difference in the constant scaling term. However, it is worth stressing that the outcome of common-term aggregation has the advantage of bypassing the 30 -word limit by merging search terms.

The search volume series, obtained from Bayesian aggregation, deliver outcomes that are very similar to those obtained by means of common-term aggregation, since the number of search terms selected using BMA accounts for a very large portion of the variability of the full set of search terms by category (i.e. their weights are significant within the category). ${ }^{38}$

Therefore, hereinafter we shall only measure the Google Trends volumes by category as obtained using the common-term aggregation approach, and the same approach is followed to sum the 8 categories into the aggregate $E U R Q$ indicator of macroeconomic uncertainty.

\footnotetext{
${ }^{37}$ As far as we know, this approach has been only used by Hacamo and Reyes (2012).

${ }^{38}$ Note that the correlation coefficients by category between Bayesian aggregation (when feasible) and common-term aggregation (always feasible) are greater than 0.96 in four cases out of five, and equal to 0.70 in the remaining cases.
} 


\section{Appendix A4 - Internet and news comparison of "government shutdown" and "debt ceiling"}

The individual search terms "government shutdown" and "debt ceiling crises" can be interpreted as policy uncertainty shocks, since during the standoff people are concerned about, and discuss, "what economic policy actions will be undertaken and when, and the economic effects of past, present and future policy actions". ${ }^{39}$ For example, with reference to the Government shutdown on October 8 2013, a White House statements reports: "After a discussion about potential paths forward, no specific determination was made [...] The President looks forward to making continued progress with members on both sides of the aisle" (source: Reuters). The thousands of comments on online newspapers articles reporting this news testify to the uncertainty surrounding this situation. ${ }^{40}$

As far as the methodological approach is concerned, we will not rely on the time series properties with VAR models, but rather on their behaviour after the trigger event, because we are only faced with a debt-ceiling crisis or (even more so) a Government shutdown - i.e. two important but rare events - "once in a blue moon". In Figures A4.1 and A4.2, the relative frequency of newspaper mentions, and the Google Trends series are in fact near to zero over a substantial portion of the sample, apart from a limited number of significant spikes.

\section{Figures A4.1 and A4.2 here}

As expected, Newsbank and EURQ indicators substantially overlap, as the same trigger events drive both. However, interestingly Google searches decline more rapidly after the peak, as if in the case of notable events, most people seek information about what is going on when the standoff is at its peak; after this peak, many of them stop caring about the uncertainty question well before newspapers do. Regarding the "Government shutdown" series in Figure A4.1, the highest spike of Internet activity (with a value of 100, considering the weekly raw series downloaded from Google Trends) was during the week from 29/09/2013 to 05/10/2013, which was to be expected given that from October 1 to October 16 certain federal agencies were temporarily closed or worked part-time. Google figures for the following two weeks were 28 and 26 respectively, and after these 3 weeks Internet searches declined rapidly to a mean value of 1.5 between 20 October and 30 November 2013. Media coverage, on the other hand, remained high for a longer period, declining more gradually: considering the standardized time-series reported in Figure A4.1, after a peak of 10.45 in October

\footnotetext{
${ }^{39}$ To quote BBD's definition of what an article about policy uncertainty should be concerned with.

${ }^{40} \mathrm{As}$ an example, in response to this news we discovered: 12,265 comments on Yahoo News ("They're talking? Really? Republicans, Obama have 'productive' meeting on debt, shutdown” by C. Moody), 5,697 in The Washington Post ("House, Senate Republicans offer competing plans on debt-limit, government shutdown", P. Kane, Z. A. Goldfarb and L. Montgomery), and 1,716 in The Wall Street Journal ("Obama, GOP Open Talks Over Temporary Debt Fix"; J.Hook and P. O'Connor).
} 
(associated with a value of 5.76 for the Google Trends index in the same month), the following two months' values were respectively 1.89 ( 0.23 the corresponding $S V I)$ and $1.31(0.15$ the corresponding $S V I$ ), well above the one standard deviation threshold, unlike the Internet searches series, the observed values of which were close to the mean of zero. A similar trend, with Internet searches declining more rapidly than media coverage in the aftermath of a shock, was observed after interest peaked regarding the debt ceiling debate of July 2011.

Given these findings, if Internet activity is perceived as a proxy of the number of people influenced by a policy uncertainty shock, then we can tentatively conclude that many people just glance at media reports, while few of them give much attention to them for any length of time. Following less severe shocks, however, news reports and Internet searches spike together, and decline together, since in the wake of a moderate shock even newspapers quickly stop concerning themselves with the issue in question.

Fig. A4.1 - News coverage and Internet searches for the term "Government Shutdown"

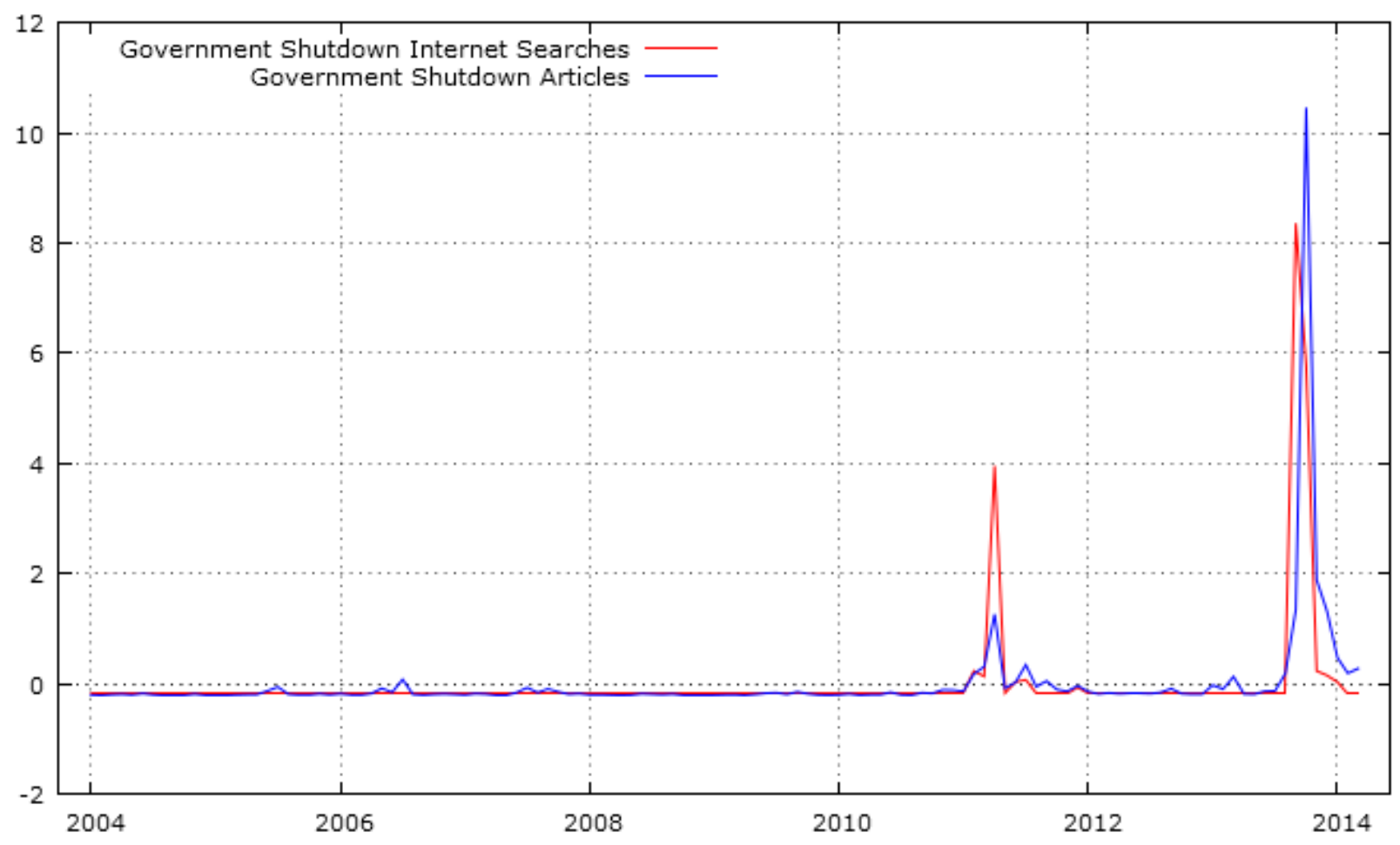


Fig. A4.2 - News coverage and Internet searches for the term "Debt Ceiling"

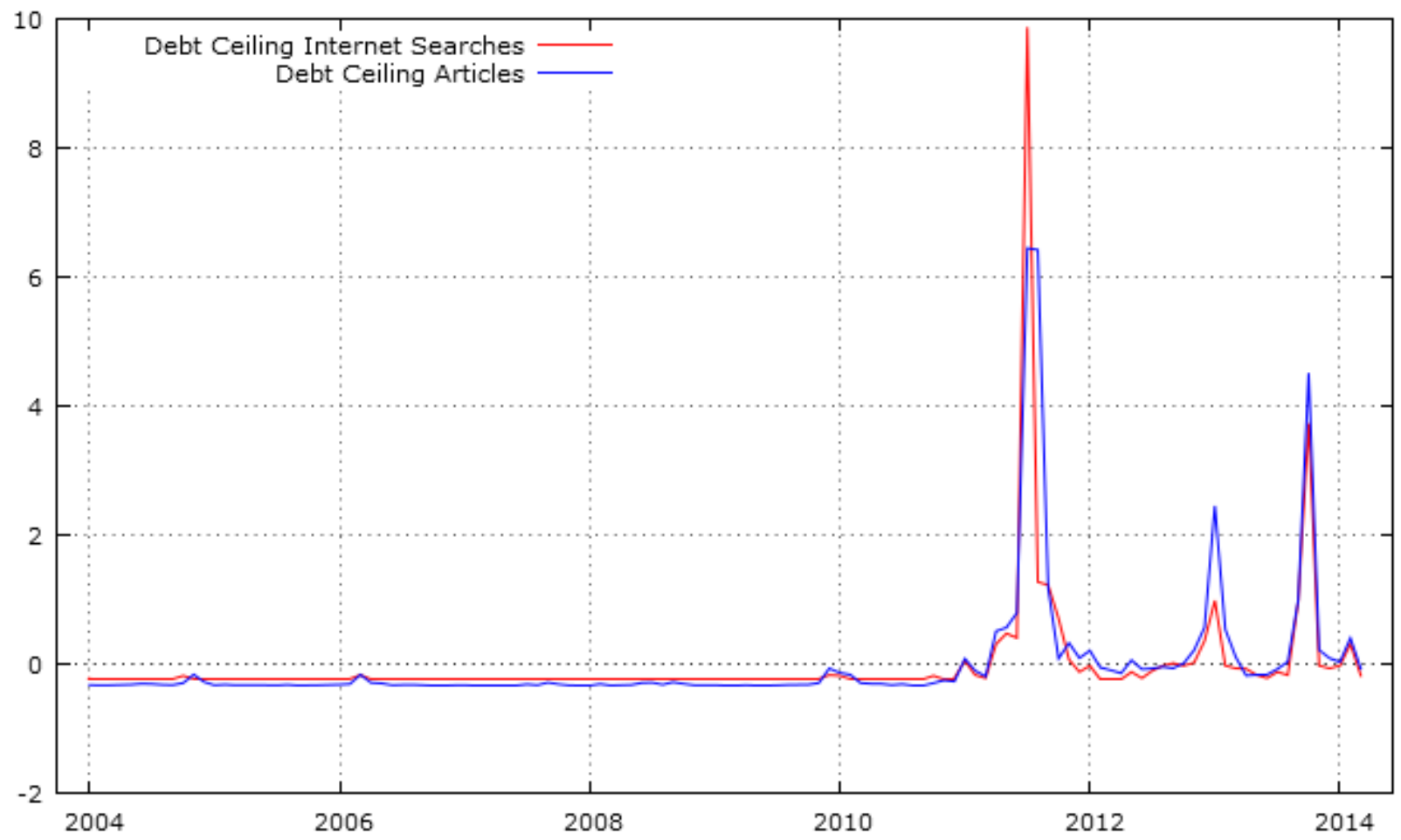

Monthly relative frequencies of mentions of "government shutdown" and "debt ceiling" in the US newspapers included in the Access World New's NewsBank service (data retrieved from www.policyuncertainty.com/categorical_epu.html) and Google Trends search volume indexes for the same search terms. The series are standardized to have a mean of 0 and a standard deviation of 1 . 


\section{Appendix A5 - The measurement of the "fantastic five" (FF): further details}

The (i) VIX proxy is obtained from the forecast 30-day volatility of the S\&P 500 Index and is computed by averaging the weighted prices of put and call options on the S\&P 500 stock market index (for details, see the CBOE White Paper, 2009). Given that VIX monthly data have been available since January 1990, we used realized (rather than implied) stock market return volatility to proxy the pre-1990 missing VIX data going back to the beginning of the 1960s (see Bloom, 2009, and Bachmann et al, 2013). Bekaert et al. (2013) show that the uncertainty component of VIX can be defined as the expected stock market variance (estimated using a projection model including the lagged squared VIX and past realized volatility), whilst risk-aversion can be defined as the difference between the squared VIX and the estimated VIX uncertainty component. De Long et al. (1990) suggest that uninformed noise traders guided by sentiment, in presence of limits to arbitrage, will lead to excessive volatility. Sentiment could also follow non-economic events such as sport or weather conditions (see footnote 1 in Da et al., 2015).

The (ii) SPREAD proxy is defined as the difference between Moody's BAA-rated corporate bond yield and the 30-year Treasury constant maturity rate (monthly). Following Bachmann et al (2013), we used the 20-yearTreasury bond data when the 30-year Treasury bond data were not available, as in the 2002-2005 period and from the 1950s to 1977. Gilchrist et al. (2014) assume that credit spreads reflect the endogenous effects of informational and contractual friction deriving from an (exogenous) uncertainty shock, which they measure using high-frequency firm-level stock market data. Their Figure 4 suggests that their measure of uncertainty shock is highly countercyclical and moves in tandem with credit spreads. Nodari (2014) provides empirical evidence of the direct effects of financial regulation policy uncertainty on credit spreads, and subsequently on the real economy.

The (iii) PREDICTh proxy is forecast-based: Jurado et al. (2015) estimate uncertainty by assuming that a more (or less) uncertain economy is less (or more) predictable, and thus uncertainty can be measured as a lack of predictability. The estimation of PREDICTh dates to $1960 \mathrm{~m} 7$, and is obtained by aggregating the individual uncertainties of 132 economic and financial time series over alternative forecast horizons $h$. Three macro-uncertainty indexes (with $h=1,3$ and 12) are obtained from the following steps: (1) $h$ months ahead forecasts are estimated using diffusion index models based on both lagged and contemporaneous common factors, autoregressive terms and other predictors such as simple non-linear transformations of factors; ${ }^{41}$ (2) the uncertainty regarding each single variable is defined as the volatility of the $h$-months ahead prediction error (conditional on the information set in period $t$ ), and is computed using stochastic volatility models; (3) all these uncertainties are combined into one single measure of overall macro uncertainty by means of simple averaging (alternative aggregation approaches deliver similar outcomes). We chose a priori to use the PREDICTI $(h=1)$ to prevent the forecast horizon from

\footnotetext{
${ }^{41}$ Factors are estimated through the principal components analysis of a set of 279 indicators that includes the 132 series on which individuals' uncertainties are computed, plus 147 additional financial time series.
} 
overlapping the sample frequency of data. Results using the PREDICT1 are robust to the use of $h=3$ and 12. In this context, Lahiri and Sheng (2010), who refer to the seminal work by Zarnowitz and Lambros (1987), and to Bomberger (1996), break down the individual forecast error into a component related to shocks common to all forecasters over the forecast period, and another component concerning forecaster-specific idiosyncratic errors. In their paper they show that ex ante forecast uncertainty can be expressed as the sum of the expected volatility of future (common) aggregate shocks over the forecast period, and the observed disagreement among forecasters. In this context, large common shocks occurring in periods of economic instability or over long forecast periods exacerbate the distance separating the concepts of disagreement and uncertainty.

The (iv) FDISP proxy of uncertainty is the standard deviation of forecasts from two or more analysts. Bachmann et al. (2013) have estimated FDISP since $1968 \mathrm{~m} 5$ by using the cross-sectional disagreement between the forecasts of large firms' management to be found in the Philadelphia Fed's Manufacturing Business Outlook Survey (BOS). The FDISP is based on the cross-section forecast dispersion of the fraction of each category of response. ${ }^{42}$ The BOS sample composition reflects the industrial mix of the Third Federal Reserve district (i.e. eastern Pennsylvania, southern New Jersey, and Delaware), thus it might not perfectly reflect the general US outlook. Bachmann et al. (2013) acknowledge this caveat, by reporting equivalent results obtained using forecast data from surveys not restricted to any area or industrial sector.

The (v) proxy EPU is the news-based policy-related economic uncertainty index. Baker et al. (2016) obtain the EPU index by mixing three basic ingredients: (1) the newspaper coverage of policyrelated economic issues (the news-based component NEWS); (2) the number of federal tax code provisions set to expire in future years; and (3) the disagreement among economic forecasters. Forecasters' disagreement is measured by the interquartile range of individual one-year forecasts reported in the Federal Reserve Bank of Philadelphia's quarterly Survey of Professional Forecasters. Among the SPF's wide range of predicted variables, BBD focus on the consumer price index, purchases of goods and services by state and local governments, and purchases of goods and services by the federal government. To obtain their global EPU index of policy-related economy uncertainty, BBD compute the average value of the three normalized components, using weights of $1 / 2$ on the broad NEWS index (1), and 1/6 on each of the other three measures (the tax provision expiration index (2), and the disagreement of forecasters (3) about both the CPI and the federal/state/local purchases measures.

Of the above three EPU components, the one with more weight and of main interest here is NEWS, which is a restricted version of the Newsbank index we used in Section 3: actually, NEWS and Newsbank

\footnotetext{
42 The responses to the BOS survey about the state of "general business conditions" over the following six months, are classified into three separate categories (up, no change, down). The three categories of interviewed forecasters are publicly available. In addition to Bachmann et al. (2013), see also http://www.phil.frb.org/research-and-data/regionaleconomy/business-outlook-survey/index.cfm
} 
have a correlation of 0.85 , as reported by BBD. But $N E W S$ is based on the search results from only 10 large newspapers: BBD perform month-by-month searches in each paper for terms relating to economic policy uncertainty and compute the ratio between the raw count of policy uncertainty articles and the total number of articles published in the same paper in the same month. They then normalize the resulting series, by newspaper, to obtain a unit standard deviation over the period from $1985 \mathrm{~m} 1$ to $2010 \mathrm{~m} 12$. Finally, they sum the values over papers, and re-normalize the multi-paper index to an average value of 100 from $1985 \mathrm{~m} 1$ to $2009 \mathrm{~m} 12 .{ }^{43}$ Since the sample period of $E P U$ index is shorter than the periods covered by previous indexes (available well before the 1980s), our long-term comparison shall refer to a recent outcome (still in progress) of the BBD project: the Historical News-Based Policy Index (HNEWS), that extends NEWS back to 1900 by performing month-by-month searches for specific terms in 6 newspapers. ${ }^{44}$ Since $H N E W S$ is presently available up to $2014 \mathrm{~m} 2$, we updated it to $2014 \mathrm{~m} 12$ by using its "twin" NEWS index (over the overlapping period their correlation is about 0.9).

\footnotetext{
${ }^{43}$ Further details are available at: http://www.policyuncertainty.com/us_monthly.html

${ }^{44}$ See details at: http://www.policyuncertainty.com/us_historical.html. 


\section{A6.1 - Univariate analysis of FF over the large sample 1970m1-2014m12}

The comparison between some univariate features across uncertainty measures involves statistics based on samples of different amplitude: the $F F$ measures share the common temporal span 1970m1-2014m12, while EURQ is available over the 2004m1-2014m12 period. Figure A6.1 allows for the visual comparison of $F F$ and $E U R Q$ over the longest temporal span.

Fig. A6.1 - Alternative uncertainty measures over the common 1970m1-2014m12 period $\left(^{a}\right)$
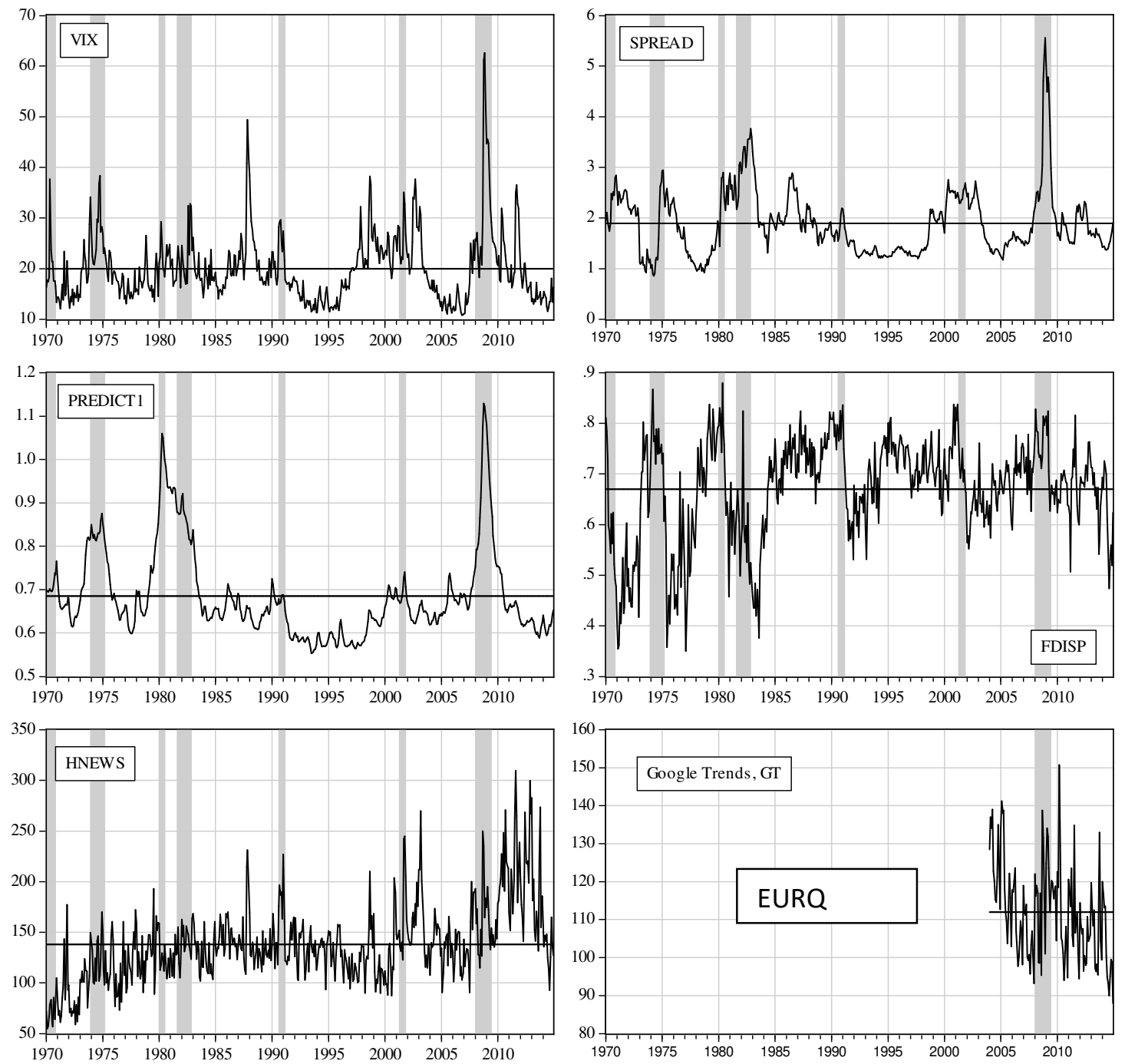

${ }^{(a)}$ Shaded areas denote NBER downturn phases. Horizontal lines measure the sample averages.

The FF measures of uncertainty cover the common sample 1970m1-2014m12 $(\mathrm{T}=540$ months, 83 of which are characterized by NBER downturns, shown by the shaded areas), while EURQ is available from $2004 \mathrm{~m} 1$ only. The patterns are not much homogeneous: some series (SPREAD and PREDICT1) are smoother and clearly spike in recession periods only, while others (FDISP and $H N E W S$ ) are affected by noisier fluctuations over time. The VIX time series shows additional spikes outside downturns, at times of financial crisis (e.g. the Black Monday of October 19th, 1987). High 
EURQ levels at the beginning of its availability do not indicate any distortive effect due to the extensive and intensive margins of the web use.Given that the shorter EURQ sample could be more strongly affected by the Great Recession, Table A6.1 reports the outcomes over the longest 1970m12014m12 period for $F F$ and the outcomes over the 2004m1-2014m12 period for EURQ.

Tab. A6.1 - Univariate analysis of uncertainty proxies over the full sample $\left(^{(a}\right)$

\begin{tabular}{|c|c|c|c|c|c|c|}
\hline & VIX & SPREAD & PREDICT1 & FDISP & HNEWS & EURQ \\
\hline \multicolumn{7}{|l|}{ Summary statistics } \\
\hline Mean, $\mu$ & 20.0 & 1.890 & 0.685 & 0.670 & 138.0 & 112.0 \\
\hline Median & 18.4 & 1.760 & 0.656 & 0.691 & 133.8 & 111.9 \\
\hline Maximum & 62.6 & 5.560 & 1.129 & 0.880 & 309.5 & 150.8 \\
\hline Minimum & 10.8 & 0.860 & 0.553 & 0.350 & 54.9 & 88.0 \\
\hline Std. Dev., $\sigma$ & 6.8 & 0.653 & 0.103 & 0.101 & 39.2 & 12.8 \\
\hline Coeff. of Variation, $\sigma \mu$ & 0.342 & 0.346 & 0.151 & 0.151 & 0.284 & 0.115 \\
\hline Skewness & 1.985 & 1.641 & 1.711 & -0.839 & 1.078 & 0.543 \\
\hline Kurtosis & 9.785 & 8.034 & 6.034 & 3.382 & 5.276 & 2.764 \\
\hline $\mathrm{T}^{a}$ & 540 & 540 & 540 & 540 & 540 & 132 \\
\hline \multicolumn{7}{|l|}{ Cyclicality } \\
\hline Downturn/upturn $\mu$ ratios & 1.406 & 1.458 & 1.262 & 1.068 & 1.003 & 1.058 \\
\hline Downturn/upturn $\sigma$ ratios & 1.652 & 2.077 & 1.714 & 0.997 & 1.121 & 0.999 \\
\hline \multicolumn{7}{|l|}{$\begin{array}{l}\text { Persistence testing and measures } \\
\text { Through unit-root tests }\left({ }^{b}\right)\end{array}$} \\
\hline - augmentation, $k$ & 8 & 2 & 2 & 6 & 15 & 11 \\
\hline - tests' p-values & 0.001 & 0.002 & 0.017 & 0.002 & 0.076 & 0.584 \\
\hline - speed of adjustment, $\pi$ & -0.120 & -0.047 & -0.017 & -0.108 & -0.098 & -0.190 \\
\hline - half-life months, $m\left({ }^{c}\right)$ & 5 & 14 & 41 & 6 & 7 & 3 \\
\hline - ARCH(1) test, p-values $\left({ }^{d}\right)$ & 0.001 & 0.022 & 0.000 & 0.000 & 0.032 & 0.113 \\
\hline \multicolumn{7}{|l|}{ Through fractional integration $\left({ }^{e}\right)$} \\
\hline - $d$ estimate & 0.339 & 0.411 & 0.410 & -0.293 & 0.427 & 0.463 \\
\hline - highest AR root & 0.55 & 0.87 & 0.90 & 0.95 & 0.12 & - \\
\hline - highest MA root & - & 0.46 & -0.35 & - & - & 0.86 \\
\hline - half-life impulse-response, $m$ & 5 & 28 & 86 & 4 & 3 & 2 \\
\hline - ARCH(1) test (p-values) ${ }^{d}$ ) & 0.000 & 0.021 & 0.000 & 0.001 & 0.002 & 0.252 \\
\hline
\end{tabular}

$\left(^{a}\right)$ 1970m1-2014m12 (2004m1-2014m12 for EURQ). T=540, of which 83 downturn periods and 457 upturns (see NBER dating); only 18 downturn periods and 114 upturns for $E U R Q$.

$\left({ }^{b}\right)$ Dickey and Fuller (1979) test equation: $\Delta y_{t}=c+\pi y_{t-1}+\sum_{i=1}^{k} \gamma_{i} \Delta y_{t-1}+u_{t}$, where $k$ is selected by using the MAIC criterion of $\mathrm{Ng}$ and Perron (2001) starting from a given maximum number of lags $\left(k_{\text {MAX }}\right)$.

$\left.{ }^{(}\right)$Months for closing $50 \%$ of the disequilibria. In general, $m=\ln (1-p) / \ln (1+\pi)$, where $p$ is the part of the initial gap to be closed between actual $y_{t}$ and its long run forecast (if $y_{t}$ is stationarity, it is its unconditional mean), and $\pi$ is the speed of adjustment (see above). Here, $p=0.50$, i.e. $50 \%$.

$\left({ }^{d}\right)$ Significant ARCH tests highlight residuals' conditional heteroscedasticity of the first order for the estimated ARMA/ARFIMA model.

$\left({ }^{e}\right)$ The first row reports the ML estimate of the fractional integration parameter $d$ in the ARFIMA (p, $d$, q) model: $\rho(L)(1-L)^{d}\left(y_{t}-\mu\right)=\vartheta(L) \varepsilon_{t}$ which is covariance stationary for $|d|<1 / 2$; the second/third rows respectively report the highest roots of the $\rho(L)$ and $\vartheta(L)$ polynomials (to check for stationary and invertible ARMA processes); the fourth row reports the number of months $m$ for closing $50 \%$ of the initial impulse to accumulate.

Unconditional statistics in Table A6.1 reveal the great variability of VIX, SPREAD and HNEWS. Apart from the FDISP and EURQ indices (which seem more Gaussian), all the other series 
show positive skewness and excess of kurtosis, indicating longer tails on the right side of the distribution than on the left side, with the bulk of the density and the medians lying on the left of the means. This is the effect of positive spikes during recession phases and of the considerable weight of the Great Recession over the 2004m1-2014m12 period. Uncertainty appears to be counter-cyclical, with means and variances that are often higher during downturns. These shifts are less pronounced for forecast-based (FDISP) and news/search-based indicators, while the opposite holds for financial and macroeconomic (PREDICT1) uncertainty measures.

Empirical results using formal unit root tests suggest that all the $F F$ indexes are stationary, as the null hypothesis is always rejected at 5\% (except for the case of HNEWS, where it is only rejected at $10 \%$ ). However, the speed of adjustment varies: after the occurrence of an uncertainty shock, the period it takes to halve the gap between actual data and the steady state, ranges between 5-7 months for VIX, FDISP and HNEWS, whereas it stands at about one year for SPREAD, and at more than three years for PREDICT1 (the slowest to adjust). The shorter time scale of EURQ explains the purely statistical non-rejection of the unit-root null hypothesis, as the point estimate of its persistence suggests that the series is stationary with shorter half-lived shocks (3 months). To uniform outcomes over a common sample period, we also conducted unit root tests for all the uncertainty measures over the $2004 \mathrm{~m} 1-2014 \mathrm{~m} 12$ period. Results corroborate the same finding from the EURQ i.e. that the short time span weakens the statistical rejection of the unit-root null. More interestingly, the individual features of the series hold over the shorter span, denoting the remarkable stability of their univariate features.

The unit-root test outcomes of ARMA models are confirmed by estimating ARFIMA models for the levels of $F F$ and $E U R Q$, as all the series fluctuate around a time-invariant steady state. ${ }^{45}$

\section{A6.2 - The ARMA/GARCH and ARMA-with-breaks modelling of uncertainty indicators}

The null hypothesis of identically distributed uncertainty shocks in the univariate modelling is almost always rejected regardless of the modelling context (ARMA or ARFIMA) because of clear hereoskedasticity evidence. Hence, we model the stationary process driving uncertainty by adopting both the ARMA model with GARCH errors (ARMA/GARCH model) and the ARMA model with breaking means (ARMA-with-breaks model), as the GARCH innovations can be otherwise explained by models featuring iid innovations with changing parameters - see Tsay (1987). ${ }^{46}$

\footnotetext{
45 The main features of the ARFIMA model specification are listed in Appendix A7.1.

${ }^{46}$ See the technical features in Appendix A7.
} 
The ARMA/GARCH approach employs the class of ARMA models with GARCH innovations as a parsimonious and flexible way of representing the dynamics of conditional mean and variance, and of preventing the insurgence of residuals' heteroscedasticity. We choose an $\operatorname{ARMA}(2,3)$ model for the conditional mean and $\operatorname{aARCH}(1,2)$ model for the conditional variance. Although simple, they can detect clusters of time where the uncertainty shocks are particularly large and can adequately represent the major features of all the uncertainty measures emerging from the preliminary analysis.

The ARMA-with-breaks model starts again from an ARMA representation, but assumes that the unconditional mean of uncertainty may vary across $m+1$ different regimes with high/low uncertainty (denoted by $r$ ) of $T_{r}$ observations. We first tested for the largest significant number and dating of breaks (shifts in uncertainty) registered by each of the six uncertainty measures over the common sample period 2004m1-2014m12. Then, we estimated the ARMA models based on the identified break dates. The corresponding residuals never reject the null hypotheses of not serially correlated and homoscedastic errors and this suggests that the ARMA-with-breaks model is a viable alternative to the ARMA/GARCH model to explain fluctuations in uncertainty over the cycle.

The Maximum Likelihood estimates for the $F F$ and $E U R Q$ following the ARMA/GARCH approach are reported in Table A6.2.

Tab. 6.2 - ARMA/GARCH model estimates $\left({ }^{a}\right)$

\begin{tabular}{|c|c|c|c|c|c|c|}
\hline Parameter estimates & VIX & SPREAD & PREDICT1 & FDISP & HNEWS & $E U R Q$ \\
\hline$\phi_{1}$ & $0.836^{* * *}$ & $0.944^{* * *}$ & $1.571^{* * *}$ & $0.604^{* * *}$ & $1.378^{* * *}$ & $0.724^{* * *}$ \\
\hline$\phi_{2}$ & & & $-0.599^{* * *}$ & $0.271^{* * * *}$ & $-0.395^{* * *}$ & \\
\hline$\vartheta_{1}$ & & $0.329^{* * *}$ & & & $-0.879^{* * *}$ & \\
\hline$\vartheta_{2}$ & & & $-0.135^{* *}$ & & & \\
\hline$\vartheta_{3}$ & & $0.033^{* * *}$ & & & & \\
\hline $\begin{array}{l}\alpha_{1} \\
\alpha_{2}\end{array}$ & $0.285^{* * *}$ & $0.204^{* * * *}$ & $0.498^{\text {**** }}$ & $\begin{aligned} & 0.180^{* * *} \\
&-0.150^{* *}\end{aligned}$ & $0.054^{* * * *}$ & $\begin{array}{r}0.202^{* * *} \\
-0.044^{* * * *}\end{array}$ \\
\hline$\beta_{1}$ & & $0.796^{* * *}$ & $0.338^{* * *}$ & $0.965^{* * *}$ & $0.909^{* * *}$ & \\
\hline \multicolumn{7}{|l|}{ Persistence in } \\
\hline $\begin{array}{l}\text { conditional mean }\left({ }^{c}\right) \\
\text { conditional variance }\end{array}$ & $\begin{array}{r}-0.164 \\
0.285\end{array}$ & $\begin{array}{r}-0.056 \\
1.000\end{array}$ & $\begin{array}{r}-0.028 \\
0.836\end{array}$ & $\begin{array}{r}-0.125 \\
0.994\end{array}$ & $\begin{array}{r}-0.017 \\
0.963\end{array}$ & $\begin{array}{r}-0.276 \\
0.158\end{array}$ \\
\hline \multicolumn{7}{|c|}{$\begin{array}{l}\text { No. of adverse shocks } \hat{\varepsilon}_{t} \text { above } \\
\left({ }^{d}\right)\end{array}$} \\
\hline$\hat{h}_{t}$ & 60 & 101 & 97 & 77 & 73 & 62 \\
\hline $1.5 \times \hat{h}_{t}$ & 36 & 50 & 47 & 29 & 38 & 33 \\
\hline $3 \times \hat{h}_{t}$ & 11 & 9 & 2 & 1 & 9 & 12 \\
\hline
\end{tabular}


$\left({ }^{a}\right)$ The general $\operatorname{ARMA}(2,3)-\operatorname{GARCH}(1,2)$ specification is: $y_{t}=\gamma_{0}+\phi_{1} y_{t-1}+\phi_{2} y_{t-2}+\vartheta_{1} \varepsilon_{t-1}+\vartheta_{2} \varepsilon_{t-2}+\vartheta_{3} \varepsilon_{t-3}+\varepsilon_{t}$, and: $h_{t}=\omega+\alpha_{1} \varepsilon_{t-1}^{2}+\alpha_{2} \varepsilon_{t-2}^{2}+\beta_{1} h_{t-1}$ for the conditional variance.

$\left.{ }^{b}\right)$ After significance tests, unreported estimates are those we restricted to zero. ${ }^{* * *},{ }^{* *}$, and ${ }^{*}$ denote $1 \%, 5 \%$ and $10 \%$ significance. Sample period 1970m1-2014m12 (except for EURQ whose sample is 2004m1-2014m12).

${ }^{(c)}$ This measure corresponds to the speed of adjustment (persistence of the process) and is obtained as: $\hat{\phi}_{1}+\hat{\phi}_{2}-1$.

${ }^{(d)}$ The number of counts for EURQ is multiplied by 540/132 to account for the shorter EURQ sample (only 132 observations against 540 for the other series).

The persistence of uncertainty levels (the estimates of $\phi_{1}+\phi_{2}-1$ parameter) confirms the preliminary outcomes: uncertainty is always characterized by large autoregressive parameter estimates with cyclical effects that are particularly evident for PREDICT1 and HNEWS. HNEWS also reveals a first-order moving average estimate, which is mirrored by the extremely long lag order of the unit root test equation.

The conditional variance components (the GARCH estimates) are reported only when they are significant. The financial SPREAD reveals the most persistent volatility (and is thus best represented by the Integrated GARCH model). At the other extreme, the less persistent volatility of the financial $V I X$ and $E U R Q$ shocks is coupled with their low first-moments persistence.

The estimated ARMA/GARCH residuals represent the unpredictable uncertainty innovations and can be interpreted as the uncertainty measures after pre-whitening to remove their predictable parts, such as the inertia and the effect of the intensive margin in the use of Internet for the EURQ index.

The ARMA/GARCH estimated conditional variances of the uncertainty indicators is shown in the upper graph of Figure A6.2.

The clusters of time-varying volatility (i.e. the periods in which large uncertainty shocks follow one other) are not very different across indicators. The variability of uncertainty shocks is pronounced at the beginning of the sample (from the 1970s to the first half of the 1980s) and it weakens during the phase of Great Moderation (starting in around 1984), except for the financial blip witnessed in $1987 \mathrm{~m} 11$. At the time of the 2008 Great Recession, variability raises again and remains at a prominent level until the end of the sample period (most clearly in the cases of the HNEWS and $E U R Q$ conditional variance estimates).

The clustering volatility of uncertainty is mirrored in the pattern of the residuals in the lower graph of Figure A6.2, which represents our best estimates of the unpredictable uncertainty innovations. Their dispersion broadly corresponds to the phases before/during/after the Great Moderation, thus enforcing the belief that the size of uncertainty innovations and the variability of the cycle are related. The prevalence of positive shocks during the recession supports again uncertainty counter-cyclicality. 
Fig. A6.2 - GARCH conditional variance estimates (standardized, top), and residuals (down)
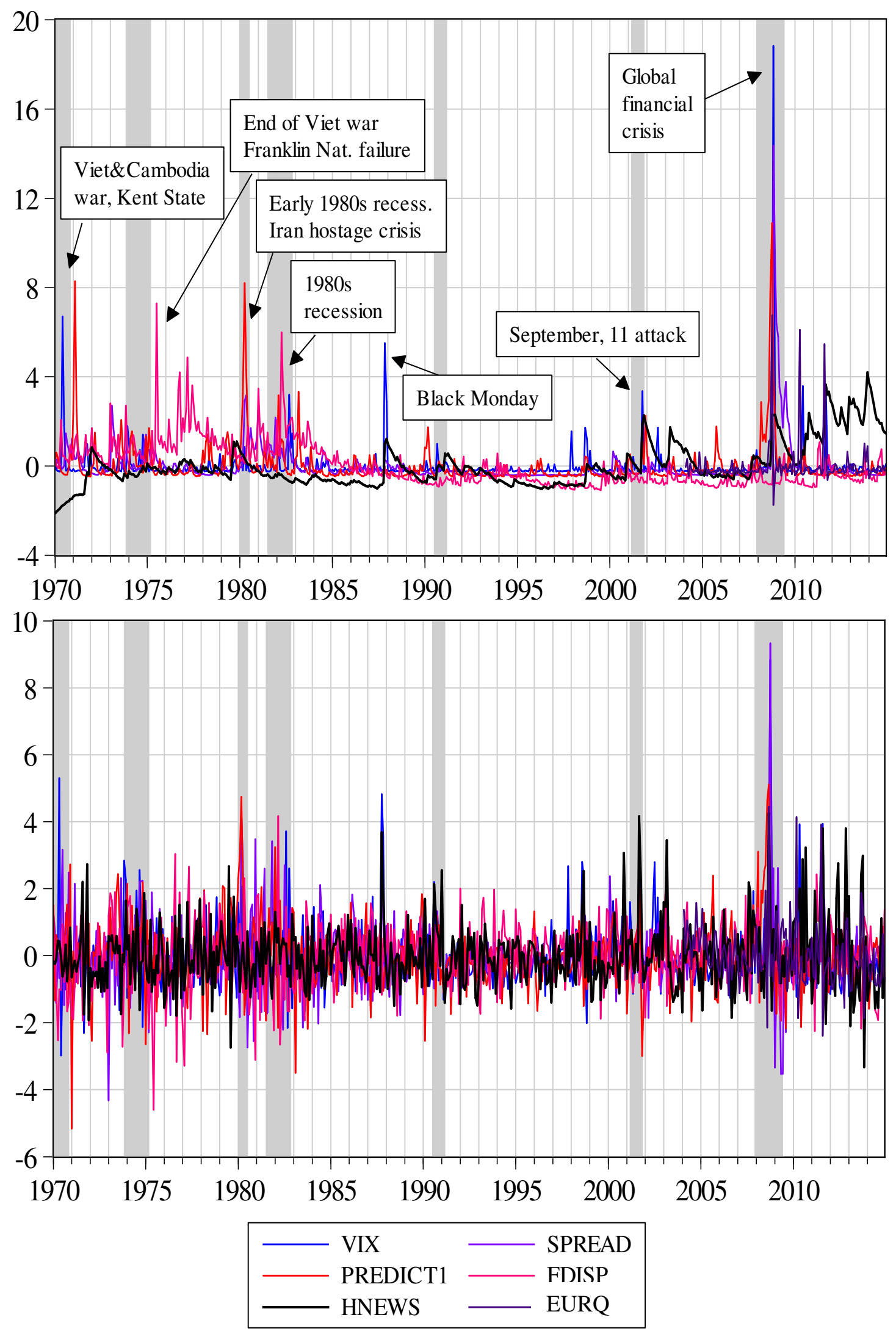

Not all the peaks of the shocks of different uncertainty measures overlap, and some indexes are affected by more shocks than other indexes. For example, peaks in uncertainty measured by the 
forecast-based indicators (PREDICT1 and FDISP) are considerably fewer than those of the financebased indicators (VIX and SPREAD). HNEWS and EURQ also peak quite frequently since news and Internet searches can be related to those financial shocks occurring outside of large macroeconomic downturns.

Estimates of the ARMA-with-breaks models are in Table A6.3. The estimated number of breaks, $m$, are tested by F-statistic on the number of breaks for which the null hypothesis of $m-1$ breaks is rejected against the alternative of $m$ breaks, and by the Bai and Perron (2003)'s 5\% critical values. This analysis has been conducted over the common sample period 2004m1-2014m12.

Tab. A6.3 - Modelling uncertainty shifts $\left({ }^{a}\right)$

\begin{tabular}{lrrrrrr} 
Testing for the number of breaks & & & & & & \\
\multicolumn{1}{c}{ Equation for } & VIX & SPREAD & PREDICT1 & FDISP & HNEWS & EURQ \\
- number of breaks, $m$ & 3 & 4 & 4 & 3 & 3 & 3 \\
- F-statistic & 21.97 & 26.79 & 36.31 & 16.13 & 12.64 & 22.01 \\
- Bai-Perron (2003) 5\% cv. & 11.14 & 11.83 & 11.83 & 11.14 & 11.14 & 11.14 \\
\hline
\end{tabular}

(a) Sample period: $2004 \mathrm{~m} 1-2014 \mathrm{~m} 12$. 


\section{Appendix A7 - The methodology of the alternative univariate models}

\section{A7.1 - The ARFIMA model specification}

Let's have the ARFIMA models for the uncertainty level $y$ :

$\rho(L)(1-L)^{d}\left(y_{t}-\mu\right)=\vartheta(L) \varepsilon_{t}$

where $d$ is the fractional-integration parameter, $\rho(L)$ is the AR polynomial in the lag operator $L, \vartheta(L)$ is the MA polynomial, and $\varepsilon$ is the iid innovation term. Since its introduction by Granger and Joyeux (1980), it has been widely acknowledged that the ARFIMA model provides a parsimonious parameterization of long memory processes that nests the ARMA model and, by allowing for fractional degrees of integration through $d$ parameter estimates, it also generalises the ARIMA model with integer degrees of integration. The ARFIMA model is covariance stationary for $|d|<1 / 2$.

\section{A7.2 - The ARMA model with GARCH errors}

The Wold representation of the class of ARMA models with GARCH innovations for the uncertainty level $y$ is:

$$
y_{t}=\mu+B(L) \varepsilon_{t}
$$

where $\mu$ is the unconditional mean of $y_{t}$ and $B(L)=1+\sum_{i=1}^{\infty} b_{i} L^{i}$ is a lag $L$ polynomial obtained from $\rho^{-1}(L) \vartheta(L)$. The shocks $\varepsilon_{t}$ are serially uncorrelated uncertainty innovations with time-varying heteroscedasticity $h_{t}$ conditional to the information set in $t-1, \Omega_{t-1}$ :

$$
\varepsilon_{t} \mid \Omega_{t-1} \sim \mathrm{N}\left(0, h_{t}\right)
$$

where $h_{t}=\omega+C(L) \varepsilon_{t}^{2}$, and $C(L)=\sum_{i=1}^{\infty} c_{i} L^{i}$ is a lag polynomial. If the two infinite-ordered autoregressive lag operator polynomials $B(L)$ and $C(L)$ are approximated by ratios of low-ordered lag operator polynomials, we obtain the classical ARMA model with GARCH errors, see e.g. Bollerslev et al. (1994). We choose an $\operatorname{ARMA}(2,3)$ model for the conditional mean and a $\operatorname{GARCH}(1,2)$ model, specified as:

$$
\begin{aligned}
& y_{t}=\gamma_{0}+\phi_{1} y_{t-1}+\phi_{2} y_{t-2}+\vartheta_{1} \varepsilon_{t-1}+\vartheta_{2} \varepsilon_{t-2}+\vartheta_{3} \varepsilon_{t-3}+\varepsilon_{t} \\
& h_{t}=\omega+\alpha_{1} \varepsilon_{t-1}^{2}+\alpha_{2} \varepsilon_{t-2}^{2}+\beta_{1} h_{t-1}
\end{aligned}
$$

\section{A7.3 - The ARMA model with breaking means}

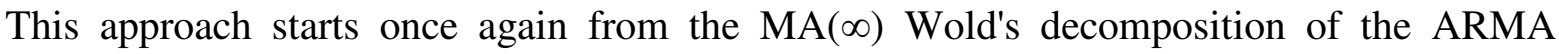
fluctuations for the uncertainty level $y$, but we now assume that the unconditional mean of uncertainty can vary across $m+1$ different regimes (denoted with $r$ ) of $T_{r}$ observations:

$$
y_{t}=\mu_{r}+B(L) \varepsilon_{t}
$$

where $\mu_{r}$ is the unconditional mean of $y_{t}$ in the $r^{\text {th }}$ regime (with $\left.r=0,1,2, \ldots, m\right), B(L)$ is a polynomial of infinite order as in equation (A7.2), and $\mathcal{E}_{t}$ are zero-mean, serially uncorrelated and homoscedastic ( iid) uncertainty innovations. In order to estimate the unknown number of break dates, we follow the Bai and Perron (1998) a procedure which starts from $m$ breaks under the null (obtained by a global minimization of the sum of squared residuals) and tests it against the alternative of $m+1$ breaks, for $m=0,1,2, \ldots, m_{\max }$ (here we set the maximum number of breaks over the 2004m1$2015 \mathrm{~m} 12$ period at five). 


\section{A8.1 - VAR modelling of ARMA/GARCH residuals over alternative samples}

Results from modelling the ARMA/GARCH residuals in a VAR for the 2004m1-2014m12 period are shown in Table A8.1.

Tab. A8.1 - Dynamic relationships between uncertainty innovations from ARMA/GARCH $\left({ }^{a}\right)$

\begin{tabular}{|c|c|c|c|c|c|c|c|}
\hline \multirow{2}{*}{\multicolumn{8}{|c|}{$\begin{array}{r}\text { Sample period } 2004 \mathbf{m} 4-\mathbf{2 0 1 4 m 1 2} \\
\text { p-values of block Granger causality tests in a VAR(2) of uncertainty innovations }\end{array}$}} \\
\hline & & & & & & & \\
\hline \multirow[b]{2}{*}{$\begin{array}{l}\text { Two lags of explanatory } \\
\text { innovations to: }\end{array}$} & \multirow[b]{2}{*}{$D f$} & \multicolumn{6}{|c|}{ Equation for the innovation to: } \\
\hline & & VIX & SPREAD & PREDICT1 & FDISP & HNEWS & $E U R Q$ \\
\hline VIX & & & 0.0045 & 0.0650 & 0.4463 & 0.7382 & 0.7054 \\
\hline SPREAD & 2 & 0.5897 & & 0.8009 & 0.9860 & 0.1646 & 0.2983 \\
\hline PREDICT1 & 2 & 0.0000 & 0.0000 & & 0.2964 & 0.2255 & 0.0312 \\
\hline FDISP & 2 & 0.8866 & 0.8796 & 0.9645 & & 0.3716 & 0.6046 \\
\hline HNEWS & 2 & 0.8448 & 0.5947 & 0.6356 & 0.1261 & & 0.3636 \\
\hline EURQ & 2 & 0.1044 & 0.0970 & 0.7566 & 0.3525 & 0.7633 & \\
\hline Joint & 10 & 0.0000 & 0.0000 & 0.2140 & 0.2354 & 0.6429 & 0.3331 \\
\hline
\end{tabular}

correlation between unpredictable uncertainty innovations (VAR(2) residuals)

$\begin{array}{lrrrrr}\text { SPREAD } & \mathbf{0 . 5 9 4 5} & & & & \\ \text { PREDICT1 } & -0.0382 & 0.0810 & & & \\ \text { FDISP } & \mathbf{0 . 1 7 0 2} & 0.1203 & 0.0527 & & \\ \text { HNEWS } & \mathbf{0 . 3 1 6 9} & \mathbf{0 . 1 9 6 3} & \mathbf{0 . 1 4 5 1} & 0.0208 & \\ \text { EURQ } & -0.0467 & -0.1128 & 0.0640 & -0.0178 & \mathbf{0 . 2 9 9 3}\end{array}$

$\left(^{a}\right)$ In bold, $10 \%$ significant estimates. The upper section of Table shows the p-values of the Granger causality test, where each column refers to a VAR equation, and each row refers to a block of explanatory lags. The lower part of the Table shows the sample correlation matrix of VAR residuals to assess the degree of simultaneity between the different indicators.

Results from modelling the ARMA/GARCH residuals in a VAR for the 1970m3-2014m12 period are shown in Table A8.2.

Tab. A8.2 - Dynamic relationships between uncertainty innovations from ARMA/GARCH $\left({ }^{a}\right)$

\section{Sample period 1970m3 - 2014m12}

p-values of block Granger causality tests in a VAR(2) of uncertainty innovations

Equation for the innovation to:

\begin{tabular}{lrrrrrr}
$\begin{array}{l}\text { Two lags of explanatory } \\
\text { innovations to: }\end{array}$ & $d f$ & VIX & SPREAD & PREDICT1 & FDISP & HNEWS \\
\cline { 3 - 7 } VIX & & & & & & \\
SPREAD & 2 & 0.5860 & & 0.6423 & $\mathbf{0 . 0 1 2 6}$ & 0.6966 \\
PREDICT1 & 2 & $\mathbf{0 . 0 0 0 0}$ & $\mathbf{0 . 0 0 0 0}$ & & $\mathbf{0 . 0 0 9 0}$ & $\mathbf{0 . 0 1 5 5}$ \\
FDISP & 2 & 0.8076 & 0.1042 & $\mathbf{0 . 0 1 3 7}$ & & 0.5002 \\
HNEWS & 2 & 0.4572 & 0.6211 & $\mathbf{0 . 0 0 6 9}$ & $\mathbf{0 . 0 5 8 3}$ & \\
Joint & 8 & $\mathbf{0 . 0 0 0 0}$ & $\mathbf{0 . 0 0 0 0}$ & $\mathbf{0 . 0 0 8 4}$ & $\mathbf{0 . 0 0 0 2}$ & $\mathbf{0 . 0 4 0 1}$
\end{tabular}


correlation between unpredictable uncertainty innovations (between VAR(2) residuals)

$\begin{array}{lrrrr}\text { SPREAD } & \mathbf{0 . 2 5 6 7} & & & \\ \text { PREDICT1 } & 0.0978 & 0.0707 & & \\ \text { FDISP } & 0.0523 & -0.0039 & 0.0177 & \\ \text { HNEWS } & \mathbf{0 . 2 9 5 6} & 0.0386 & \mathbf{0 . 1 1 9 9} & \mathbf{0 . 1 3 1 3}\end{array}$

$\left({ }^{a}\right)$ In bold, $10 \%$ significant estimates. The upper section of Table shows the p-values of the Granger causality test, where each column refers to a VAR equation, and each row refers to a block of explanatory lags. The lower part of the Table shows the sample correlation matrix of VAR residuals to assess the degree of simultaneity between the different indicators.

\section{A8.2 - VAR modelling of ARMA-with-breaks residuals}

Table A8.3 reports the results, over the period 2004m1-2014m12, from the ARMA-withbreaks model, with a two-step procedure. We first estimate a VAR(2) model for the vector of the $F F$ and $E U R Q$ uncertainty measures conditional on the significant break dates. Then we estimate the restricted VAR(2) conditional on the jointly significant break dates, and we examine Granger causality and simultaneity. ${ }^{47}$

$E U R Q$ significant break dates are broadly close to those of the other indexes: the anomalous EURQ levels' fluctuations, shown in Figure A6.1, are cleared by the VAR "pre-whitening". Some indexes show fewer, or lower, multivariate breaks than univariate ones, due to co-breaking (i.e. some breaks can be cleared across measures), while in other indexes the breaks can induce further shifts. For example, an index such as the FDISP displays fewer multivariate breaks than in the univariate case, since it probably co-breaks with significant explanatory lags of $H N E W S$ and $E U R Q$. Conversely, the PREDICT1 equation is strongly puzzling, probably because of the excess in smoothness of its series that could make it difficult for the ARMA-with-breaks model to detect any clear shift-points over the 2004m1-2014m12 period.

Overall, the multivariate outcomes are in line with those from ARMA/GARCH, with the sole exception of the simultaneous correlations: here they are slightly lower because part of the simultaneity between variables is captured by common breaking dates, such as the general upward shift in $2008 \mathrm{~m} 9$ identified as a huge increase in uncertainty at the beginning of the Great Recession. Finance-based measures are the only ones affected by the surge in uncertainty in May 2010 (associated with the Greek/Eurozone crisis). ${ }^{48}$

\footnotetext{
${ }^{47}$ The 20 break dates detected at the univariate stage are measured in the VAR model by 19 step-dummies because one of them was the same in both the PREDICT1 and EURQ equations. All the step dummies were included in the VAR(2) and tested for their significance. In the end, only 9 break dates survived.

${ }^{48}$ See also the calendar of events reported in Table A1.1 of Appendix A1.
} 
Tab. A8.3 - Dynamic relationships between innovations from ARMA-with-breaks $\left({ }^{a}\right)$

Estimates of the VAR(2) conditional on joint significant break dates, sample period 2004m1 - 2014m12

\begin{tabular}{rrrrrr}
\multicolumn{7}{c}{ VAR equation for: } \\
\hline VIX & SPREAD & PREDICT1 & \multicolumn{1}{c}{ FDISP } & HNEWS & EURQ \\
& & & & & \\
$\mathbf{0 . 1 1 6 0}$ & 0.0296 & 0.0039 & $\mathbf{0 . 0 6 9 4}$ & 0.0072 & -0.0886 \\
$\mathbf{0 . 6 2 0 6}$ & $\mathbf{0 . 2 3 4 1}$ & -0.0049 & 0.0121 & $\mathbf{0 . 4 8 6 9}$ & $\mathbf{0 . 2 5 6 6}$ \\
-0.1786 & $\mathbf{- 0 . 1 7 9 1}$ & -0.0007 & $\mathbf{- 0 . 1 7 3 4}$ & -0.1509 & -0.0942 \\
$\mathbf{- 0 . 4 1 2 0}$ & $\mathbf{- 0 . 1 6 2 8}$ & -0.0006 & 0.0836 & -0.2065 & -0.0496 \\
$\mathbf{- 0 . 3 3 1 9}$ & -0.0630 & -0.0010 & -0.0495 & $\mathbf{0 . 2 2 3 4}$ & $\mathbf{0 . 1 5 2 8}$ \\
$\mathbf{0 . 4 2 8 7}$ & $\mathbf{0 . 1 4 9 7}$ & 0.0040 & 0.0608 & -0.0493 & $\mathbf{- 0 . 2 4 3 8}$ \\
0.1172 & $\mathbf{0 . 1 8 3 8}$ & -0.0027 & 0.0030 & 0.0016 & -0.0563 \\
$\mathbf{- 0 . 2 2 3 0}$ & $\mathbf{- 0 . 1 2 0 6}$ & 0.0035 & 0.0028 & 0.1379 & 0.0350 \\
0.0695 & 0.0295 & -0.0049 & -0.0297 & $\mathbf{- 0 . 3 8 7 0}$ & -0.0418
\end{tabular}

p-values of block Granger causality tests in a VAR(2) of uncertainty innovations

Equation for the innovation to:

Two lags of explanatory innovations to:

VIX
SPREAD
PREDICT1
FDISP
HNEWS
EURQ
Joint

\begin{tabular}{rrrrrrrr}
\hline$d f$ & VIX & SPREAD & PREDICT1 & FDISP & HNEWS & EURQ \\
\hline & & $\mathbf{0 . 0 0 0 4}$ & 0.1803 & 0.1334 & 0.1087 & 0.9419 \\
\hline 2 & $\mathbf{0 . 0 0 4 1}$ & & 0.9017 & 0.7415 & 0.1200 & 0.7514 \\
2 & $\mathbf{0 . 0 0 0 0}$ & $\mathbf{0 . 0 0 0 0}$ & & 0.9340 & 0.2771 & 0.5584 \\
2 & 0.8994 & 0.9888 & 0.9326 & & 0.4792 & 0.7222 \\
2 & 0.4633 & 0.1910 & 0.5978 & $\mathbf{0 . 0 1 6 0}$ & & 0.4730 \\
\hline 10 & $\mathbf{0 . 0 5 0 3}$ & 0.5095 & 0.1383 & $\mathbf{0 . 0 1 6 7}$ & 0.1466 & \\
\hline & $\mathbf{0 . 0 0 0 0}$ & $\mathbf{0 . 0 0 0 0}$ & 0.1183 & $\mathbf{0 . 0 3 6 5}$ & 0.1349 & 0.7317 \\
\hline
\end{tabular}

correlation between unpredictable uncertainty innovations (VAR(2) residuals)

SPREAD
PREDICT1
FDISP
HNEWS
EURQ

$\begin{array}{rr}\mathbf{0 . 4 9 0 4} & \\ -0.0164 & 0.1303 \\ 0.1217 & 0.0637 \\ \mathbf{0 . 3 0 7 5} & \mathbf{0 . 1 3 9 3} \\ -0.0988 & -0.1192\end{array}$

0.0684
$\mathbf{0 . 1 6 7 3}$
0.0217

0.0606

0.0119

0.1734

\begin{abstract}
$\left({ }^{a}\right)$ In bold, $10 \%$ significant estimates. The lower panel in Table A8.2 reports both the p-values of the Granger causality test, and the VAR's residual correlation matrix.

$\left({ }^{b}\right)$ The 9 break dates in the restricted VAR are listed in the upper panel of Table A8.2. In order to better understand their economic relevance and size, estimates of the step dummies parameters are reported as ratios over the respective averages of uncertainty measures.
\end{abstract}


Appendix A9 - Details about macro VAR modelling

A9.1 - Tests of seasonal adjustment of all the uncertainty measures

Tab. A9.1 -Seasonality tests (X13 filter context)

\begin{tabular}{cccccc}
\hline & $\begin{array}{c}\text { Stable } \\
\text { Seasonality }\end{array}$ & $\begin{array}{c}\text { Moving } \\
\text { Seasonality }\end{array}$ & $\begin{array}{c}\text { Identifiable } \\
\text { Seasonality }\end{array}$ & $\begin{array}{c}\text { Monitoring and Quality } \\
\text { Assessment Statistics }\end{array}$ \\
\hline Variable & Ftest & $K$ & $F$ test $^{c}$ & $M^{d}$ & $\begin{array}{c}Q \text { (without } \\
\text { M2) }\end{array}$ \\
\hline EURQ & & & & & \\
EPU & $47.454^{a}$ & $108.5798^{b}$ & $2.171^{*}$ & $0.377^{* *}$ & $0.53^{e}$ \\
VIX & $6.087^{a}$ & $61.5886^{b}$ & 1.301 & $0.946^{*}$ & 1.27 \\
MPRED & $4.826^{a}$ & $59.675^{b}$ & $2.033^{* *}$ & 1.165 & 1.30 \\
FPRED & $29.432^{a}$ & $232.551^{b}$ & $3.373^{* *}$ & $0.539^{* *}$ & $0.64^{e}$ \\
SCOTTI & $14.658^{a}$ & $147.072^{b}$ & $4.132^{* *}$ & $0.813^{* *}$ & $0.74^{e}$ \\
FDISP & 1.971 & 21.848 & 2.739 & 1.965 & 1.40 \\
\hline
\end{tabular}

(a) Seasonality present at the $0.1 \%$ level

(b) Seasonality present at the one percent level

(c) ${ }^{* *}$ and ${ }^{*}$ denote moving seasonality present at the one and five percent levels

(d) ${ }^{* *}$ and *denote Identifiable seasonality present and probably not present

(e) Accepted 


\section{A9.2 - The optimal lag length selection of macro VARs}

Tab. A9.2 -Test for the optimal lag length over each sample period ${ }^{a}$

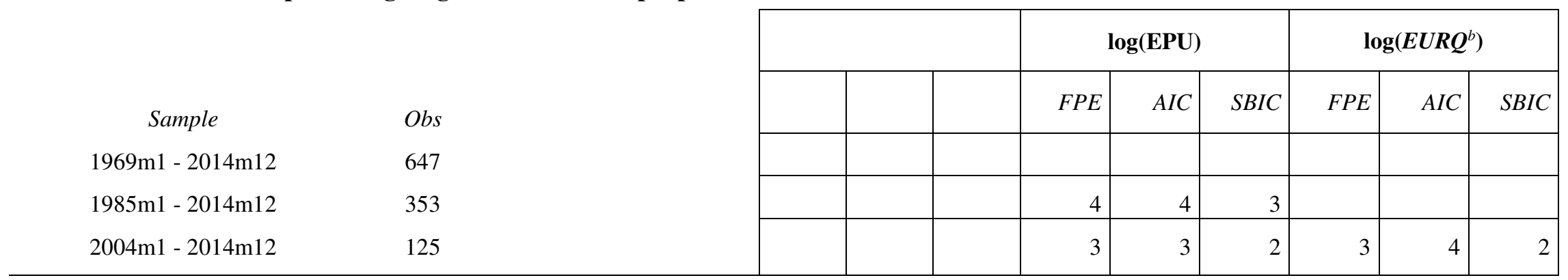

\begin{tabular}{|c|c|c|c|c|c|c|c|c|c|c|c|c|c|c|c|c|}
\hline \multirow[b]{2}{*}{ Sample } & \multirow[b]{2}{*}{ Obs } & \multicolumn{3}{|c|}{$\log ($ VIX) } & \multicolumn{3}{|c|}{ MPRE $^{b}$} & \multicolumn{3}{|c|}{ FPRED $^{b}$} & \multicolumn{3}{|c|}{ SCOTTI } & \multicolumn{3}{|c|}{$\log ($ FDISP) } \\
\hline & & $F P E$ & $A I C$ & $S B I C$ & $F P E$ & $A I C$ & $S B I C$ & $F P E$ & $A I C$ & SBIC & $F P E$ & $A I C$ & SBIC & $F P E$ & $A I C$ & $S B I C$ \\
\hline 1969m1 - 2014m12 & 647 & 5 & 5 & 2 & 5 & 5 & 2 & 5 & 5 & 2 & & & & 5 & 5 & 2 \\
\hline $1985 \mathrm{~m} 1-2014 \mathrm{~m} 12$ & 353 & 4 & 4 & 3 & 4 & 4 & 2 & 4 & 4 & 3 & & & & 4 & 4 & 3 \\
\hline $2004 \mathrm{~m} 1-2014 \mathrm{~m} 12$ & 125 & 5 & 5 & 2 & 4 & 5 & 2 & 5 & 5 & 2 & 3 & 3 & 2 & 4 & 4 & 2 \\
\hline
\end{tabular}

(a) Maximum lags allowed: 5 . Test based on a 5 -variables VAR with uncertainty, $\log (\mathrm{SP} 500), \log (1+\mathrm{Fed}$ funds effective rate/100), log manufacturing employment and log manufacturing industrial production.

(b) Seasonally adjusted using the X13 procedure 


\section{Appendix A10 - The making of EURQ for Italy: technical details}

\section{A10.1 - The technical implementation of the EURQ index for Italy}

The Italian EURQ index has been obtained, as for the American one, starting from the 210 terms used by Baker et al. (2016) for their uncertainty index. Through a judgmental approach, each American term has been transformed into an Italian equivalent. We ended with a final list of 163 search terms, 27 of which have been excluded due to their low relevance in the Web searches over the $2004 \mathrm{~m} 1-2015 \mathrm{~m} 12$ period. The survived terms are listed below sorted from the highest to the lower peaks:

\author{
1. inps - orari - numero - pin - in \\ 2. ingv \\ 3. "agenzia delle entrate" \\ 4. "elezioni politiche" \\ 5. riforma - protestante \\ 6. inail \\ 7. $\mathrm{tfr}$ \\ 8. "protezione civile" \\ 9. isee \\ 10. sanità - istituto - rione - quotidiano \\ 11. ccnl \\ 12. arpa - orari \\ 13. terrorismo \\ 14. "garanzia giovani" \\ 15. "pubblica amministrazione" \\ 16. tassazione \\ 17. disoccupazione \\ 18. caf \\ 19. "assegni familiari" \\ 20. corte dei conti - concorso \\ 21. anac \\ 22. "spread btp bund" \\ 23. fallimenti \\ 24. invalidità - punteggio \\ 25. consob \\ 26. "debito pubblico" \\ 27. aams \\ 28. servizi sociali - Berlusconi \\ 29. protocollo di Kyoto - riassunto \\ 30. "titoli di stato" \\ 31. "bail in" \\ 32. pari opportunità - carfagna \\ 33. concorrenza - esercizi \\ 34. "cuneo fiscale" \\ 35. "detassazione straordinari"
}

36. "reddito minimo garantito"

37. bankitalia - concorso

38. wto - wikipedia - significato

39. antitrust - significato - wikipedia

40. Mario Draghi - moglie - stipendio

41. "detrazione fiscale"

42. "exchange rate"

43. "detrazioni fiscali"

44. "class action"

45. sussidio

46. "banca centrale europea"

47. welfare state - keynes - significato definizione - beveridge

48. rivalutazione monetaria - Andreani avvocati

49. "patto di stabilità"

50. banca centrale - sede

51. "diritto di abitazione"

52. "aliquote fiscali"

53. "tasso di interesse"

54. brevetti e marchi

55. "agenzia per il lavoro"

56. "Ignazio Visco"

57. embargo

58. "quantitative easing"

59. "portale fallimenti"

60. "fondo di garanzia"

61. "federal reserve"

62. "indennità di disoccupazione"

63. svalutazione

64. "stress test banche"

65. "tassi bce"

66. "tasso di cambio"

67. "Bank of America"

68. "trattato di Schengen" 
69. "assegno sociale"

70. "assegno familiare"

71. "politica monetaria"

72. "concorrenza sleale"

73. "dazi doganali"

74. "corte di giustizia europea"

75. banca d italia - concorso - concorsi

76. "carbon tax"

77. "assicurazione vita"

78. "Bank of England"

79. "contrattazione collettiva"

80. "bonus sociale"

81. "autorità vigilanza contratti pubblici"

82. "diritto alla disoccupazione"

83. "Bank of Japan"

84. "copyright law"

85. "sicurezza nazionale"

86. Bundesbank

87. "emission trading"

88. ECB

89. agcm

90. "sicurezza sociale"

91. "legge droghe"

92. "sussidio di disoccupazione"

93. "pareggio di bilancio"

94. "uruguay round"

95. "spesa pubblica"

96. "assegno di disoccupazione"

97. "Bank of China"

98. tassato

99. Trichet

100. "legge immigrazione"

101. "vigilanza bancaria"

102. "organizzazione mondiale del commercio"
103. "spese militari"

104. "no-fly zone"

105. trattato internazionale

106. "salario minimo"

107. "mutuo surroga"

108. "politica energetica"

109. "centro per l'impiego"

110. "fondo interbancario di tutela dei depositi"

111. "derivati finanziari"

112. "aliquota fiscale"

113. military spending

114. "forze armate italiane"

115. "crisi russa"

116. "Crisi asiatica"

117. "crisi euro"

118. "accordi di Basilea"

119. "anti dumping"

120. "prestito senza busta paga"

121. "pensione di invalidità civile"

122. "svalutazione monetaria"

123. "offerta di moneta"

124. "guerra al terrorismo"

125. "doha round"

126. "pratiche commerciali scorrette"

127. "trivellazioni petrolifere"

128. "blocco navale"

129. "prestatore di ultima istanza"

130. "tasso overnight"

131. "deficit di bilancio"

132. "rapporto debito pil italia"

133. "operazioni di mercato aperto"

134. "assicurazione infortuni e malattia"

135. "debiti sovrani"

136. "Presidente Federal Reserve"

The 27 search terms excluded from the final list are:

1. azione positiva

2. diritto di lavorare

3. tassa sull'energia

4. salario sufficiente

5. accordo commerciale

6. chiusura basi militari

7. quote europee

8. politica commerciale

9. atto commerciale

10. crisi valutarie

11. bilancio dell'Italia

12. invasione militare

13. tasse per importazione

14. Interventi sul mercato dei cambi
15. Banca di Francia

16. caduta della valuta

17. requisiti patrimoniali

18. obbligo di avviso anticipato

19. politica sulle fusioni

20. cartello

21. restrizioni alle perforazioni

22. restrizioni ambientali

23. barriere alle importazioni

24. inmp

25. fondo di solidarietà sospensione mutuo

26. sostegno all'affitto

27. assegno ordinario d'invalidità 
To respect the maximum limit of characters set by Google Trends for each query, the search terms of the final list and search terms have been aggregated in the following 32 queries:

- inps - orari - numero - pin - in + "Presidente Federal Reserve" + "debiti sovrani" + "blocco navale"

- ingv + "assicurazione infortuni e malattia" + "operazioni di mercato aperto" + "tasso overnight"

- " agenzia delle entrate" + "rapporto debito pil italia" + "deficit di bilancio" + "doha round"

- "elezioni politiche" + "prestatore di ultima istanza" + "trivellazioni petrolifere" + "crisi euro"

- riforma - protestante + "pratiche commerciali scorrette" + "guerra al terrorismo" + "Crisi asiatica"

- inail + "offerta di moneta" + "svalutazione monetaria" + "pensione di invalidità civile"

- $\quad \mathrm{tfr}+$ "prestito senza busta paga" + "anti dumping" + "accordi di Basilea + "crisi russa"

- "protezione civile" + "forze armate italiane" + military spending + "aliquota fiscale"

- isee + "derivati finanziari" + "fondo interbancario di tutela dei depositi" + "centro per l'impiego"

- sanità - istituto - rione - quotidiano + "politica energetica" + "mutuo surroga" + "salario minimo"

- ccnl + trattato internazionale + "no-fly zone" + "spese militari" + "vigilanza bancaria"

- arpa - orari + "organizzazione mondiale del commercio" + "legge immigrazione" + Trichet + tassato

- terrorismo + "Bank of China" + "assegno di disoccupazione" + "spesa pubblica" + "uruguay round"

- "garanzia giovani" + "pareggio di bilancio" + "sussidio di disoccupazione" + "legge droghe"

- $\quad$ "pubblica amministrazione" + "sicurezza sociale" + agcm + ECB + "emission trading" + Bundesbank

- tassazione + "sicurezza nazionale" + "copyright law" + "Bank of Japan" + "contrattazione collettiva"

- disoccupazione + "diritto alla disoccupazione" + "autorità vigilanza contratti pubblici"

- caf + "bonus sociale" + "Bank of England" + "assicurazione vita" + "carbon tax" + "dazi doganali"

- "assegni familiari" + banca d italia - concorso - concorsi + "corte di giustizia europea"

- corte dei conti - concorso + "concorrenza sleale" + "politica monetaria" + "assegno familiare"

- anac + "assegno sociale" + "trattato di Schengen" + "Bank of America" + "tasso di cambio"

- "spread btp bund" + "tassi bce" + "stress test banche" + svalutazione + "federal reserve"

- fallimenti + "indennità di disoccupazione" + "fondo di garanzia" + "portale fallimenti"

- invalidità - punteggio + "quantitative easing" + embargo + "Ignazio Visco" + brevetti e marchi

- consob + "agenzia per il lavoro" + "tasso di interesse" + "aliquote fiscali" + sussidio

- "debito pubblico" + "diritto di abitazione" + banca centrale - sede + "patto di stabilità"

- aams + rivalutazione monetaria - Andreani - avvocati + "banca centrale europea" + "class action"

- servizi sociali - Berlusconi + welfare state - keynes - significato - definizione - beveridge

- protocollo di Kyoto - riassunto + "detrazioni fiscali" + "exchange rate" + "detrazione fiscale"

- "titoli di stato" + Mario Draghi - moglie - stipendio + antitrust - significato - wikipedia

- "bail in" + wto - wikipedia - significato + bankitalia - concorso + "reddito minimo garantito"

- pari opportunità - carfagna + "detassazione straordinari" + "cuneo fiscale" + concorrenza - esercizi

The $E U R Q$ index for Italy is the result of the sum of the monthly searches' volumes of each query weighted by the highest peak. 


\section{A10.2 - Specific search used for alternative Google Trends-based indices}

The GSI, ECON and UI uncertainty indices have been obtained through aggregation of the Italian translation of the American terms used, respectively, by Donadelli (2014), Dzielinski (2012) and BBVA (2012) for their own indices as shown in the table below:

\begin{tabular}{|c|c|c|}
\hline Index & English term & Italian term \\
\hline \multirow{2}{*}{ GSI (Donadelli) } & US stock market & mercato azionario italiano \\
& US fed & Bce \\
& US politics & politica italiana \\
\hline \multirow{2}{*}{ ECON (Dzielinski) } & Economy & Economia \\
\hline & Tax & Tasse \\
& Debt & Debito \\
& Fiscal & Fiscale \\
& Medicare & Riforma \\
& social security & sicurezza sociale \\
& Iran & Iran \\
& Israel & Israele \\
& Terrorism & Terrorismo \\
& Revolution & Rivoluzione \\
& Iraq & Iraq \\
& Inflation & Inflazione \\
& Economy & Economia \\
& Jobs & Lavoro \\
& Fed & Bce \\
& stock market & mercato azionario \\
\hline
\end{tabular}

Due to the amount of UI's search terms, it has been necessary to divide them in two queries and, then, to proceed with their aggregation as for $E U R Q$. The two queries are:

- $\quad$ tasse+debito+fiscale+riforma+"sicurezza sociale"+iran+"mercato azionario"

- $\quad$ israele+terrorismo+rivoluzione+iraq+inflazione+economia+lavoro+bce

The EPUGT index, instead, has been the result of the aggregation of the translated policy terms defined by Baker et al. (2016) to implement their Italian uncertainty index. The original terms, from the two newspapers, Corriere Della Sera and La Repubblica, drawn for Italy are:

1. tassa

2. tasse

3. politica

4. regolamento

5. regolamenti

6. spesa
7. spese

8. deficit

9. "Banca Centrale"

10. "Banca d'Italia"

11. budget

12. bilancio 
while the translated terms are:

1.politica - carta - cartina - mappa - filosofia

7. spese

2. spesa pubblica

8. deficit

3. tassa

9. banca d italia - concorso - concorsi

4. tasse

10. banca centrale - sede

5. deficit - attenzione - cognitivo - iga

6. legge di bilancio

11. regolamentazione

Also in this case, we divided them in 3 different queries before peak-normalizing and summing for every month:

- politica - carta - cartina - mappa - filosofia + "spesa pubblica"

- tassa + deficit - attenzione - cognitivo - iga + "legge di bilancio"

- tasse + banca d italia - concorso - concorsi + banca centrale - sede + regolamentazione

\section{A10.3 - Univariate and multivariate analysis of EURQ for Italy}

Table A10.1 - Univariate analysis of Italian uncertainty proxies

\begin{tabular}{|c|c|c|c|c|c|c|c|c|}
\hline $\begin{array}{l}\text { Summary } \\
\text { statistics }\end{array}$ & EURQ & GSI & ECON & $\mathbf{U I}$ & EPUGT & NEWS & $\operatorname{MUI}\left({ }^{a}\right)$ & $\operatorname{SVOL}\left({ }^{a}\right)$ \\
\hline Mean, $\mu$ & 173.78 & 36.42 & 61.98 & 80.25 & 107.54 & 107.88 & 0.69 & 1.02 \\
\hline Median & 170.50 & 32.50 & 61 & 77 & 101 & 103.57 & 0.68 & 0.92 \\
\hline Maximum & 249 & 100 & 100 & 128 & 186 & 241.02 & 0.86 & 4.33 \\
\hline Minimum & 106 & 13 & 31 & 52 & 67 & 31.70 & 0.60 & 0.24 \\
\hline $\begin{array}{l}\text { Std. Dev., } \sigma \\
\text { Coeff. of }\end{array}$ & 26.94 & 14.65 & 13.14 & 14.46 & 23.10 & 38.91 & 0.05 & 0.56 \\
\hline Variation, $\sigma \mu \mu$ & 0.16 & 0.40 & 0.21 & 0.18 & 0.21 & 0.36 & 0.08 & 0.55 \\
\hline Skewness $\left({ }^{b}\right)$ & $0.35^{*}$ & $1.79^{* * *}$ & 0.27 & $0.68^{* * * *}$ & $1.04^{* * * *}$ & $0.68^{* * * *}$ & $1.03^{* * * *}$ & $2.16^{* * *}$ \\
\hline Kurtosis $\left({ }^{b}\right)$ & 3.32 & $7.56^{* * *}$ & 3.04 & 3.38 & $4.04^{* *}$ & 3.43 & $3.80^{*}$ & $10.92^{* * *}$ \\
\hline $\mathrm{N}$ & 168 & 168 & 168 & 168 & 168 & 168 & 144 & 144 \\
\hline $\begin{array}{l}\text { Persistence } \\
\text { testing through } \\
\text { unit-root tests } \\
\left({ }^{c}\right)\end{array}$ & & & & & & & & \\
\hline $\begin{array}{l}\text { - augmentation, } \\
k\end{array}$ & 9 & 2 & 7 & 8 & 9 & 3 & 1 & 6 \\
\hline $\begin{array}{l}\text { - p-value } \\
\text { - speed of }\end{array}$ & 0.3189 & 0.0054 & 0.8363 & 0.1634 & 0.0125 & 0.0908 & 0.2660 & 0.1151 \\
\hline $\begin{array}{l}\text { adjustment, } \pi \\
\text { - half-life }\end{array}$ & -0.1656 & -0.2434 & -0.0634 & -0.1075 & -0.1389 & -0.1801 & -0.0414 & -0.22 \\
\hline months, $m\left({ }^{d}\right)$ & 4 & 3 & 11 & 6 & 5 & 3 & 16 & 3 \\
\hline
\end{tabular}

$\left({ }^{a}\right) 2004 \mathrm{~m} 1-2015 \mathrm{~m} 12$.

$\left({ }^{b}\right){ }^{* * *},{ }^{* *},{ }^{*}$ denote a $1 \%, 5 \%$ and $10 \%$ statistical significance respectively.

$\left(^{c}\right)$ Dickey and Fuller (1979) test equation: $\Delta y_{t}=c+\pi y_{t-1}+\sum_{i=1}^{k} \gamma_{i} \Delta y_{t-1}+u_{t}$, where $k$ is selected by using the MAIC criterion of $\mathrm{Ng}$ and Perron (2001) starting from a given maximum number of lags ( $\left.k_{\text {MAX }}\right)$.

$\left.{ }^{d}\right)$ Months for closing $50 \%$ of the disequilibria. In general, $m=\ln (1-p) / \ln (1+\pi)$, where $p$ is the part of the initial gap to be closed between actual $y_{t}$ and its long run forecast (if $y_{t}$ is stationarity, it is its unconditional mean), and $\pi$ is the speed of adjustment (see above). Here, $p=0.50$, i.e. $50 \%$. 
Table A10.2 - Tests of seasonal adjustment of uncertainty indices (X13 filter)

\begin{tabular}{cccccc} 
& \multicolumn{2}{c}{ Stable Seasonality } & $\begin{array}{c}\text { Moving } \\
\text { Seasonality }\end{array}$ & $\begin{array}{c}\text { Identifiable } \\
\text { Seasonality }\end{array}$ & $\begin{array}{c}\text { Monitoring and Quality } \\
\text { Assessment Statistics }\end{array}$ \\
\hline Variable & $F$ test & $K$ & $F$ test $^{c}$ & $M 7^{d}$ & $Q$ (without M2) \\
\hline EURQ & $43.07^{a}$ & $111.93^{b}$ & $2.10^{*}$ & $0.39^{* *}$ & $0.55^{e}$ \\
GSI & $3.65^{a}$ & $35.78^{b}$ & 1.11 & 1.19 & 1.13 \\
ECON & $134.95^{a}$ & $150.53^{b}$ & $2.43^{* *}$ & $0.23^{* *}$ & $0.39^{e}$ \\
UI & $160.76^{a}$ & $150.86^{b}$ & 0.52 & $0.16^{* *}$ & $0.38^{e}$ \\
EPUGT & $47.52^{a}$ & $117.68^{b}$ & 1.65 & $0.36^{* *}$ & $0.62^{e}$ \\
NEWS & 2.83 & $32.37^{b}$ & 0.59 & 1.25 & 1.48 \\
MUI & $16.72^{a}$ & $84.43^{b}$ & $4.16^{* *}$ & $0.76^{* *}$ & $0.50^{e}$ \\
SVOL & 1.11 & $13.01^{b}$ & 0.94 & 2.10 & 1.62 \\
\hline
\end{tabular}

(a) Seasonality present at the $0.1 \%$ level

(b) Seasonality present at the one percent level

(c) ${ }^{*}$ and ${ }^{*}$ denote moving seasonality present at the one and five percent levels

(d) ${ }^{* *}$ denote Identifiable seasonality present

(e) Accepted

Table A10.3.3 - Test for the optimal lag length $\left({ }^{a}\right)$

\begin{tabular}{|c|c|c|c|c|c|c|c|}
\hline \multirow[b]{2}{*}{ Sample } & \multirow[b]{2}{*}{ Obs } & \multicolumn{3}{|c|}{$\log (E U R Q)\left({ }^{b}\right)$} & \multicolumn{3}{|c|}{$\log (\mathrm{NEWS})$} \\
\hline & & $F P E$ & $A I C$ & $S B I C$ & FPE & $A I C$ & $S B I C$ \\
\hline \multirow{2}{*}{$\begin{array}{l}2004 \mathrm{~m} 1- \\
2017 \mathrm{~m} 12\end{array}$} & 168 & 2 & 2 & 1 & 2 & 2 & 1 \\
\hline & & \multicolumn{3}{|c|}{$\log \left(\right.$ MUI) $\left({ }^{b}\right)$} & \multicolumn{3}{|c|}{$\log ($ SVOL $)$} \\
\hline Sample & Obs & $F P E$ & $A I C$ & $S B I C$ & $F P E$ & $A I C$ & $S B I C$ \\
\hline $\begin{array}{l}2004 \mathrm{~m} 1- \\
2015 \mathrm{~m} 12\end{array}$ & 144 & 2 & 2 & 1 & 4 & 4 & 1 \\
\hline
\end{tabular}

(a) Maximum lags allowed: 5. Test based on a 5-variables VAR with uncertainty, $\log (\mathrm{FTSE}$ MIB), $\log (1+$ Euribor 1 month), $\log$ (employment) e $\log ($ industrial production).

(b) Seasonally adjusted using the X13 procedure 
Appendix A11 - Newsbank and EURQ VARs by category, sub-group and search terms: detailed results

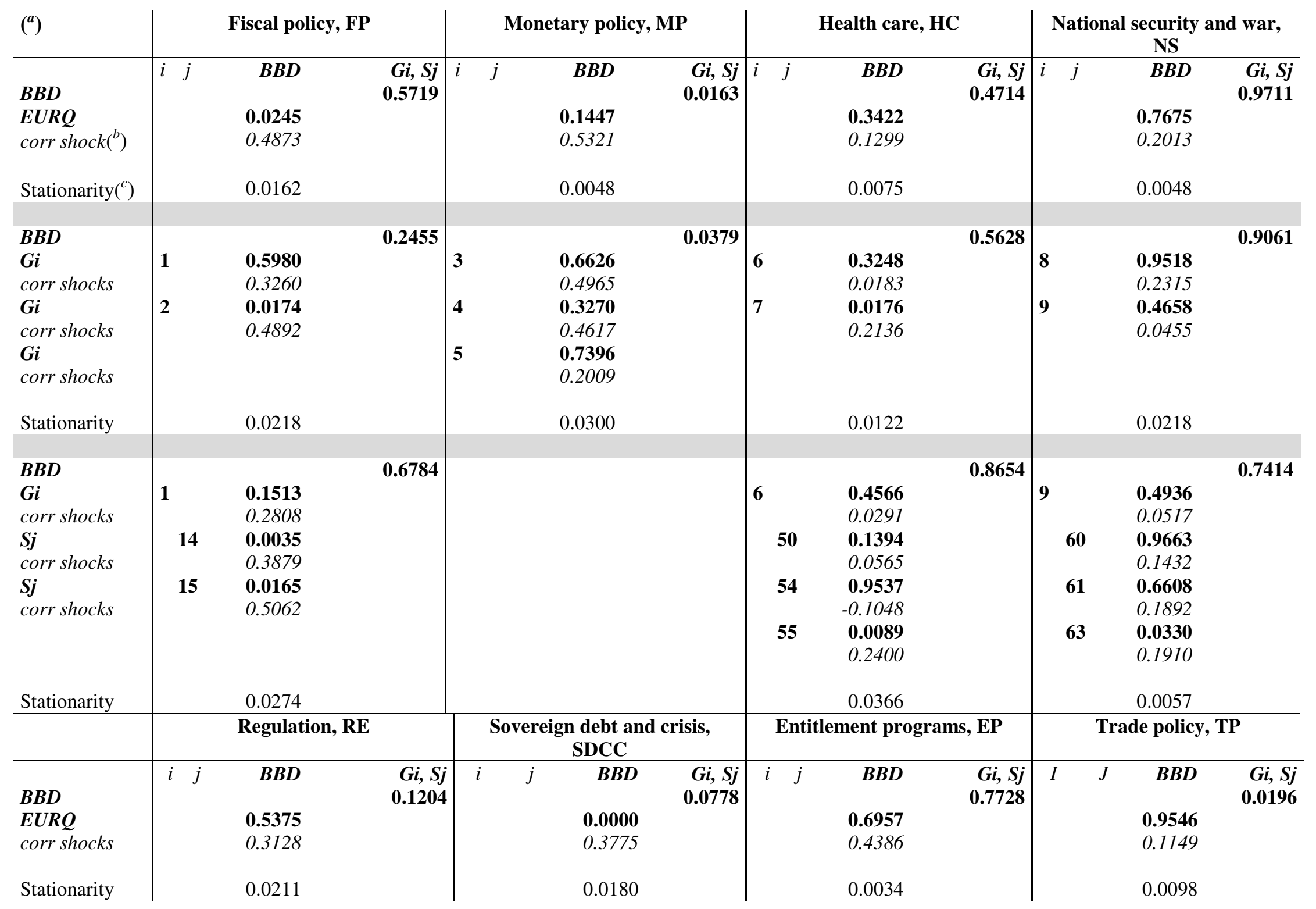




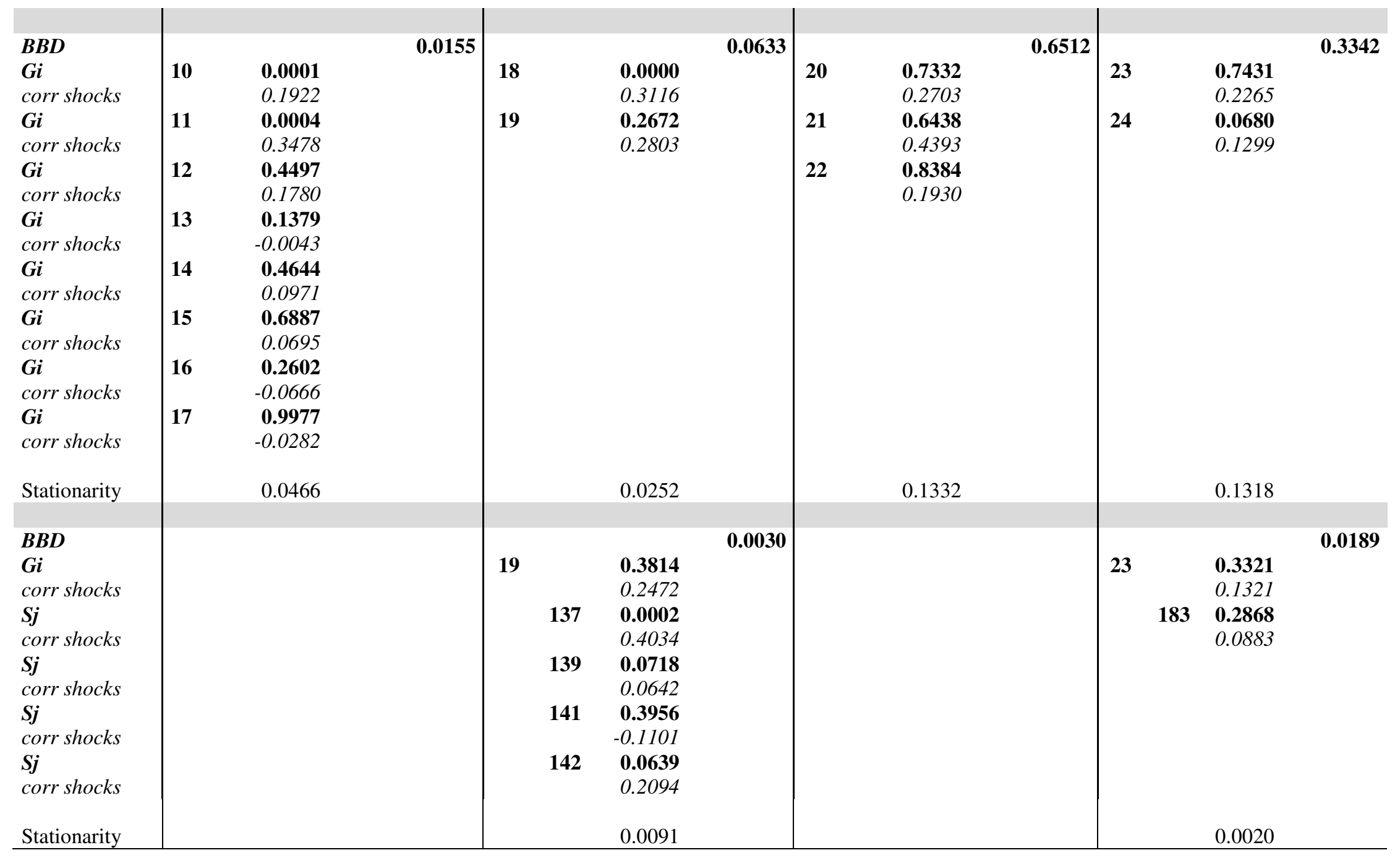

${ }^{(a}$ ) In each block of columns (one for each of the 8 categories $c$ ), rows are grouped in 3 sets (delimited by grey shadows) corresponding to the results obtained from 3 different VAR specifications: the upper set reports the results of the bivariate VAR for aggregate-by- $c$ BBD and $E U R Q$ indicators; the middle one is for the VAR with the aggregate-by-c $B B D$ indicator and the $E U R Q$ index disaggregated by sub-groups (Gi) belonging to the considered category $c$; the lower set deepens middle results by substituting significant $G i$ indexes with the single $E U R Q$ search terms $(S j)$ which emerged as the most relevant in the Gi sub-group (according to the BMA analysis in Table A3.1). In each of the 3 sets, figures in bold report the pvalues of the Granger causality tests. Those in the central column of each block (labelled as "BBD") assess the causality from the single Google 
Trends series (either $E U R Q$, or $G i$, or $S j$ ) to the news-based index (BBD); figures in the last column of each block (labelled as "Gi, $\left.\mathbf{S j}^{\prime \prime}\right)$ assess the joint reverse causality from BBD to all the $E U R Q$ series.

$\left({ }^{b}\right)$ "corr shocks" = instantaneous correlations between the residuals of the BBD equation and each of the Google Trends indicator equations (either $E U R Q$, or $G i$, or $S j$ ).

$\left({ }^{c}\right)$ "Stationarity" = p-values of the Johansen (1995) trace test for assessing the full rank: if the null hypothesis is rejected, all the variables in VAR are jointly stationary. When such null is not rejected (i.e. in the middle VAR of EP and TP), the non-standard Granger causality is assessed as suggested in Toda and Yamamoto (1995).

\section{NOTE: SUB-GROUPS AND SINGLE SEARCH TERMS LEGENDA ARE E.G. IN TAB A.3.1 OF APPENDIX A.3}




\section{References}

Bachmann, R, S. Elstner and E. R. Sims (2013), "Uncertainty and the economic activity: evidence from business survey data", American Economic Journal: Macroeconomics, Vol. 5, No. 2, pp. 217-249.

Bai, J. and P. Perron (1998), "Estimating and testing linear models with multiple structural changes", Econometrica, Vol. 66, pp. 47-78.

Bai, J. and P. Perron (2003), "Critical values for multiple structural change tests”, Econometrics Journal, Vol. 18, pp. 1-22.

Baker, S. R., N. Bloom and S. J. Davis (2016), "Measuring economic policy uncertainty", The Quarterly Journal of Economics, Vol.131, No. 4, pp. 1593-1636.

BBVA (2012), "Uncertainty: models and impacts", Economic Watch https://www.bbvaresearch.com/KETD/fbin/mult/120321_EconomicWatchEEUU_155_tcm348297922.pdf

Bekaert, G., M. Hoerova and M. Lo Duca (2013), "Risk, uncertainty and monetary policy", Journal of Monetary Economics, Vol. 60, No. 7, pp. 771-788.

Bloom, N. (2009), "The Impact of uncertainty shocks", Econometrica, Vol. 77, No. 3, pp. 623-685.

Bollerslev, T., R. F. Engle and D. B. Nelson (1994), "ARCH Models" in R. F. Engle and D. L. McFadden (eds.), Handbook of Econometrics, Vol. 4, Ch. 49, Elsevier.

Bomberger, W. A. (1996), "Disagreement as a measure of uncertainty", Journal of Money, Credit and Banking, Vol. 28, No. 3, pp. 381-392.

Chicago Board Options Exchange, (2009), "The CBOE Volatility Index- VIX", CBOE White Paper.

Da, Z., J. Engelberg and P. Gao (2011), "In search of attention", The Journal of Finance, Vol. 66, pp 14611499.

De Long, J. B., A. Shleifer, L. H. Summers, and R. J. Waldmann (1990), "Noise trader risk in financial markets", Journal of Political Economy, Vol. 98, pp. 703-738.

De Luca, G. and J. R. Magnus (2011), "Bayesian model averaging and weighted-average least squares: equivalence, stability, and numerical issues", The Stata Journal, Vol. 11, No. 4, pp. 518-544.

Dickey, D. A. and W. A. Fuller (1979), "Distribution of the estimators for autoregressive time series with a unit root", Journal of the American Statistical Association, Vol. 74, No. 366, pp. 427-431.

Donadelli, M. (2015), "Google search-based metrics, policy-related uncertainty and macroeconomic conditions", Applied Economic Letters, Vol. 22, No. 10, pp. 801-807.

Dzielinski, M. (2012), "Measuring economic uncertainty and its impact on the stock market", Finance Research Letters, Vol. 9, pp. 167-175.

Efron, B., T. Hastie, I. Johnstone and R. Tibshirani (2004), "Least angle regression", The Annals of Statistics, Vol. 32, No. 2, pp. 407-499.

Gilchrist, S., J. W. Sim and E. Zakrajsek (2014), "Uncertainty, financial frictions and investment dynamics", NBER Working Papers Series, No. 20038.

Granger, C. W. J. and R. Joyeux (1980), “An introduction to long memory time series models and fractional differencing”, Journal of Time Series Analysis, Vol. 1, pp. 15-29.

Hacamo, I. and T. Reyes (2012), "Negativity bias in attention allocation: retail investors' reaction to stock returns", downloadable at:

http://finance.uc.cl/docs/conferences/6th/Negativity\%20Bias\%20in\%20Attention\%20Allocation\%20\%20November\%202012.pdf 
Johansen, S. (1995), Likelihood-based Inference in Cointegrated Vector Autoregressive Models, Oxford University Press.

Jurado, K., S.C. Ludvingson and S. Ng (2015), "Measuring uncertainty", American Economic Review, Vol. 105, No. 3, pp. 1177-1216.

Lahiri, K. and X. Sheng (2010), "Measuring forecast uncertainty by disagreement: The missing link", Journal of Applied Econometrics, Vol.25, pp. 514-538.

Leamer, E. E. (1978), Specification Search: Ad Hoc Inference with Nonexperimental Data, Wiley.

Magnus, J. R., O. Powell and P. Prufer (2010), "A comparison of two model averaging techniques with an application to growth empirics", Journal of Econometrics, Vol. 154, pp. 139-153.

Mander (2006), "LARS: Stata module to perform least angle regression", Statistical Software Components S456860, Boston College Department of Economics, revised 22 July 2014.

Moore, A. (2016), "Measuring economic uncertainty and its effects", RBA Research Discussion Paper, No. 2016-01

$\mathrm{Ng}$, S. and P. Perron (2001), "Lag length selection and the construction of unit root tests with good size and power", Econometrica, Vol. 69, No. 6, pp. 1519-1554.

Nodari, G. (2014), "Financial regulation policy uncertainty and credit spreads in the US", Journal of Macroeconomics, Vol. 41, pp. 122-132.

Ruths, D. and J. Pfeffer (2014), "Social media for large studies of behavior", Science, Vol. 346, No. 6213, pp. 1063-1064.

Toda, H. Y. and T. Yamamoto (1995), "Statistical inference in vector autoregressions with possibly integrated processes", Journal of Econometrics, Vol. 66, pp. 225-250.

van den Bosch, A., T. Bogers and M. de Kunde (2016), "Estimating search engine index size variability: a 9year longitudinal study", Scintometrics, Vol. 107, No. 2, pp 839-856.

Zarnowitz, V. and L. A. Lambros (1987), "Consensus and uncertainty in economic prediction", Journal of Political Economy, Vol. 95, No. 3, pp. 591-621. 


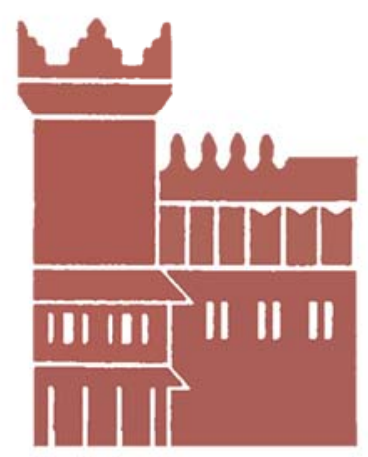

Alma Mater Studiorum - Università di Bologna DEPARTMENT OF ECONOMICS

Strada Maggiore 45

40125 Bologna - Italy

Tel. +39051 2092604

Fax +390512092664

http://www.dse.unibo.it 